San Jose State University

SJSU ScholarWorks

Master's Theses

Master's Theses and Graduate Research

1990

\title{
A Computer-assisted engineering geologic investigation of the Blucher Valley Landslide, Sebastopol, California
}

John E. Romie

San Jose State University

Follow this and additional works at: https://scholarworks.sjsu.edu/etd_theses

\section{Recommended Citation}

Romie, John E., "A Computer-assisted engineering geologic investigation of the Blucher Valley Landslide, Sebastopol, California" (1990). Master's Theses. 73.

DOI: https://doi.org/10.31979/etd.k75k-9942

https://scholarworks.sjsu.edu/etd_theses/73

This Thesis is brought to you for free and open access by the Master's Theses and Graduate Research at SJSU ScholarWorks. It has been accepted for inclusion in Master's Theses by an authorized administrator of SJSU ScholarWorks. For more information, please contact scholarworks@sjsu.edu. 


\section{INFORMATION TO USERS}

The most advanced technology has been used to photograph and reproduce this manuscript from the microfilm master. UMI films the text directly from the original or copy submitted. Thus, some thesis and dissertation copies are in typewriter face, while others may be from any type of computer printer.

The quality of this reproduction is dependent upon the quality of the copy submitted. Broken or indistinct print, colored or poor quality illustrations and photographs, print bleedthrough, substandard margins, and improper alignment can adversely affect reproduction.

In the unlikely event that the author did not send UMI a complete manuscript and there are missing pages, these will be noted. Also, if unauthorized copyright material had to be removed, a note will indicate the deletion.

Oversize materials (e.g., maps, drawings, charts) are reproduced by sectioning the original, beginning at the upper left-hand corner and continuing from left to right in equal sections with small overlaps. Each original is also photographed in one exposure and is included in reduced form at the back of the book.

Photographs included in the original manuscript have been reproduced xerographically in this copy. Higher quality $6^{\prime \prime} \times 9^{\prime \prime}$ black and white photographic prints are available for any photographs or illustrations appearing in this copy for an additional charge. Contact UMI directly to orcier.

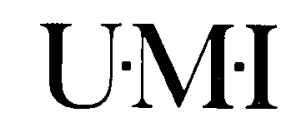

University Microfilms International

A Bell \& Howell Information Company

300 North Zeeb Road. Ann Arbor, MI 48106-1346 USA

313:761.4700 800/521-0600 
A computer-assisted engineering geologic investigation of the Blucher Valley Landslide, Sebastopol, California

\author{
Romie, John Ernest, M.S.
}

San Jose State University, 1990 


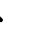




\section{NOTE TO USERS}

THE ORIGINAL DOCUMENT RECEIVED BY U.M.I. CONTAINED PAGES WITH PHOTOGRAPHS WHICH MAY NOT REPRODUCE PROPERLY.

THIS REPRODUCTION IS THE BEST AVAILABLE COPY. 

A COMPUTER-ASSISTED ENGINEERING GEOLOGIC INVESTIGATION OF THE BLUCHER VALLEY LANDSLIDE, SEBASTOPOL, CALIFORNIA

\author{
A Thesis \\ Presented to \\ The Faculty of the \\ Department of Geology \\ San Jose State University \\ In partial Fulfillment \\ of the Requirements for the Degree \\ Master of Science
}

By

John E. Romie

December, 1990 


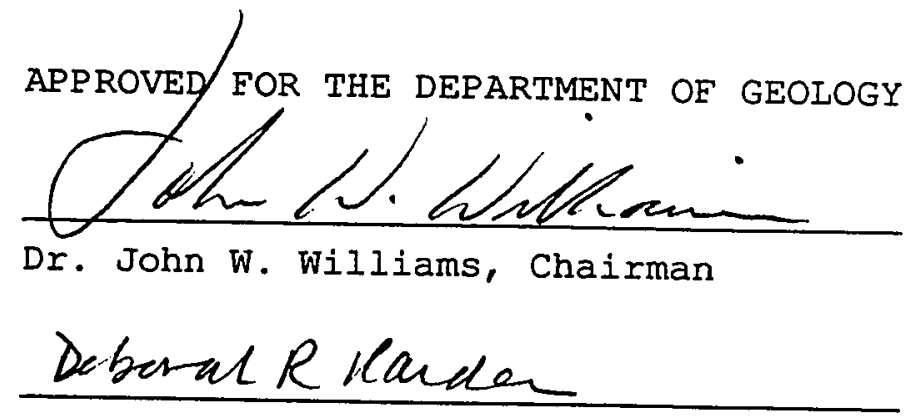

Dr. Deborah R. Harden, Professor

Reval Getrow

Ron Petersen, Independent Consultant

Approved for the University

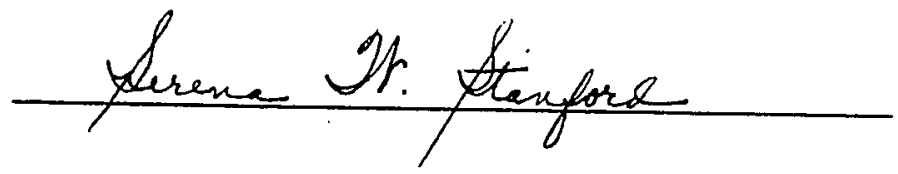




\section{ACKNOWLEDGEMENTS}

The author gratefully acknowledges input and assistance provided by previous investigators of the landslide, thesis advisors, and other interested colleagues. Professors John Williams and Debbie Harden provided high levels of encouragement for, assistance in, and technical review of the research and this thesis. Ron Petersen furnished much needed support and assistance in geophysical aspects of the research, and in review of the final product. The research was also greatly assisted by site specific information provided by Eric Olsborg, Bill Fowler, and Tom Anderson. Access to the landslide was granted by numerous property owners and dwellers, who put up with numerous site visits by the author, field assistants, and friends.

Development of the computer model and the stability analysis techniques presented herein required the use of computing resources far beyond what is typically available to student researchers. I extend my sincere thanks to Dynamic Graphics, Inc., for providing the use of hardware, software, countless hours of Eomputer time, and enthusiastic support of this project.

Finally, thanks go to Jeff Mccleary for long continuing support of my educational and professional pursuits, and for suggesting this landslide as an interesting topic. And most importantly, I thank my wife, Dawn Romie, for putting up with long nights, early mornings, lonely weekends, and overall support of my efforts. 
TABLE OF CONTENTS

ABSTRACT

INTRODUCT ION

Scope of Investigation .................6

Prior Investigations $\ldots \ldots \ldots \ldots \ldots \ldots \ldots \ldots \ldots$

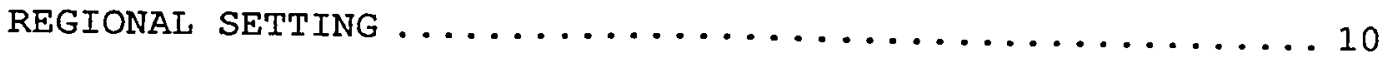

Physical Setting .................... 10

Geologic setting .................... 10

Franciscan Complex .................. 11

Wilson Grove Formation .................. 11

Slope Stability ........................ 13

SITE GEOLOGY ......................... 15

Subsurface Stratigraphy ............... 18

Boring Logs ...................... 18

Seismic Survey ................... 22

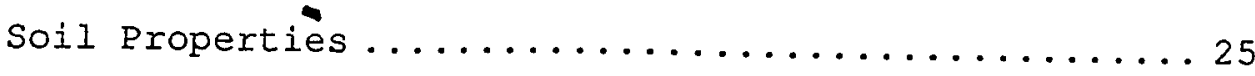

PRECIPITATION ANALYSIS .................. 27

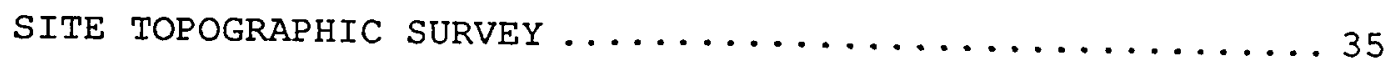

Prior Survey work .................... 35

Initial (Round 1) Site Survey .............. 35

Project Coordinate System ............ 36

Survey Accuracy .................. 37

Round 2 site survey ........................ 39 
SITE GEOLOGIC MODEL $\ldots \ldots \ldots \ldots \ldots \ldots \ldots \ldots \ldots \ldots 4$

Computer Methodology ................. 44

Topography .................... 45

Failure surface ................. 45

Groundwater Elevation ..............46

Geologic Cross Sections............. 46

FACTOR OF SAFETY ANALYSIS ................ 48

Analysis Type ..................... 48

Results ..................... 52

Low Water Level,

$\phi=27$ degrees, $c=0$ psf ...........55

High Water Level,

$\phi=27$ degrees, $\mathrm{C}=0$ psf ...........54

High Water Level,

$\phi=13$ degrees, $\mathrm{C}=0$ psf $\ldots \ldots \ldots \ldots \ldots 6$

High Water Level,

$\phi=7$ degrees, $\mathrm{C}=0$ psf...........57

High Water Level,

$\phi=0$ degrees, $c=200$ psf ..........59

High Water Level,

$\phi=7$ degrees, $C=200$ psf ...........59

Discussion $\ldots \ldots \ldots \ldots \ldots \ldots \ldots \ldots \ldots \ldots \ldots \ldots \ldots \ldots \ldots \ldots \ldots$

Wedge Failure Analysis .............663

Assumptions and Limitations ...........65

The Geologic Model..............65

Factor of Safety Analysis .........67 67 


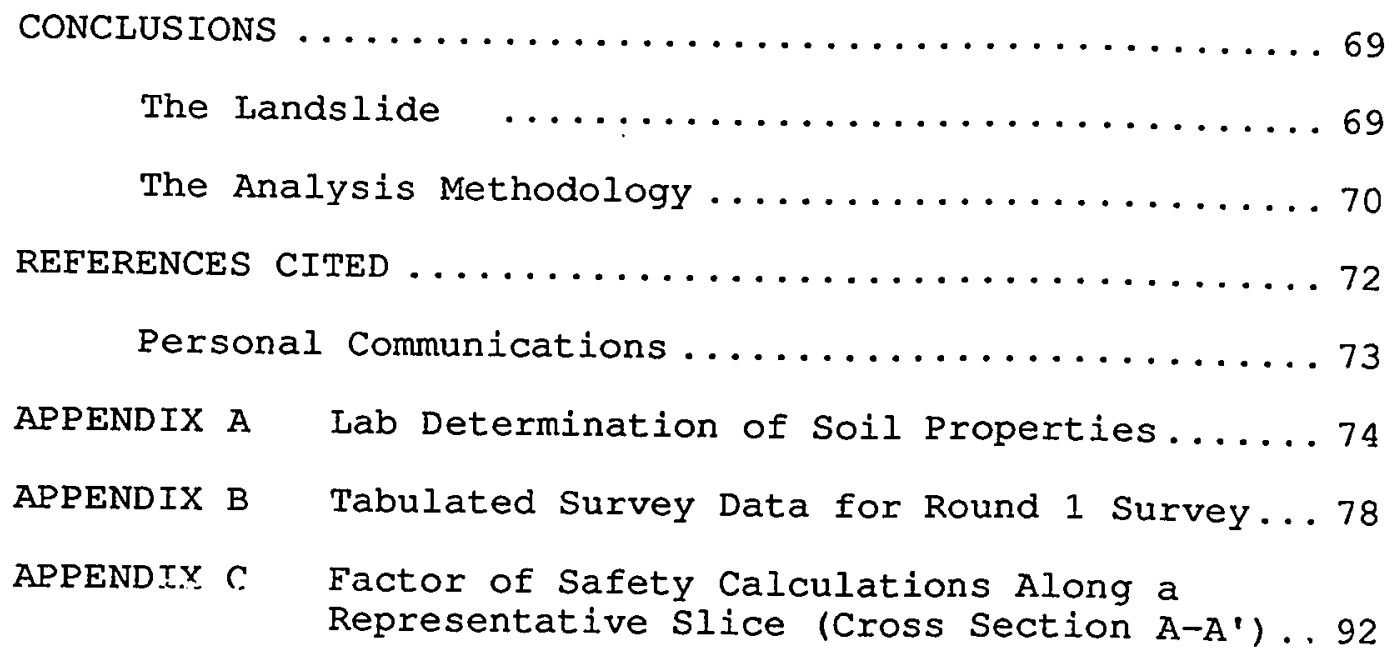


LIST OF ILLUSTRATIONS

Figure

Page

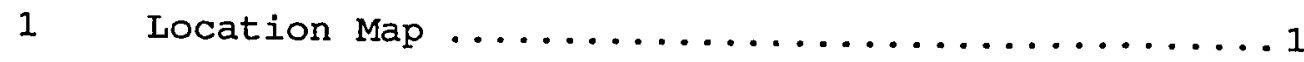

2 Aerial View of Slide From Northeast $\ldots \ldots \ldots \ldots 2$

3 Aerial View of Slide From West ................

4 Aerial Close-up View of Crown Fissure ........4

5 Aerial Close-up View of Pressure Ridges .......5

6 View Along Pressure Ridge ............. 6

7 View Into Deepest Section of Crown Fissure ....16

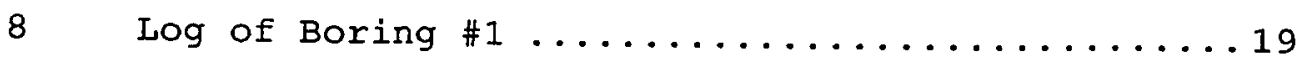

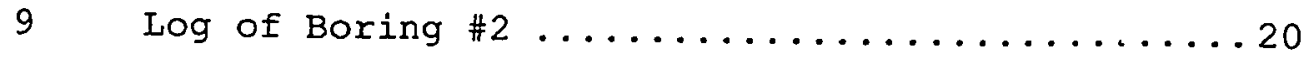

10 Cross Section Along Trace of Seismic Line, Depicting Four Major Velocity Units .........23

11 Yearly Rainfall, 1978 Through $1987 \ldots . . \ldots . . .28$

12 Monthly Rainfall, 1981-1982 and 1982-1983

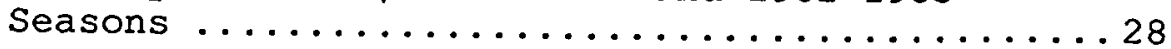

13 . Graphs Showing Correlation Between Daily

Rainfall and Slide Rate of Movement .........29

14 Pond in Crown Fissure Resulting From $15.9 \mathrm{~cm}$ (6.27 in) of Rain that Fell Over a Four Day

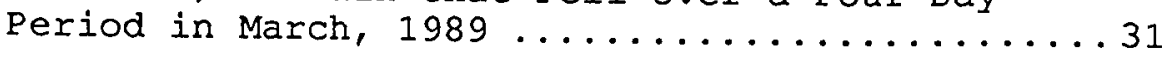

15 Water Emanating from Gopher Hole ........... 32

16 Color Infrared Aerial Photograph of Landslide .. 33

17 Geologic Cross Section at Low and High water . . 47

18 Factor of Safety Determination by the Infinite Slope Method .................49 
19 A Method of Factor of Safety Determination that Takes into Consideration Information

from the Geologic Model ................51

20 Factor of Safety Contours Under Conditions

of Low Water, where $\phi=27 \mathrm{deg}$. and $c=0$ psf...53

21 Factor of Safety Contours Under Conditions

of High Water, Where $\phi=27 \mathrm{deg}$.

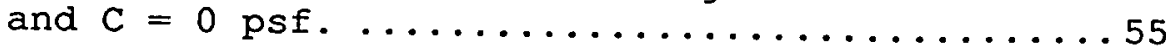

22 Factor of Safety Contours Under Conditions

of High Water, Where $\phi=13 \mathrm{deg}$.

and $\mathrm{C}=0$ psf. ..................... 57

23 Factor of Safety Contours Under Conditions

of High Water, where $\phi=7 \mathrm{deg}$.

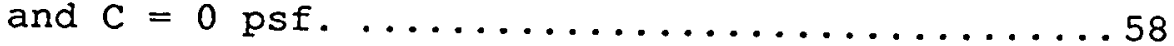

24 Factor of Safety Contours Under Conditions

of High Water, Where $\phi=0 \mathrm{deg}$.

and $\mathrm{C}=200$ psf. .................... 60

25 Factor of Safety Contours Under Conditions

of. High Water, Where $\phi=7 \mathrm{deg}$.

and $c=200$ psf. ...................61

26 Analysis as a Wedge Failure .............64

Plate

1 Site Base Map ................ in pocket

2 Site Topographic Map .............. in pocket

3 Topographic Perspective ........... in pocket 


\section{LIST OF TABLES}

Table

1 Error in Survey Readings From Multiple

Instrument Stations ................ 38

2 Variation Between Round 1 Survey Points

Located From Multiple Instrument Stations .....39

3 Comparison of Data From Round 1 and Round 2

Surveys .......................41

4 Variation Between Round 1 and Round 2 Survey

Results .......................42 
ABSTRACT

A COMPUTER-ASSISTED ENGINEERING GEOLOGIC INVESTIGATION

OF THE BLUCHER VALLEY LANDSLIDE,

SEBASTOPOL, CALIFORNIA

by John E. Romie

In March, 1983, following two years of abnormally high rainfall, a landslide formed in gently rolling hills southwest of Sebastopol, California. Tue Blucher Valley Landslide, a translational block glide, is characterized by deep crown fissures, which are oriented roughly parallel to two orthogonal joint sets, and conspicuous toe pressure ridges. The landslide, covering an area of approximately 8 acres, occurred on the nose of a spur ricge, where structural and topographic dips are 3 to 5 degrees and 8 to 12 degrees respectively.

Tiis study was undertaken to assess the geometry, causes, and stability of the landslide. Standard investigative techniques (site surveying, geologic mapping geophysics, and precipitation analysis) provided the level of information necessary to conclude that the landslide was likely caused by excessive rainfall, and that movement of the slide has ceased. To gain an improved understanding of landslide geometry, stability, and causative factors however, a new method of examining the variation of stability over the extent of the landslide was employed, through the generation of a computer model. The results of the analyses are presented in the form of contour maps depicting variations in factor of safety that are caused by subtle changes in water level and failed mass thickness. The new analysis method, in combination with analysis as a wedge failure, has lead to the 
conclusion that the landslide was likely caused by excessive pore pressures along the failure surface, in combination with wedging of the failed block caused by water filled fractures. A topographic high at the toe of the landslide probably helped to cease movement and acts as a buttress against future movement. 
During the early morning hours of March 3, 1983, following two consecutive seasons of abnormally high rainfall, a landslide covering an area of approximately 8 acres developed in gently rolling hills southwest of Sebastopol, in Sonoma County, California (fig. 1). Residents

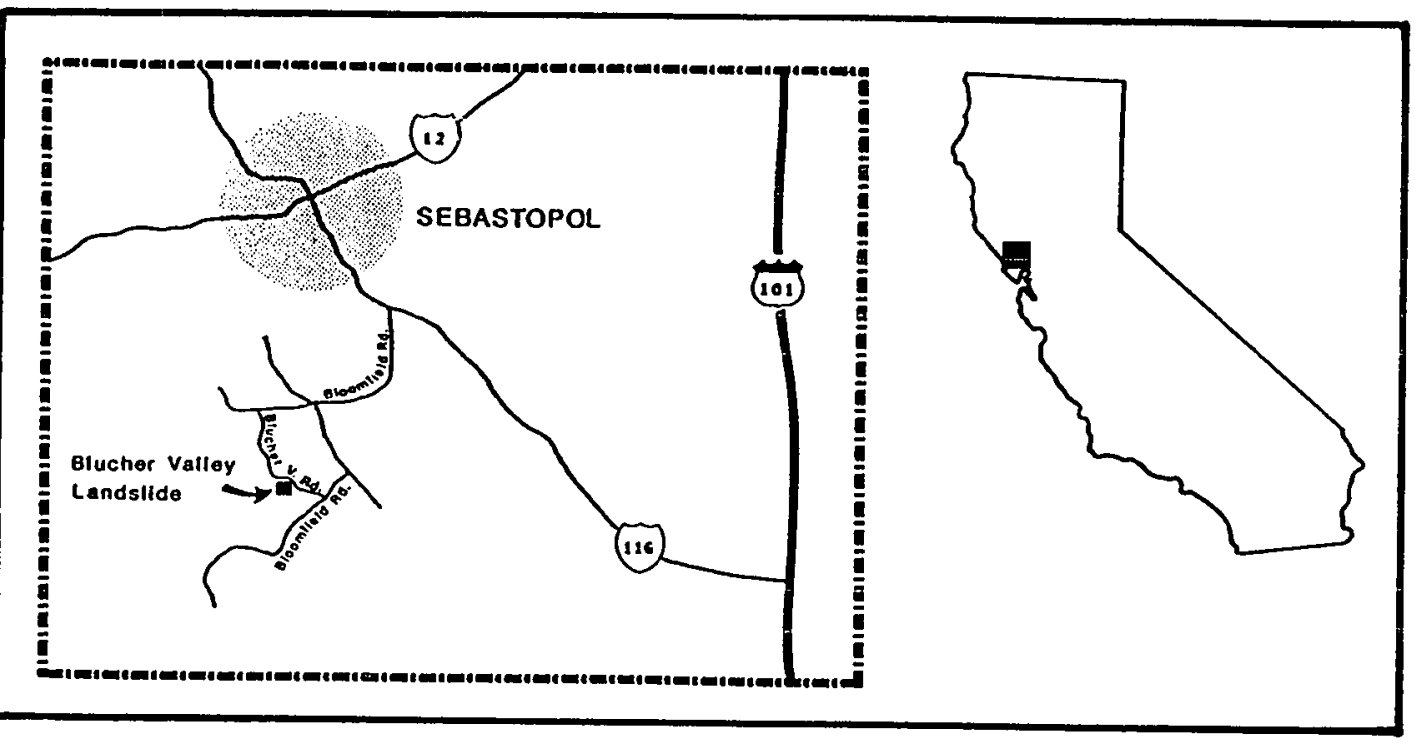

Fig. 1. Location Map

along Blucher Valley Road reported hearing what sounded like rolling thunder in the early morning hours as the slide mass moved down a shallowly inclined slide plane, forning a crown fissure up to $18.3 \mathrm{~m}$ (60 ft.) deep (Spittler, 1983; William cotton and Associates, 1983). The crown fissure forms an irregular shape that consists of nearly orthogonal segments oriented north and east, almost parallel to two nearly vertical joint sets (figs. 2, 3 and 4 ). The arcuate toe of 


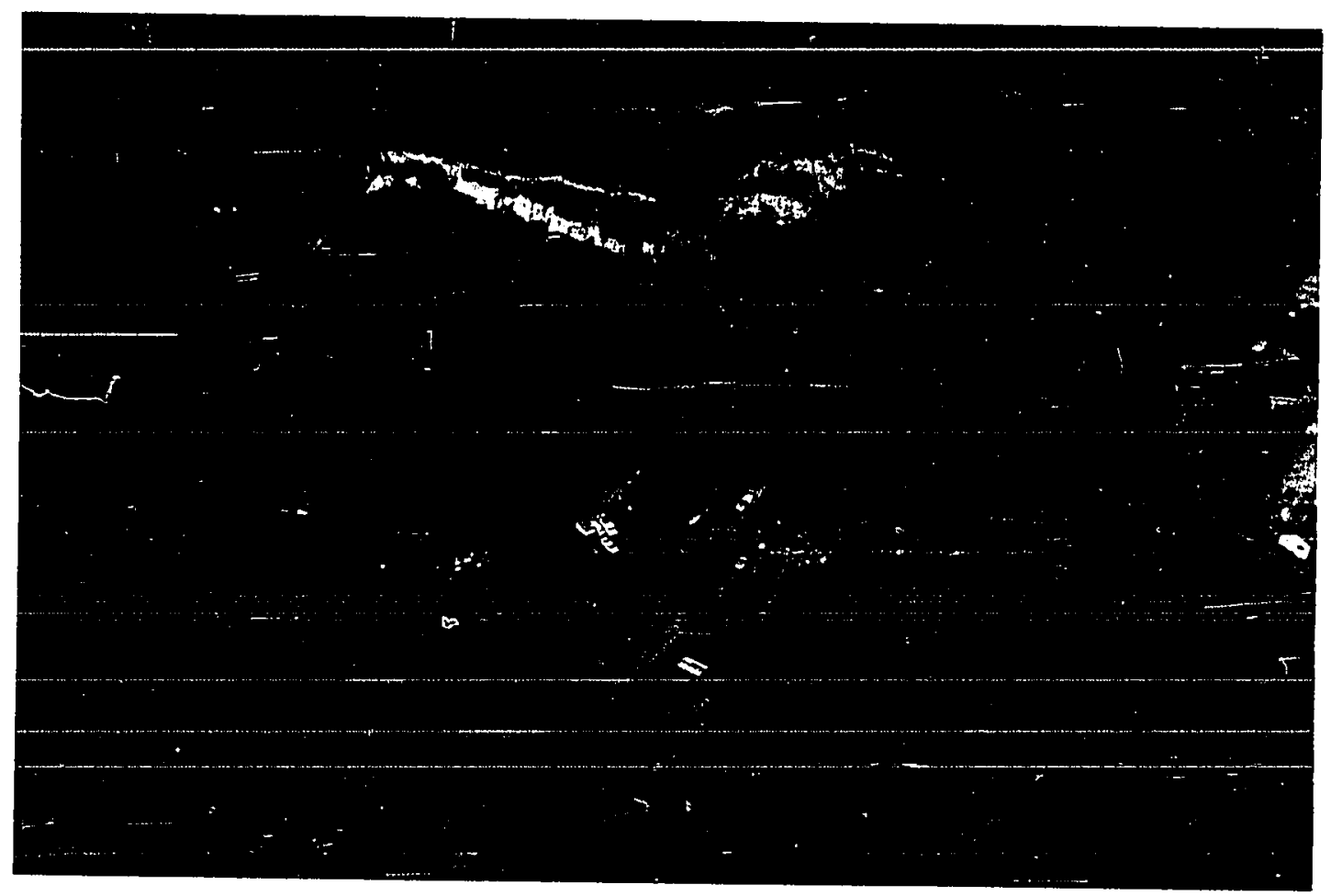

Figure 2. Aerial view of slide from northeast

the landslide is marked by conspicuous pressure ridges up to $2.5 \mathrm{~m}$ (8 ft.) high and $5 \mathrm{~m}$ (16 ft.) wide (Spittler, 1983), formed in response to movement of the slide mass against stable ground (figs. 2, 3 and 5).

The Blucher Valley landslide continued moving for a period of several weeks at rates of up to nearly $1 \mathrm{~m}$ (3 ft) per day. The landslide is generally confined to fenced pasture land, and damage, although severe, was limited to two homes, several utility structures, underground utilities, and driveways (fig. 6). Horizontal drainage wells were installed near the toe of the slide in an attempt to drain the slope 


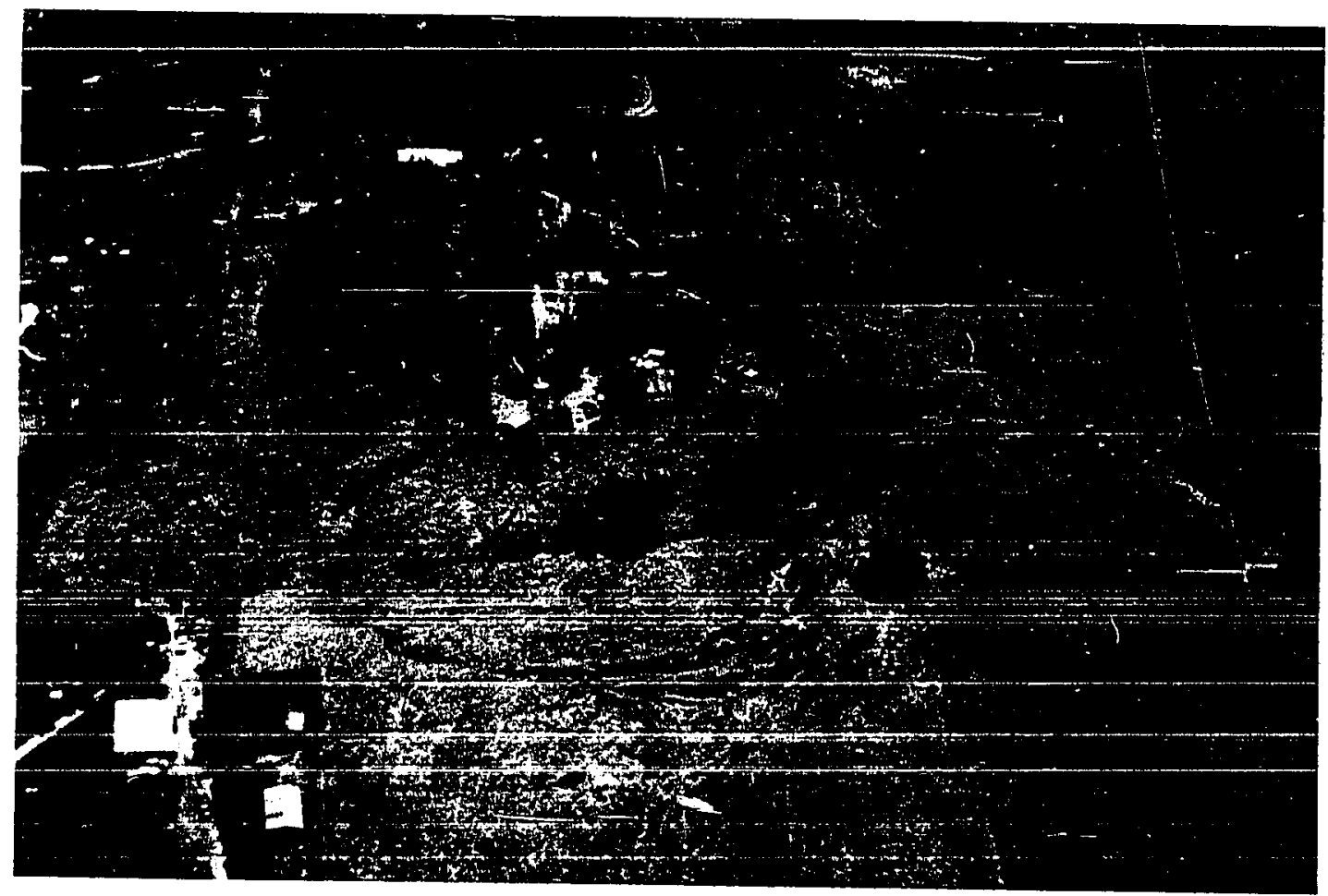

Figure 3. Aerial view from west.

and reduce pore pressures that were believed to be a major cause of the failure. While little success resulted from this activity, it is believed that no movement has occurred in recent years. This may be partially a result of greatly reduced yearly rainfall averages in the years following initial movement.

While landsliding is considered relatively common in Sonoma County, the Blucher Valley Landslide is unusual in several aspects (Spittler, 1983): 


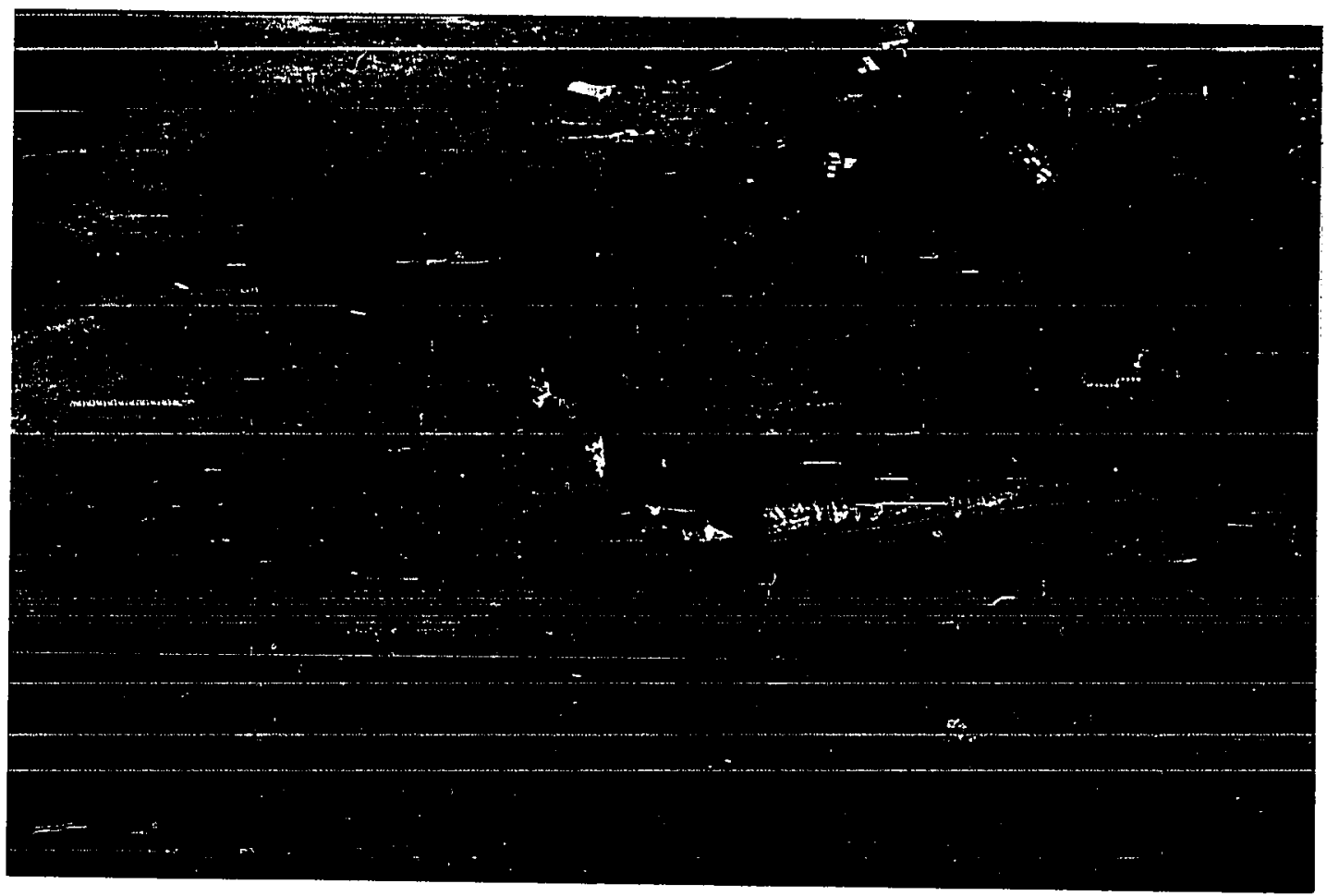

Figure 4. Aerial close-up view of crown fissure. View is from southwest and shows the orthogonal orientation of the fissures.

1) The geometry of the landslide and the competence of the failed block suggest that it is a translational block glide, as opposed to the more typical rotational slumps and debris flows that occur in the vicinity;

2) the topographic slope of the landslide is only between 10 and 20 degrees;

3) bedding planes within the wilson Grove formation, along which the landslide moved are inclined at less than 10 degrees; 


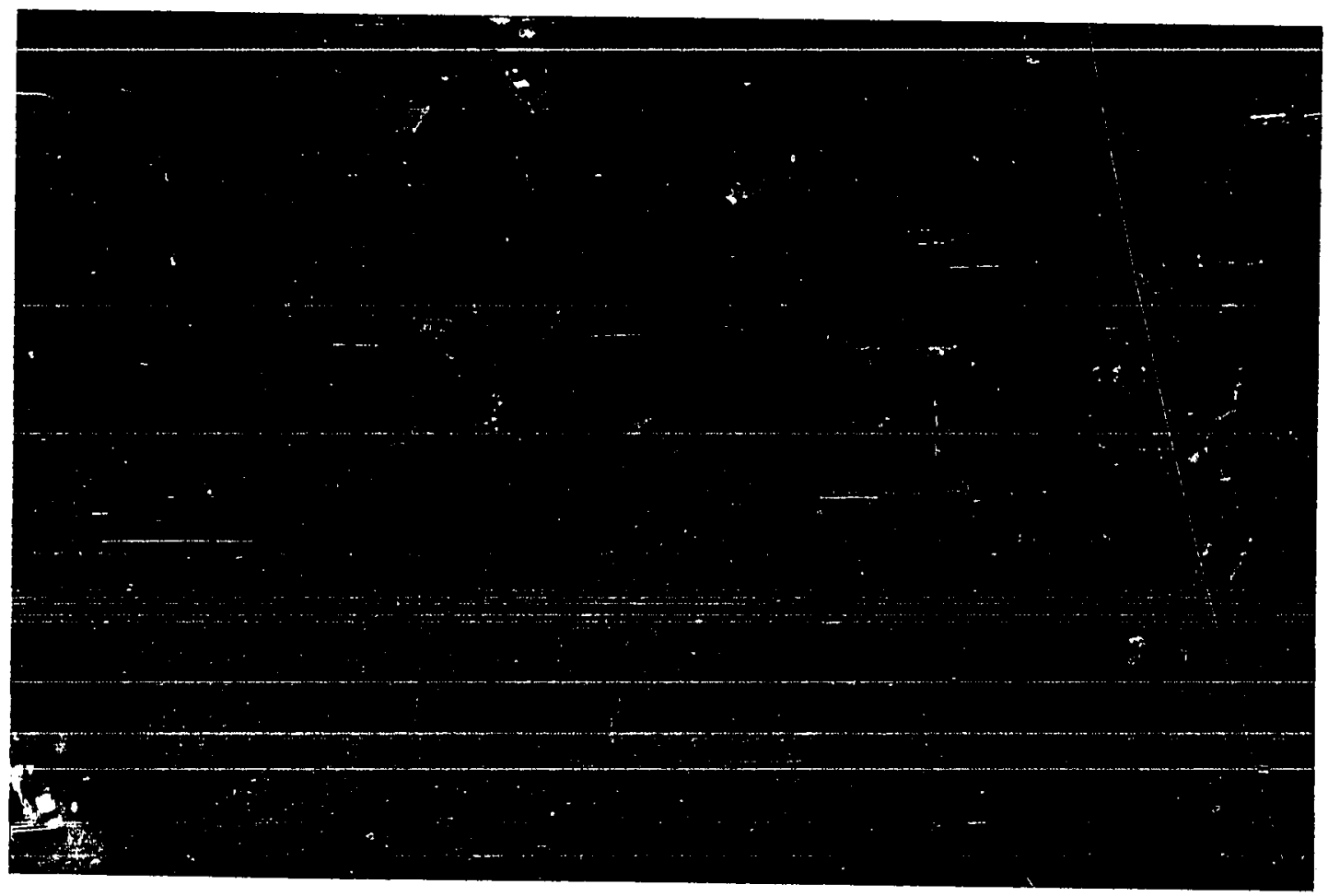

Figure 5. Aerial close-up view of pressure ridges. View is from northwest at high angle, and also shows the lack of disruption of topography from landslide movement.

4) failure occurred on the nose of a spur ridge;

5) the crown of the landslide opened as a deep, verticalwalled chasm; and

6) no evidence indicates that previous failures have occurred at this location. 


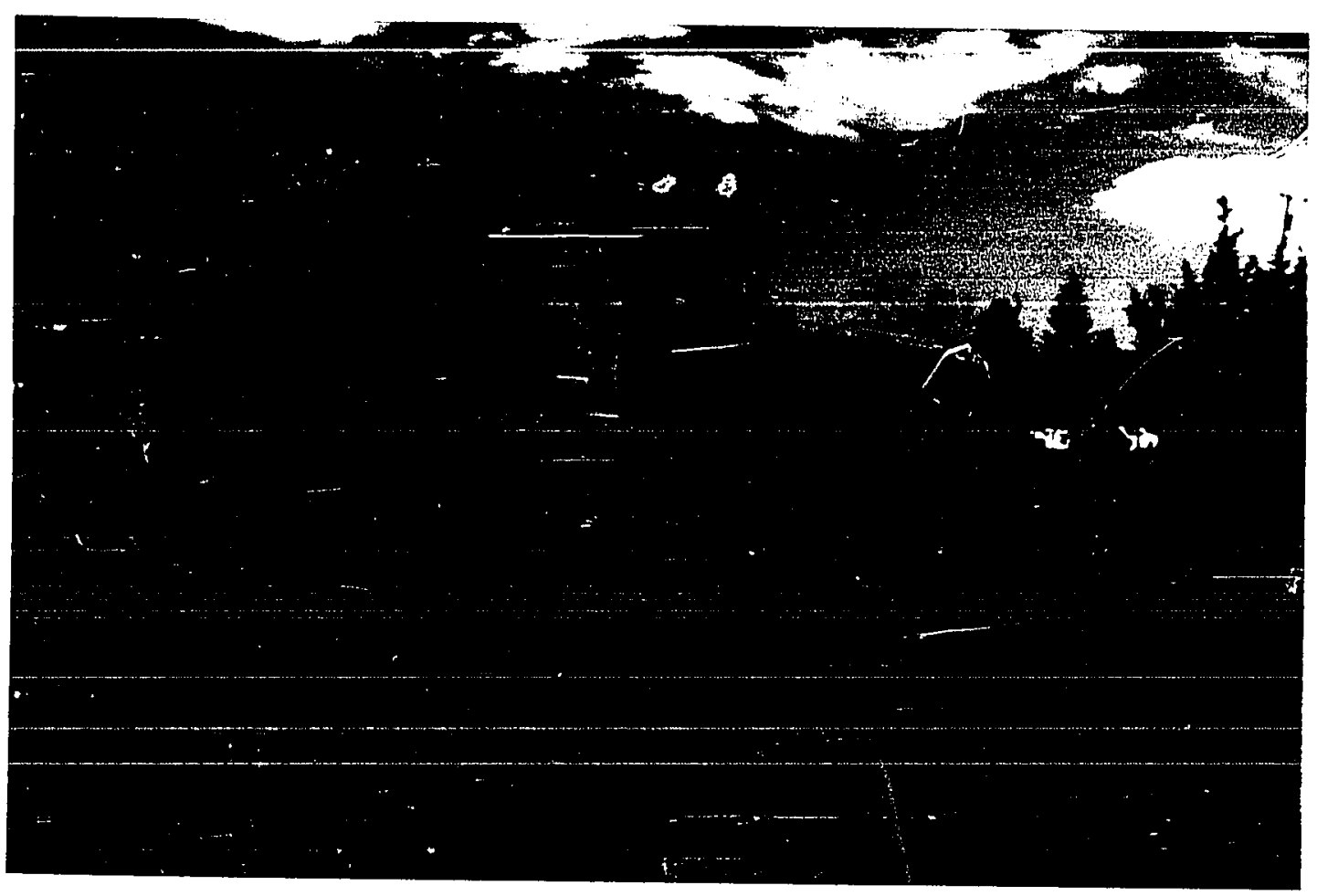

Figure 6. View along pressure ridge, showing resultant damage to a barn along the toe of the slide.

\section{Scope of Investigation}

The purpose of this investigation has been to determine the geometry of the landslide, causes for the failure, and the current state of stability. These factors have been addressed to a limited extent by previous investigators; the intent of this study has been to perform a more complete assessment than previously conducted. A further purpose of this study is to investigate new computer applications for the generation and display of models depicting the geologic 
and morphologic configuration of the slide, and the analysis of the current state of stability of the landslide.

In summary, this investigation has involved the following primary activities:

1) geophysics and engineering geologic mapping to determine landslide geometry and material characteristics;

2) topographic surveying, conducted in two phases, for the generation of a topographic map, and to acquire evidence of any continued movement;

3) an analysis of rainfall in the vicinity of the landslide, to determine the likelihood of increased rainfall as an underlying factor causing failure;

4) the development of a geologic model of the landslide as a means of depicting slide geometry, and;

5) use of the computer model to investigate the cause of failure and current state of stability.

\section{Prior Investigations}

Previous investigations of the Blucher Valley Landslide resulted primarily in overviews of slide geometry, causative factors, and suggested remedial measures. To date, investigators have relied on relatively limited detailed information with which to fully define the slide, largely because sufficient funds have not been available to perform a complete geologic investigation.

Spittler (1983) presented an overview of the areal geology, slide geometry, timing, and structural damage. He has described the material in the Wilson Grove Formation as 
massive, poorly bedded, very fine grained clayey marine sandstone with suspected lenses and beds of sandy shale. Because of the nearly flat-lying failure surface, he noted that the material in this surface must be quite weak and inferred that it is likely a clay bed.

Eric Olsborg (1987, North Coast Consultants, personal communication), drilled two shallow test borings within the slide, roughly midway between the crown and toe, yielding boring logs and penetration blow-counts at various intervals within the borings (figs 7 and 8 ). Casing in both boreholes was subsequently sheared by movement of the slide, yielding the greatest level of information that is currently available on location (depth) of the failure surface. Boring logs supplied by olsborg indicate the presence of brown to gray clayey sandstone of low hardness in the vicinity of the slide plane. Although samples from this interval have since been discarded, he noted that clays in the interval consist of discreet thin laminae within the friable sand matrix. Although one of the boreholes completed by olsborg has been destroyed, the second has been utilized during the course of this investigation for water level monitoring.

William Cotton and Associates (1983) completed a detailed topographic and engineering geologic map, based on their own survey of the site. Also generated were a series of preliminary cross sections, based on detailed mapping within the crown fissures, logging of horizontal drain holes placed within the landslide mass, and well logs provided by Eric olsborg. The primary purpose of the study was to ascertain the necessary actions required to control movement of the landslide mass. Conclusions were presented in an unpublished report to the landowners affected by the slide. Bill Fowler (1987, personal communication) took part in this 
study and observed what appeared to be minor sand boils in the vicinity of the tension fractures, indicating the possibility that very high pore pressures and/or liquefaction occurred at depth.

The cause of the slide suggested by all previous investigators is high pore-water pressure, combined with adverse bedrock structure and low shear strength of materials along the slide failure surface. 
REGIONAL SETTING

\section{Physical Setting}

The Blucher valley landslide is located within the coast Ranges geomorphic province, approximately $72 \mathrm{~km}$ (45 mi) north-northwest of San Francisco, and approximately $6 \mathrm{~km} \mathrm{(4}$ mi) southwest of the Sebastopol city center, California. The area is a broad dissected plateau recognizable throughout the area between Santa Rosa Valley and the Pacific Ocean (Travis, 1952) and is expressed by flat topped hills and ridges. In the vicinity of the slide, topography ranges in elevation from 30 to $300 \mathrm{~m}$ (100 to $1000 \mathrm{ft}$.) above mean sea level (MSL). Surface elevation on the landslide ranges from 55 to $100 \mathrm{~m} \mathrm{(180} \mathrm{to} 330 \mathrm{ft}$. ) MSL.

Climate in the area is temperate, with pronounced wet and dry seasons. Annual precipitation averages between approximately 81 and $91 \mathrm{~cm}$ (32 and $36 \mathrm{in}$ ), and daytime temperatures range from about 4 to 32 degrees $C(40$ to 90 degrees F) during winter and summer months respectively.

Geologic setting

Only two formations are present in the immediate vicinity of the Blucher Valley slide. Basement rocks consist of sedimentary, volcanic and metamorphic lithologies of the Franciscan Complex. These rocks are overlain by fine-grained sandstone of the Late Miocene and Pliocene Wilson Grove (formerly Merced) Formation. The Blucher Valley landslide formed within the Wilson Grove formation. 
Franciscan Complex

The Franciscan Complex consists chiefly of tectonically as well as depositionally juxtaposed bodies of graywacke, shale, sandstone, mafic volcanic rocks (greenstone), melange, broken formation, and ultramafic rocks (Fox, 1983). The complex may be the product of several episodes of structural accretion, and the age of the complex as a whole may vary from place to place. Fox (1983) assigns a Paleocene and/or Eocene age to the Franciscan Complex in this area on the basis of its proximity to parts of the complex to the northwest, which contain fossils of this age. Other investigators have placed the age of the Franciscan Complex at Upper Jurassic to Cretaceous (Travis, 1952; Bedrossian, 1982).

Wilson Grove Formation

The wilson Grove Formaition is characterized for the most part by well sorted, white to buff or gray, fine-grained unconsolidated, massive to thickly bedded sandstone (Fox, 1983; Bedrossian, 1982; Spittler, 1983). Also present are minor amounts of gravel, clay and tuff. The formation is up to $150 \mathrm{~m}$ (500 ft.) thick and was deposited under beach and shallow marine conditions in a relatively shallow marine embayment which opened to the ocean to the west (Travis, 1952).

Interbedded with the sandstones that characterize the Wilson Grove Formation is a thin, discontinuous but predominant bed of water laid tuff (Travis, 1952; Bedrossian, 
1982). The tuff is characteristically white where freshly exposed and tends to form resistant bluffs on hillsides, and waterfalls where it crosses drainages. Ashy sands are also present stratigraphically above and below the tuff bed at some localities. Examination of the tuff indicates a thickness of 1.5 to $12 \mathrm{~m}$ ( 5 to $40 \mathrm{ft}$ ) and, while it appears that the unit was deposited on a somewhat irregular surface, it is generally flat lying and follows close to contour where exposed (Bedrossian, 1982). In several places, the tuff bed appears to be offset 24 to $30 \mathrm{~m}$ ( 80 to $100 \mathrm{ft}$ ), suggesting the possibility two or more tuff beds may be present (Bedrossian, 1982). Although they may exist at depth, none of these lithologies have been found exposed in close proximity to the Blucher valley Landslide.

Early workers correlated Wilson Grove strata with the type Merced Formation of the San Francisco peninsula, on the basis of marine megafauna that were considered Pliocene (Fox, 1983). The correlation was later questioned on the basis of faunal and Iithologic differences between the type Merced and Wilson Grove Formation. In addition, the pumice lapilli tuff that is exposed at or near the type locality of the wilson Grove Formation, $11 \mathrm{~km}(6.8 \mathrm{mi})$ north of Sebastopol, has yielded $\mathrm{K}-\mathrm{Ar}$ ages that place its formation in late Miocene and Pliocene (Sarna-Wojcicki, 1976; Bartow and others, 1973; Fox, 1983). The Merced Formation has been considered to be of middle to upper Pliocene age or younger (Travis, 1952), and Fox (1983) proposed the name Wilson Grove Formation to distinguish deposits of the Sebastopol region from those of San Francisco. 


\section{Slope stability}

Landslides are relatively common in Sonoma County and are largely a result of geologic characteristics and processes, and precipitation. The largest, most abundant, and most obvious landslides are located in Franciscan terrain and are principally classified as earthflows and rotational slides (Smith, 1986). Bedrosian (1982) cites the following primary geologic factors as affecting slopes in the vicinity:

(1) intensely sheared Franciscan melange matrix, which commonly weathers to clay-rich, highly expansive soils that swell when wet, and shrink when dry, contributing to the development of landslides;

(2) sheared blocks of serpentine of the Franciscan melange, especially when combined with high proportions of sheared matrix, which are prone to downslope movement;

(3) erosion (especially of Franciscan matrix, serpentine, and Wilson Grove Formation where dissected with animal burrows), which commonly produces steep sided gullies and ravines, increasing sediment load in streams and removing vegetation and lateral support

(4) faults, shear zones and related creep and earthquake shaking which form zones of weakness, distorted ground, and disturbances to the equilibrium state of slopes by breaking intergranular bonds and decreasing the shear strength of slope materials, and;

(5) concentrated precipitation, which reduces the stability of rocks and slopes by increasing erosion, disturbing soil cohesion, increasing soil density, and increasing pore pressures. 
Smith (1986) conducted a slope stability investigation in the area referred to as the Petaluma Dairy Belt in southern Sonoma County, approximately $16 \mathrm{~km}$ (10 $\mathrm{mi}$ ) southeast of the Blucher Valley Landslide. A notable conclusion of his study, as it applies to this investigation, is as follows:

Scarps and graben-like features within the Wilson Grove Formation strongly suggest that the underlying Franciscan material is slowly creeping outward and downward, undermining the overlying Wilson Grove deposits. As the underlying slopes slowly fail, the dip of the overlying Wilson Grove Formation increases until it, too, is oversteepened and begins to fail, usually as a block glide landslide. The failure surfaces normally are within tuff or clay beds within the Wilson Grove Formation, or along the contact with the underlying Franciscan melange. 
SITE GEOLOGY

The Blucher Valley Landslide is located entirely within Wilson Grove Formation sediments. The geologic section exposed within the crown fissures, and logs of two borings drilled at the sice clearly indicate the presence of wilson Grove Formation from ground surface to depths below the failure surface. Exposed material within the crown fissures consists primarily of buff-to-brown, very fine grained silty and clayey sandstone. The sands are well sorted, consisting mostly of feldspar, quartz(?), and lithic fragments. Sands of the Wilson Grove Formation at this locality do not contain noticeable amounts of tuff or volcanic glass that is present elsewhere in Sonoma County; they are probably somewhat above or below the tuffaceous section of the formation that is described by Bedrossian (1982), Fox (1983) and Travis (1952). The unit is massive to poorly bedded, and bedding is expressed by subtle color changes, thin gray clay beds and laminations, and thin lenses of red-brown sandy shale. The sandstones are weakly consolidated, and probably exhibit moderate shear strength, as indicated by the vertical walls of the fissure, which have continued to stand for 7 years (fig. 7).

Two sets of near-vertical joints are clearly visible within the fissure, trending east-west and N5-10W. They are variably spaced, from approximately 0.6 to $1.5 \mathrm{~m}$ (2 to $5 \mathrm{ft}$ ) or greater. The orientation of the crown fissure closely parallels these joint systems, and the fissure walls are often nearly planar from the influence of the joints. Sandstone parting also parallels jointing. 


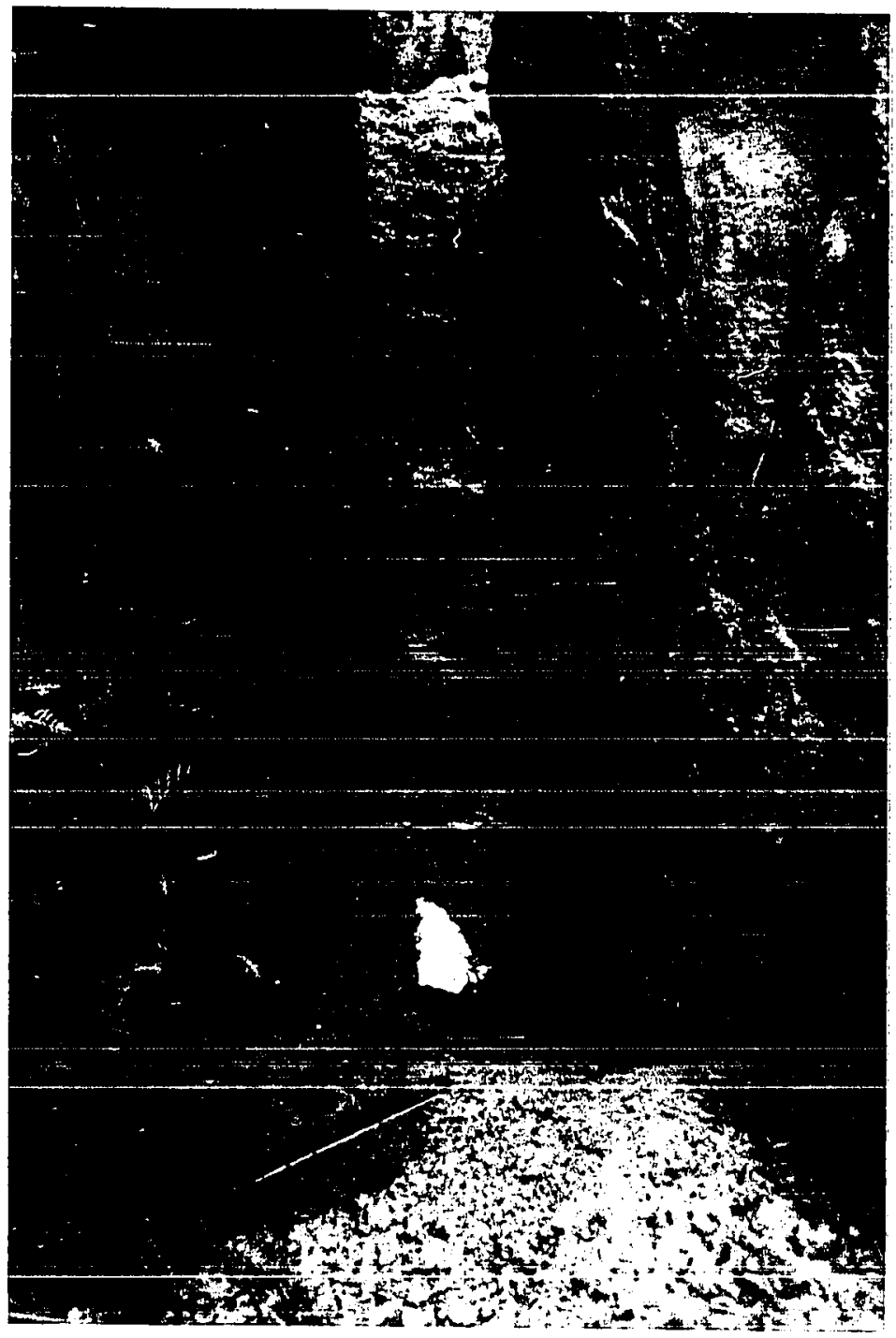

Figure 7. View into deepest section of crown fissure, showing vertical walls which remain standing after 7 years.

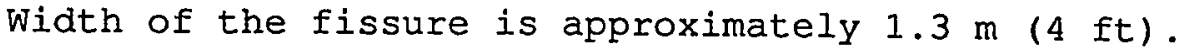

Bedding within the Blucher Valley Landslide dips gently to the northeast. Accurate bedding orientations at the site are difficult to obtain with a field compass, but were 
determined by surveying, with a theodolite and EDM, three points at the same stratigraphic level, and then performing three-point calculations as described in many field geology texts, (Compton, 1962). The method was employed at three areas within the crown fissure and the results were averaged, yielding a structural orientation of N31W, 4.5NE. The direction of movement of the failed material suggests that the structural orientation is also the orientation of the failure surface. Measurements taken along the upslope fissure wall differed only slightly from those along the lower wall, indicating that very little, if any, rotatior of the failed mass took place.

Exposures within the deepest section of the crown fissures display units that are relatively uniform in composition but can be divided based on subtle variations in weathering into: (1) a 3 to $3.7 \mathrm{~m}$ (10 to $12 \mathrm{ft}$ ) thick section of moderately weathered fine sand that is exposed at the base of the fissure; (2) a 5 to $7.6 \mathrm{~cm}$ (2 to $3 \mathrm{in}$ ) thick bed of sandy shale that appears to be continuous throughout the fissure, and; (3) an upper sand unit that is 3 to $3.7 \mathrm{~m}$ (10 to $12 \mathrm{ft}$ ) thick and moderately to heavily weathered. Approximately 0.3 to $0.6 \mathrm{~m}$ ( 1 to $2 \mathrm{ft}$ ) of $\mathrm{A}$ horizon has formed on the upper sand unit. The upper sand unit is clearly more weathered, and more heavily fractured than the lower sands. Clay-filled burrows are locally present in both of the sandstone units. Occasional thin beds or laminations of gray clay are present in both of the sand units, but appear more prevalent in the lower unit. This clay is very hard when dry, and very plastic when saturated. 


\section{Subsurface Stratigraphy}

Boring Logs

Boring logs prepared and supplied by Eric Olsborg (figs. 8 and 9 [1987, personal communication]) reveal a subsurface stratigraphy that appears consistent with that exposed in the crown fissures. The borings are located approximately midway between the crown fissure and the pressure ridge (plate 1). Lithologies within the borings consist generally of fine silty sand and silt, with clay existing in variable amounts both within the matrix and as thin lenses. Both borings were drilled approximately 3 weeks after initial movement of the slide, and perforated PVC casing was installed from ground surface to total depth in each. The slide plane in each of the borings has been inferred by Olsborg, based on the location of sheared casing that resulted as the landslide continued movement.

Samples were collected during drilling in both Boring \#1 and Boring \#2. In Boring \#1, samples were obtained with an FEA (Spargue \& Henwood) sampler, driven by a $127 \mathrm{~kg}$ (230 lb) hammer with a $0.76 \mathrm{~m}$ (30 in) drop. The FEA sampler has an outside diameter of $7.62 \mathrm{~cm}(3.0 \mathrm{in})$, and an inside diameter of $6.17 \mathrm{~cm}(2.43 \mathrm{in})$. Standard penetration resistance $(\mathrm{N})$ is determined using a standard penetration sampler $15.08 \mathrm{~cm}[2.0$ in] outside diameter, $3.61 \mathrm{~cm}$ [1.42 in] inside diameter, driven by a $63.5 \mathrm{~kg}$ [140 1b] hammer dropped from a height of $0.9 \mathrm{~m}$ [3 ft]), The blows per foot counted during drilling at Boring \#1 are significantly different from those resulting from a standard penetration sampler, due largely to increased end area of the FEA sampler and the increased hammer weight. Simple ratios of the end area of the samplers, and of the force applied by each weighted hammer have been applied to 


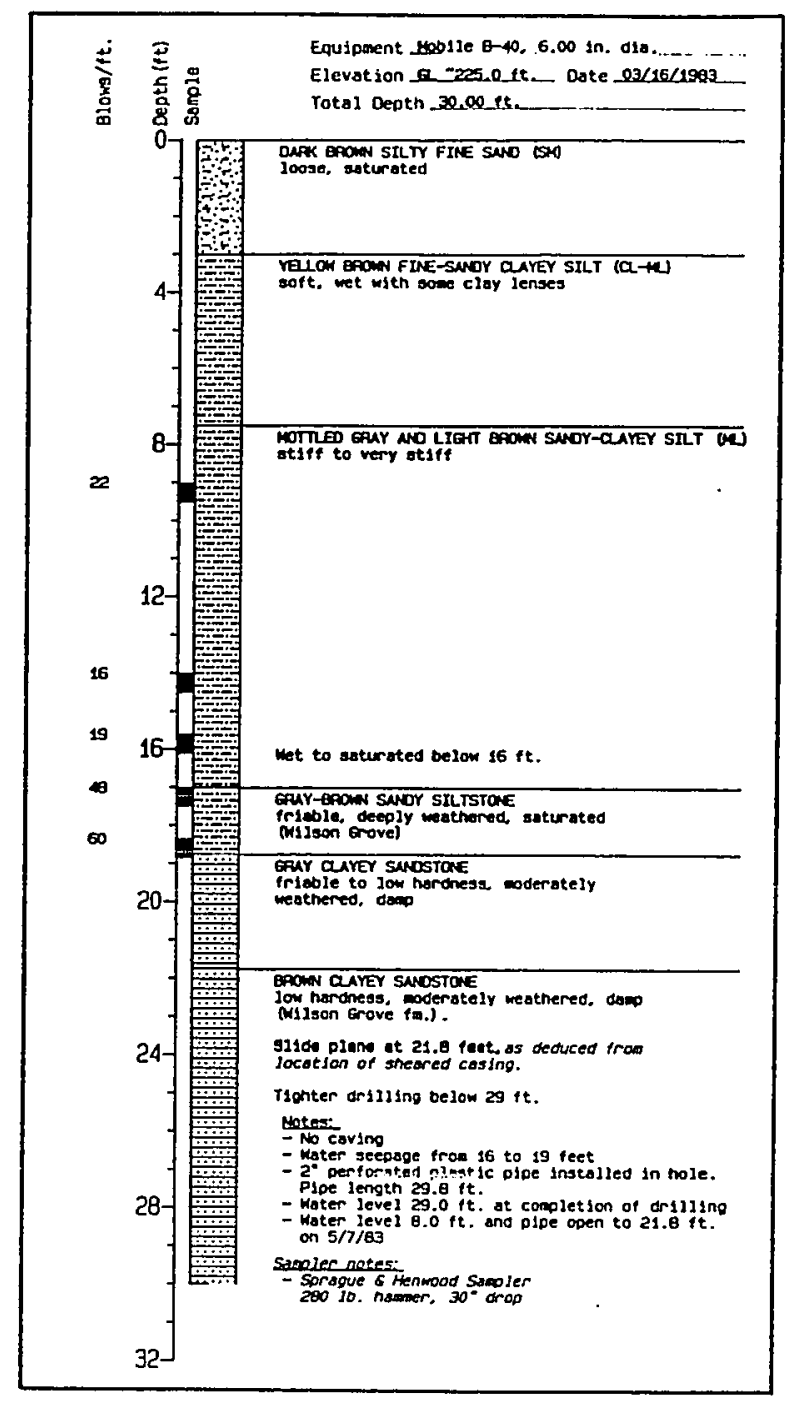

Figure 8. Log of Boring \#1. This boring was destroyed in the several years following installation. This is a rendition of the original boring log supplied by Olsborg (1987, personal communication), in which descriptive text and soil data are identical to that of the original log. Italicized text in descriptions was not present on the original log, but was added following discussions with the originator. Refer to plate 1 for boring location. 


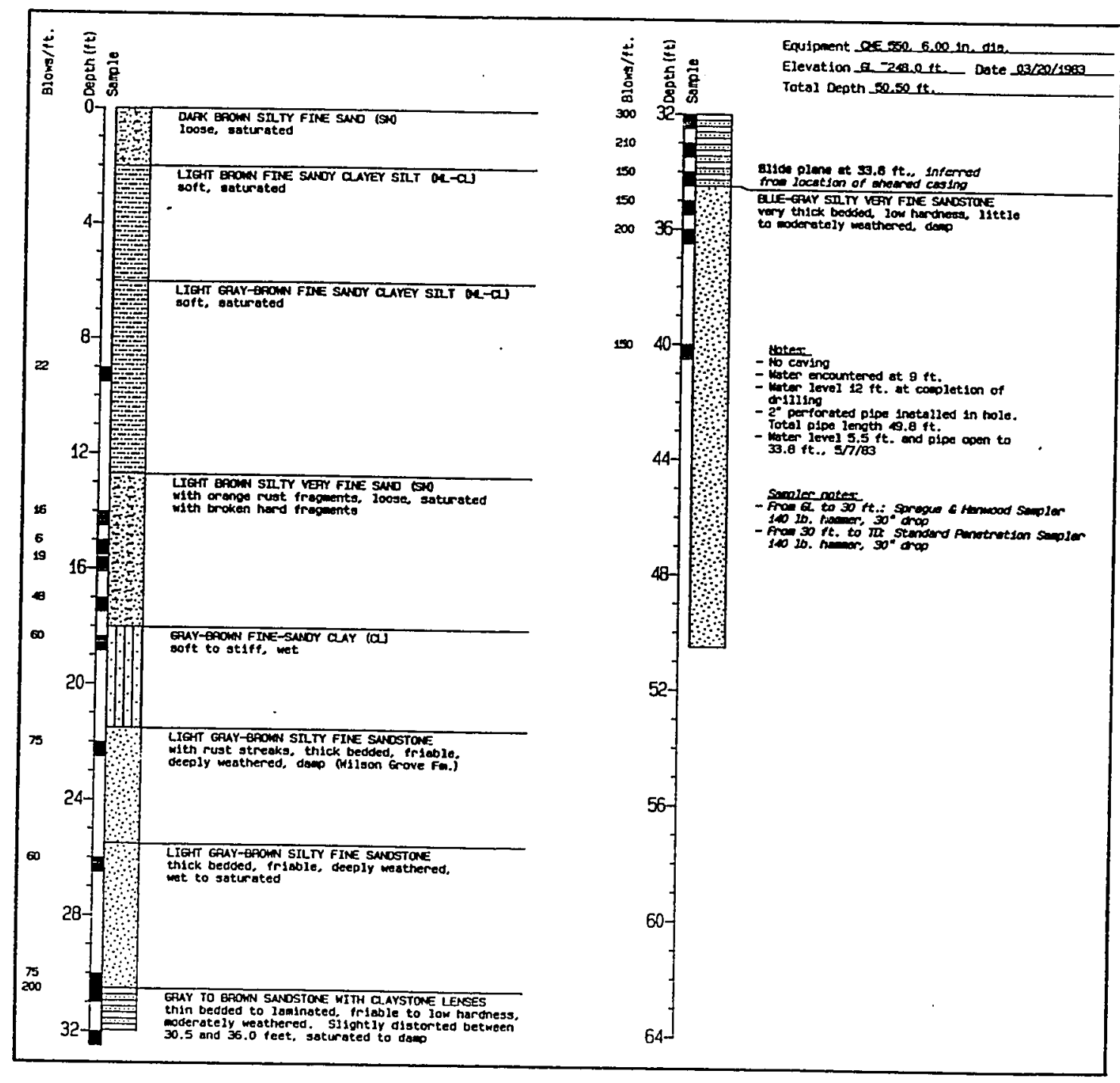

Figure 9. Log of Boring \#2. This is a rendition of the original boring log supplied by olsborg (1987, personal communication), in which descriptive text and soil data are identical to that of the original log. Italicized text in descriptions was not present on the original log, but was added following discussions with the originator. Refer to plate 1 for boring location. 
arrive at a conversion between $\mathbf{N}$ and the penetration blowcounts of the FEA sampler:

$$
\begin{aligned}
& N=0.64 \times \text { FEA counts }\left(63.5 \mathrm{~kg}\left[\begin{array}{lll}
140 & 1 \mathrm{~b}
\end{array}\right] \text { hammer }\right) \\
& N=1.28 \times \text { FEA counts }(127 \mathrm{~kg}[280 \mathrm{lb}] \text { hammer })
\end{aligned}
$$

Blowcount data in intervals sampled with the FEA sampler were roughly converted to standard counts by olsborg, and the data presented on both logs take this conversion into account:

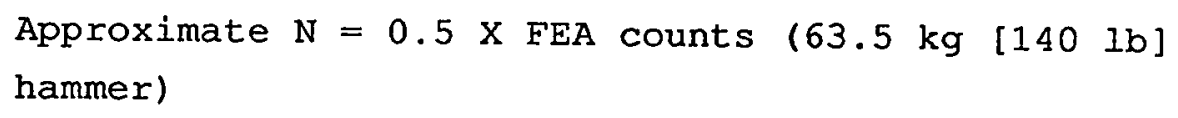

Lambe and Whitman (1969) present a correlation between $N$ and the friction angle of the material. Although this correlation is only an approximation, it can be used to estimate strength at the failure surface. Samples (and $\mathrm{N}$ values) were not collected at the depth of the failure surface in Boring \#1. Those in Boring \#2, however, would seem to indicate very high strength materials at the failure 
surface (friction angle greater than $44 \mathrm{deg}$ ). The blowcounts, however, take into consideration a relatively thick section ( 0.15 to $0.3 \cdot \mathrm{m}$ [6 to $12 \mathrm{in}])$, and thin laminations or seams of weaker material which could conceivably have provided surfaces of movement, are not necessarily taken into account.

Seismic Survey

A shallow seismic cefraction survey was conducted during this investigation in an effort to gain further information on subsurface stratigraphy and structure, especially at or near the failure surface. An initial single channel survey, located along a southwest-northeast trending line from Boring \#2 to a point downslope of the pressure ridge (plate 1), was conducted so that the lithology in the borehole could act as a control. The seismic line was oriented roughly parallel to structural dip with the hope that improved information on the location and dip of the failure surface could be discerned. Geophones were spaced at intervals of $3 \mathrm{~m}$ (10 ft), in an effort to gain the greatest density and quality of information from the relatively shallow depths that can be studied with the low seismic energy provided by hammer blows.

Interpretation of the seismic data acquired, in the form of an elevation profile, is presented in figure 10. Four different units were established based on distinct variations in velocity. The determination of probable lithologic units based on longitudinal wave velocities is not a simple task, due to the range of velocities that may be exhibited by any material, and the variations in lithology that may exist within any unit. Lithologies suggested herein are based on the ranges of velocities for representative materials, as presented in Mooney (1984). 


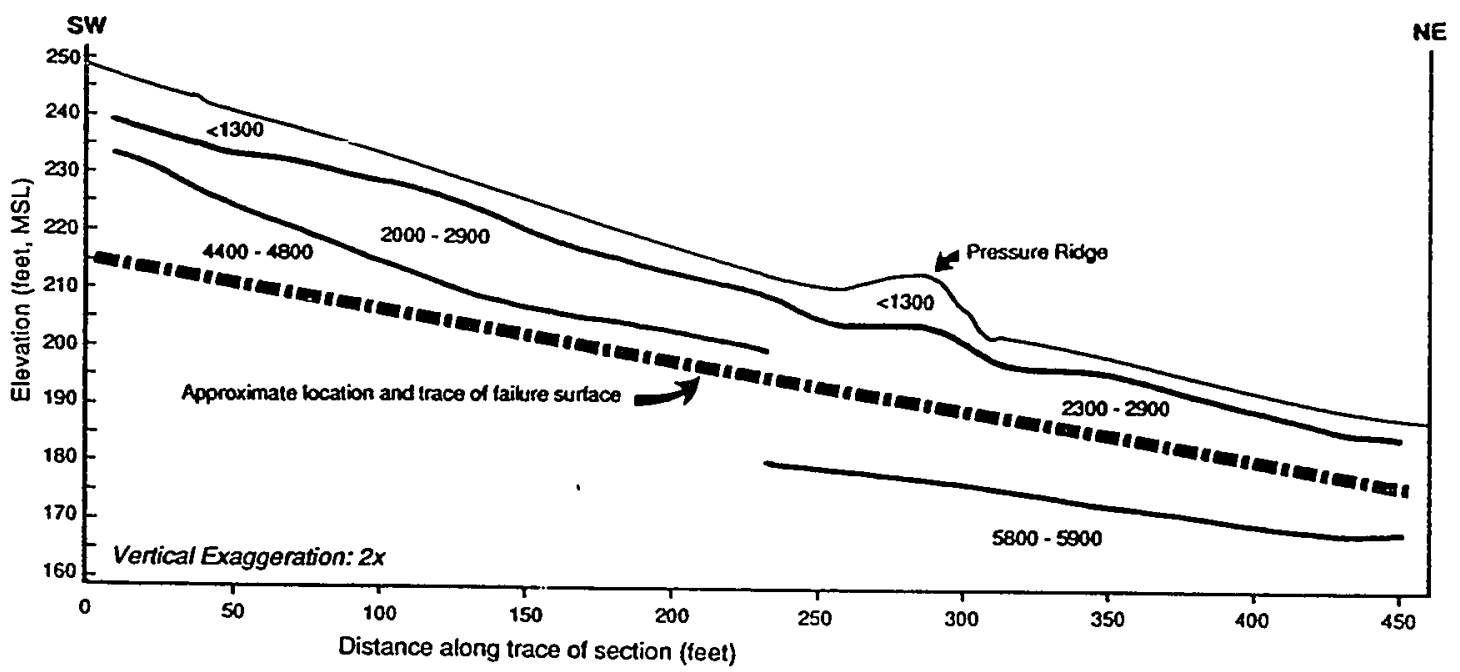

Figure 10. Cross section along trace of seismic line (plate 1), depicting four major velocity units interpreted from the data. Velocities are in $\mathrm{ft} / \mathrm{sec}$.

The uppermost unit, exhibiting a velocity of 300 to 400 $\mathrm{m} / \mathrm{sec}$ (1000 to $1300 \mathrm{ft} / \mathrm{sec}$.$) , is present to a depth of 1.0$ to $2.4 \mathrm{~m}$ ( 3 to $8 \mathrm{ft.}$ ) along the entire length of the profile and probably represents the weathered zone of material. The zone generally decreases in thickness from the southern (upslope) to the northern (downslope) end of the line.

Beneath the weathered zone lies a unit that varies in thickness from $1.8 \mathrm{~m}$ ( $6 \mathrm{ft}$. ) along the southern half of the seismic line, to as much as $8.5 \mathrm{~m}$ (28 ft.) along the northern half. Velocity in this unit varies between 610 and $884 \mathrm{~m} / \mathrm{sec}$ (2000 and $2900 \mathrm{ft} / \mathrm{sec}$.$) , and probably indicates the presence$ of weakly consolidated sands, possibly with varying clay and/or moisture contents. 
Along the southern half of the line, the existence of a third velocity unit beneath the weakly consolidated material is suggested. Velocities within the unit range from 1340 to $1463 \mathrm{~m} / \mathrm{sec}$ (4400 to $4800 \mathrm{ft} / \mathrm{sec}$ ). These velocities may indicate an increase in moisture, clay content, and/or consolidation in the sandy material.

Along the northern half of the seismic line, at depths of $5 \mathrm{~m}$ (17 ft.) at the north end to $8.5 \mathrm{~m}$ (28 ft.) to the south, much higher velocities are encountered. The velocities, in the range of $1768 \mathrm{~m} / \mathrm{sec}$. (5800 ft/sec) to 1798 $\mathrm{m} / \mathrm{sec}(5900 \mathrm{ft} / \mathrm{sec})$, may indicate either greatly increased consolidation of the material and/or increased clay contents, or the presence of relatively weak bedrock. The velocity of water generally falls in the range of 1430 to $1680 \mathrm{~m} / \mathrm{sec}$ (4700 to $5500 \mathrm{ft} / \mathrm{sec})$, which is considerably lower than that observed within this velocity unit. It is possible, however, that water exists within bedrock materials in this unit.

Some correlation exists between the interpreted seismic data and the log of Boring \#2 (fig. 9), which lies approximately $1.8 \mathrm{~m}(6.0 \mathrm{ft}$.$) west of the southern end of the$ seismic line. Most notably, the abrupt increase in velocity at a depth of approximately $4.3 \mathrm{~m}$ ( $14 \mathrm{ft}$. ) is roughly correlative with an increase in blow counts that occurs at a

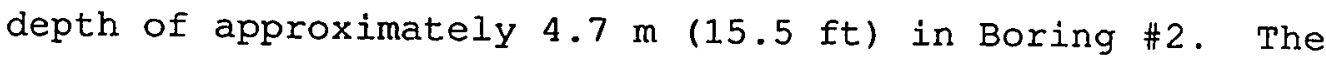
contact between weathered and unweathered materials that is indicated by a velocity increase at $2.7 \mathrm{~m}(9 \mathrm{ft}$.$) depth$ however, is less clear in the boring.

In terms of providing an improved definition of the geometry of the landslide, this seismic refraction survey fell short of expectations. The seismic line provided no clear indication of the location of the failure surface, most 
likely because there is no true velocity contrast across the failure surface that is strong enough to be seen in the data. The failure surface, however, generally parallels the interfaces defined in the seismic section. This suggests the possibility that some controlling relationship might exist, which is not resolvable in the seismic data. This possibility is also indicated by an abrupt change in velocity in the deeper materials below the pressure ridge (fig. 10).

\section{Soil Properties}

Soil samples were collected from within the crown fissures using a split spoon sampling device, driven into the fissure walls with a hammer. The samples were collected for $\mathrm{lab}$ analysis and determination of wet and dry densities of the failed material, and an estimate of the friction angle of materials on the slide plane, all of which are necessary for factor of safety analyses. Sand samples were collected for the purpose of determining specific gravity and void ratio, which together allowed for the following approximation of soil density in dry, saturated and submerged conditions.

$$
\begin{array}{ll}
\text { Specific Gravity: } & 2.65 \\
\text { Dry Density: } & 1.2 \mathrm{gm} / \mathrm{cm}^{3} \text { (72.2 pcf) } \\
\text { Void Ratio: } & 1.29 \\
\text { Saturated Weight: } & 1.7 \mathrm{gm} / \mathrm{cm}^{3} \text { (107.4 pcf) } \\
\text { Submerged Weight: } & 0.7 \mathrm{gm} / \mathrm{cm}^{3} \text { (45.0 pcf) }
\end{array}
$$

Laboratory data and calculations for the above values are presented in Appendix A. 
Representative samples of gray plastic clay (noted on page 17), thought to possibly exist along the failure surface, were collected for the determination of liquid limit, plastic limit, and plasticity index, resulting in the following values:

$$
\begin{array}{ll}
\text { Liquid Limit: } & 82.5 \% \\
\text { Plastic Limit: } & 44.8 \% \\
\text { Plasticity Index: } & 37.3 \%
\end{array}
$$

Laboratory data and calculations for the above values are presented in Appendix A.

Lambe and Whitman (1969) present a graphical relationship between plasticity index and approximate friction angle, which yielded a friction angle of 27 degrees for the gray clay. Although this value seems relatively high, given that the clay seems to exhibit very high plasticity and low strength under saturated conditions in the field, it served as an initial index friction angle for use in factor of safety analyses (page 53). 
PRECIPITATION ANALYSIS

Average yearly rainfall in the sebastopol area (July through June) is approximately 86 to $91 \mathrm{~cm}$ (34-36 in).

Abnormally heavy rainfall occurred during the rainy seasons of 1981-1982 and 1982-1983, and has been considered a factor in the development of the Blucher Valley Landslide (Cotton, 1983; Spittler, 1983). Anderson (1987, Personal

Communication) provided daily rainfall records covering the period of January, 1978 through June, 1987, from a private gauging station, located approximately $4.2 \mathrm{~km}$ (2.6 $\mathrm{mi})$

northwest of the landslide. Graphs of yearly, monthly, and daily rainfall were generated from these data (figs 11, 12, and 13), allowing for an improved understanding of precipitation as a factor in landslide development.

Rainfall during the rainy seasons of 1981-1982 and 19821983 amounted to 152.3 and $180.5 \mathrm{~cm} \mathrm{(59.95} \mathrm{and} 71.06 \mathrm{in}$ ), or approximately $160 \%$ and $200 \%$ of average yearly rainfall respectively (fig. 11). In the two months prior to the date of initial landslide movement (January 1 through March 3), 70 $\mathrm{cm}$ (27.5 in), or approximately $76 \%$ of average yearly rainfall, fell in the vicinity of the Blucher valley Landslide (fig. 12). Numerous landslides were triggered over a widespread area in northern California as a result of these rains (Smith and Hart, 1982).

Figure 13 presents superposed graphs of daily precipitation and rate of movement of the Blucher valley Landslide. As is evident in this figure, initial movement of the landslide immediately followed an intense storm period during which $23.7 \mathrm{~cm}$ (9.35 in) of rain fell over a period of 


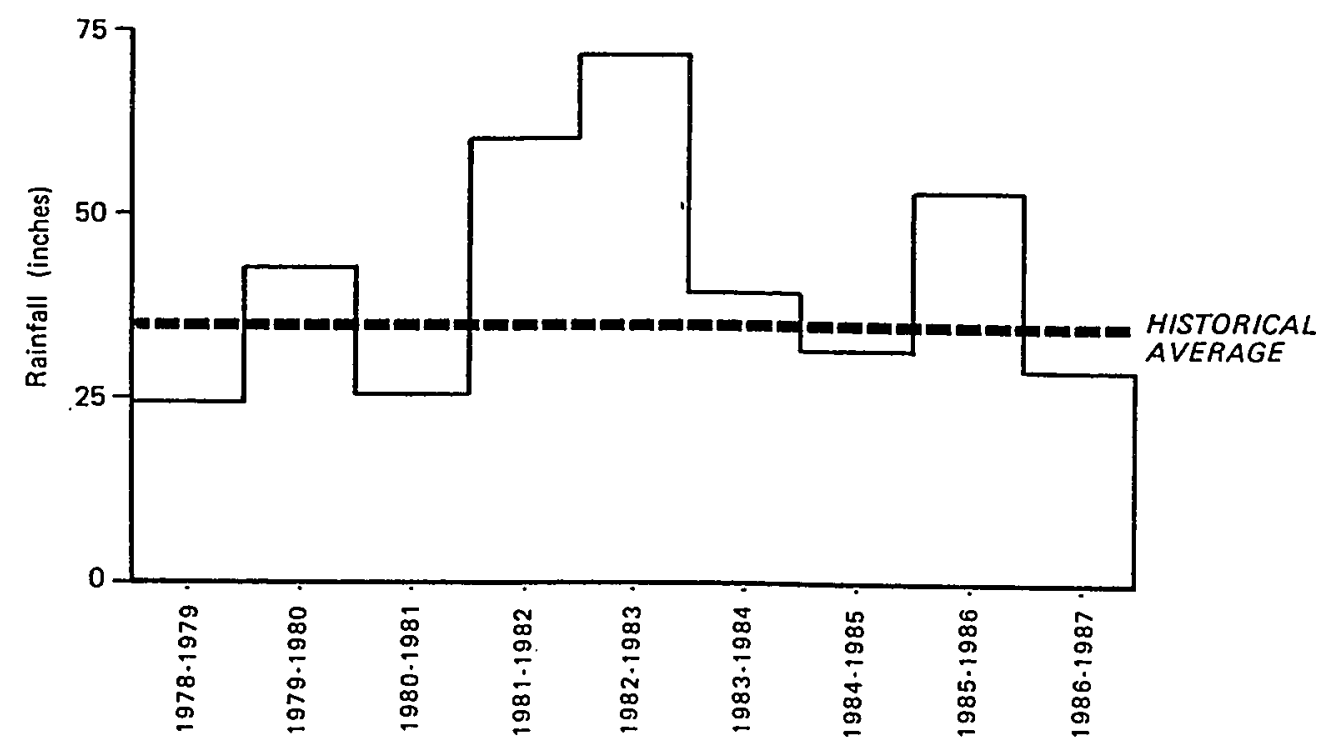

Figure 11. Yearly rainfall, 1978 through 1987 (July through June) at a recording gauge $4.2 \mathrm{~km}$ northwest of slide.

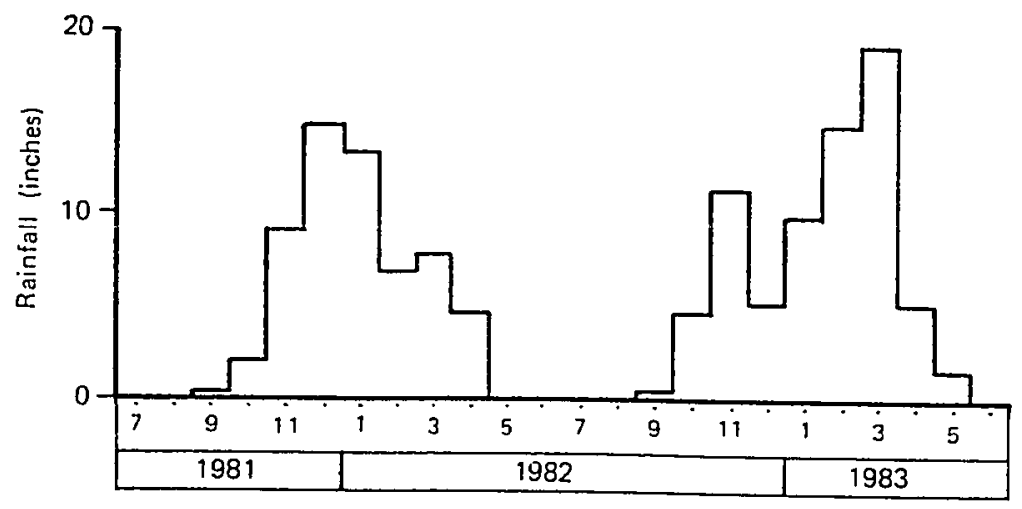

Figure 12. Monthly rainfall, 1981-1982 and 1982-1983 seasons (July through June) at a recording gauge $4.2 \mathrm{~km}$ northwest of slide. 


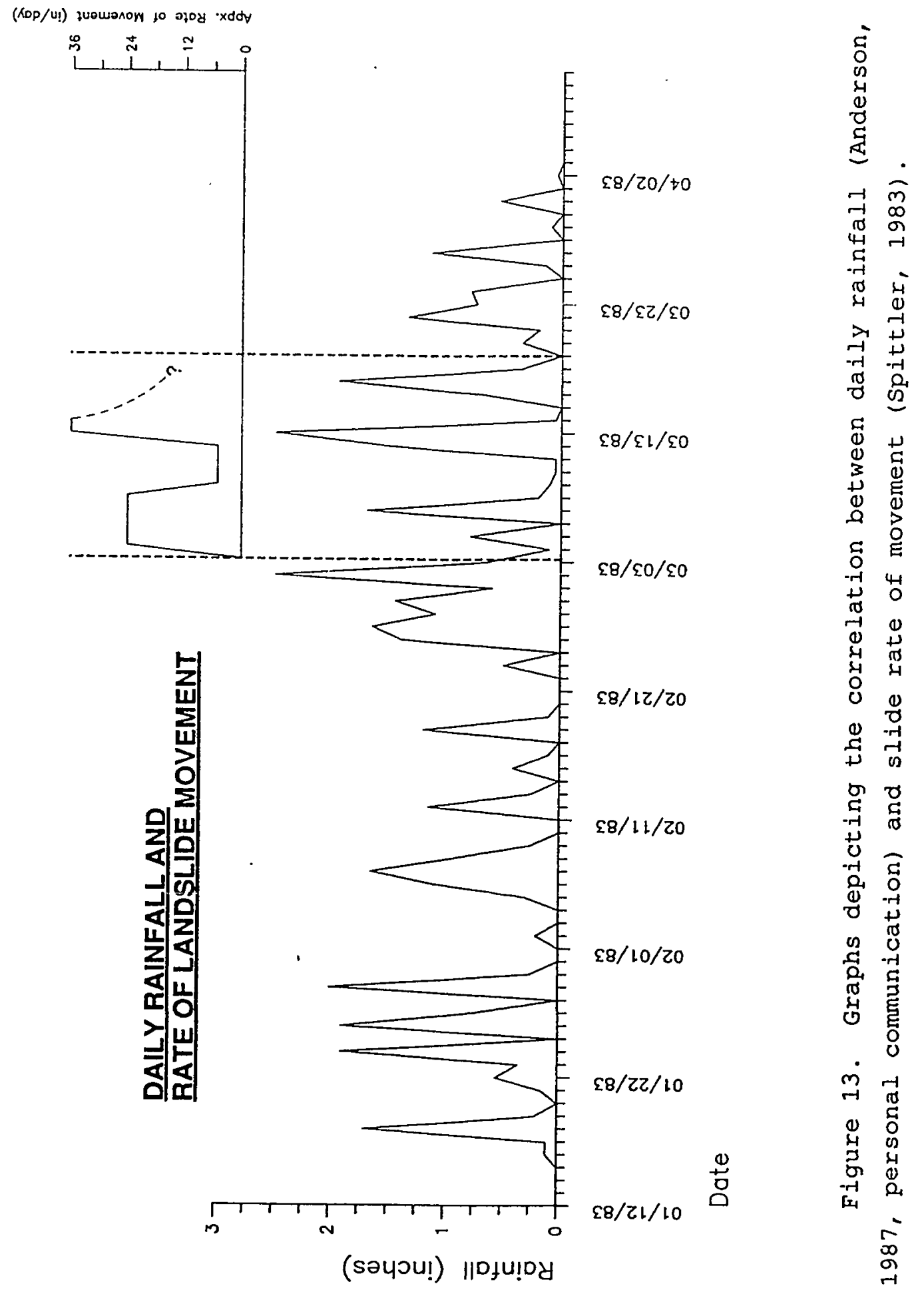


7 days. The initial rate of movement was approximately $0.6 \mathrm{~m}$ (2 ft) per day (Spittler, 1983). The rate of movement dropped to approximately $0.2 \mathrm{~m}(0.5 \mathrm{ft})$ during a lull in rainfall, and then increased to a maximum rate of approximately $0.9 \mathrm{~m}$ (3 ft.) per day in response to a storm that resulted in $10.2 \mathrm{~cm}$ (4.0 in) of new rain on March 12 and 13, 1983. The rate of movement of the landslide correlates very well with rainfall amounts (fig. 13), indicating a likelihood that rainfall was a major factor in the development and continued movement of the landslide.

A site visit was conducted immediately after a rainstorm in March, 1989, during which $15.9 \mathrm{~cm}(6.27 \mathrm{in})$ of rain had fallen over a four day period (Koons, 1989, personal communication), to observe surface runoff and ponding of water in fractures and low lying areas. Approximately $1.2 \mathrm{~m}$ (4 ft) of water had accumulated within the crown fissure, during this and prior storms $(60.27 \mathrm{~cm}[23.73 \mathrm{in}]$ of rain had fallen between January 1 and March 18, 1989) (fig. 14). In addition, surface and near-surface runoff could be heard and seen in increasing amounts towards the toe of the landslide. At one location, immediately below the northernmost toe pressure ridge, a moderate flow of water was seen emanating from one of numerous gopher holes (fig. 15), indicating that the volume of runoff water at or near the surface is very high during stormy periods. Landowners have confirmed that this has been a common sight in the years they have Iived at the site.

Another visit several days later, however, found little or no discernable runoff, but still 1.1 to $1.2 \mathrm{~m}(3.5$ to 4 $f t)$ of standing water within the crown fissures, indicating 


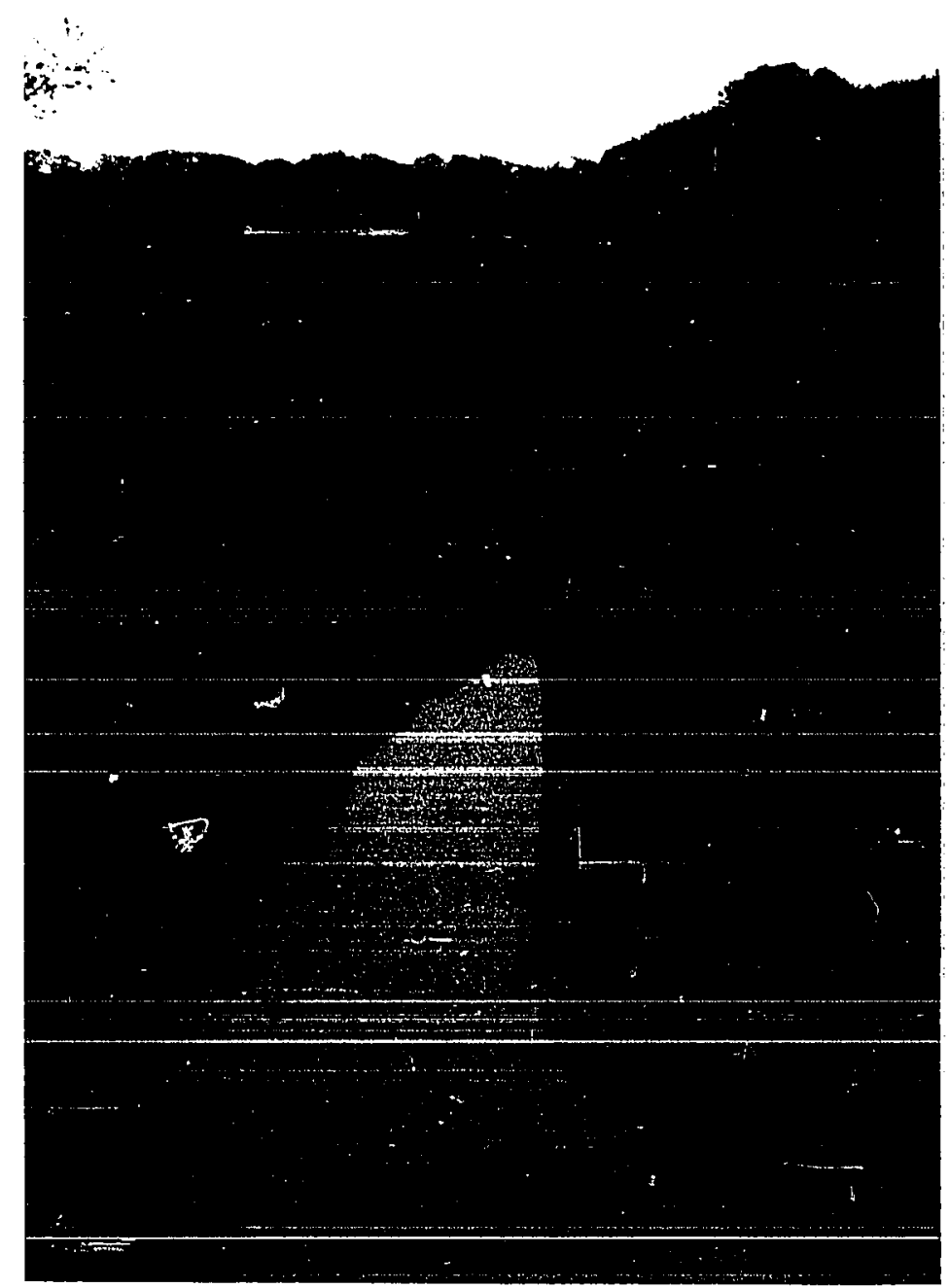

Figure 14. Pond in crown fissure resulting from $15.9 \mathrm{~cm}$ (6.27 in) of rain that fell over a 4 day period in March, 1989. Depth of water is approximately $1.3 \mathrm{~m}(4 \mathrm{ft}$ ) at fencepost (center of photo). 


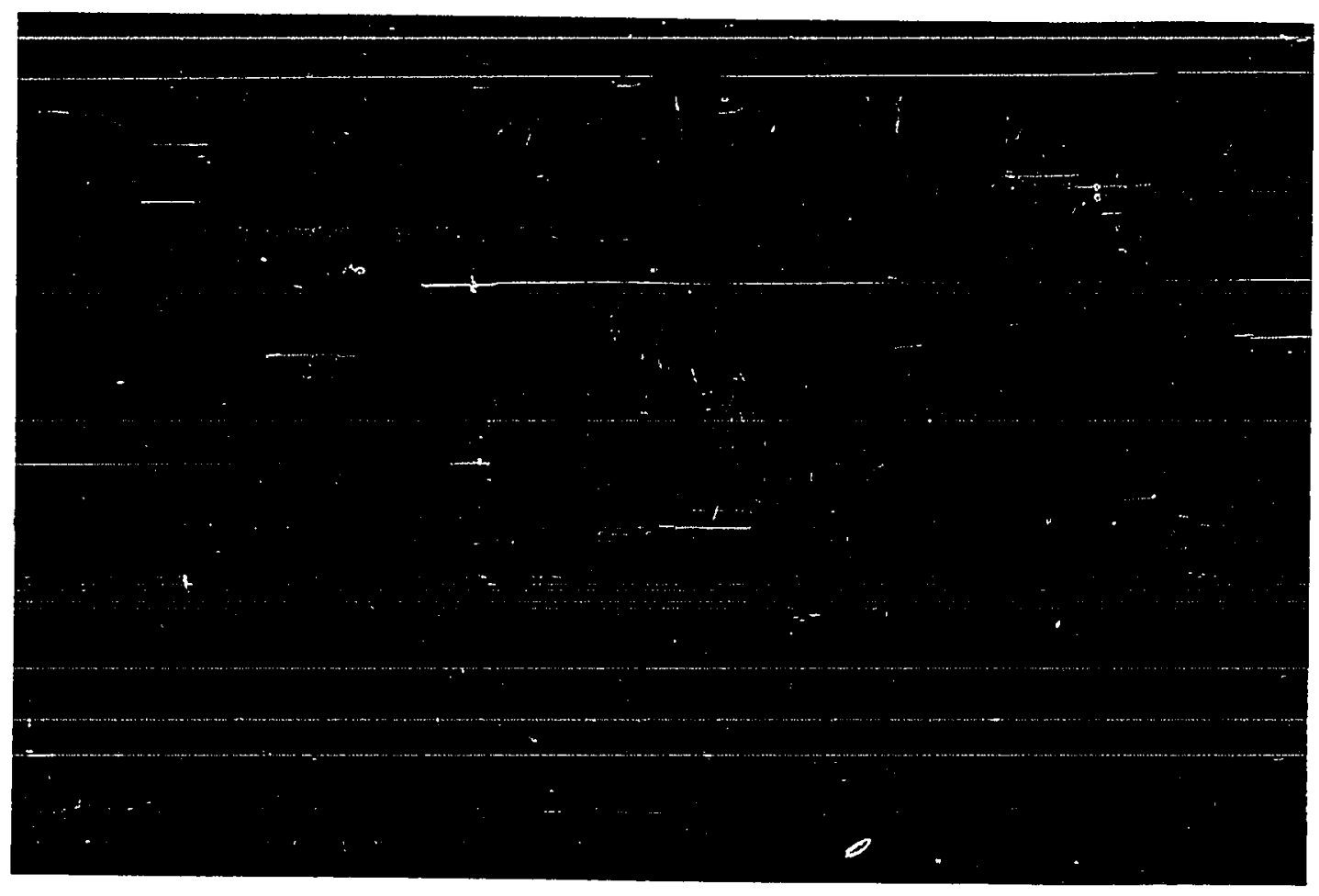

Figure 15. Rainwater emanating from gopher hole,

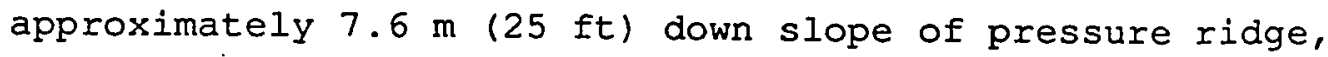
following rainfall in March, 1989.

that little or none of the surface and near-surface runoff acted to drain the fissures. This observation was confirmed by monitoring water levels within Borehole \#2. During the late summer months, the borehole is dry to its total depth (approximately $6.4 \mathrm{~m}$ [21 ft]). Immediately following the March rainy period, however, the depth to water was $0.55 \mathrm{~m}$ (1.79 ft.) below ground surface. Between March 18 and June 25, 1989, the water level in the boring dropped to a depth of $4.7 \mathrm{~m}(15.4 \mathrm{ft}$.$) . At the end of this period, the depth of$ 


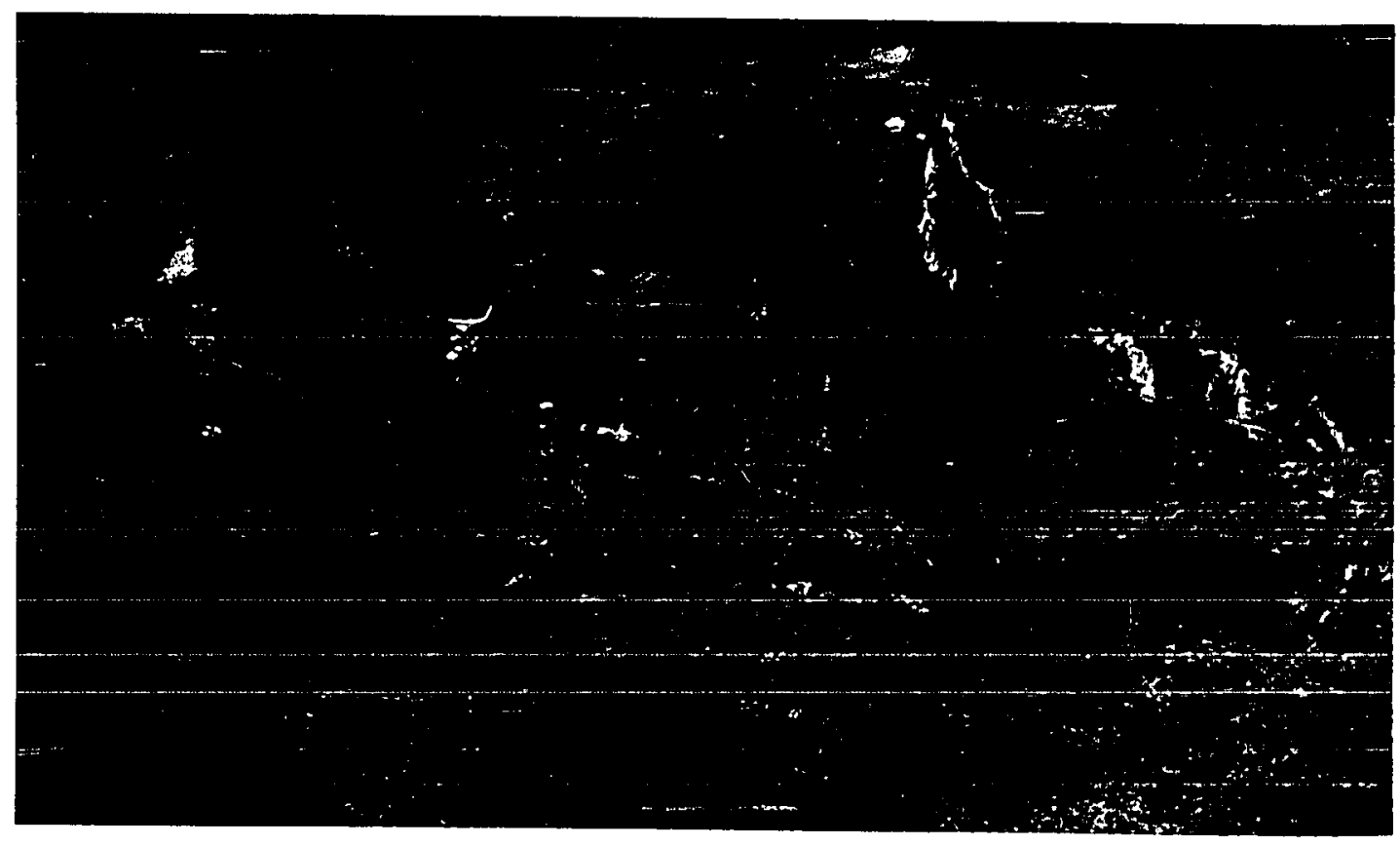

Figure 16. Color infrared aerial photograph of landslide, taken in June, 1989, approximately 2 months after significant rainfall in March. Photo was taken during same overflight as figs. 2, 3, 4, and 5. Subtle red tones in vicinity of pressure ridges indicate that moisture remains in surface and near-surface soils.

water within the crown fissure was approximately 20.3 to 25.4 $\mathrm{cm}$ ( 8 to $10 \mathrm{in}$ ). Color infrared photographs taken in June, 1989 (fig. 16) also indicate, as subtle red tones, moisture remaining below and immediately above the pressure ridges.

As has been suggested by Cotton (1983), Spittler (1983), and the data and field observations collected during this 
investigation, rainfall was most likely the underlying cause of the Blucher Valley Landslide. Not only did the rate of landslide movement correlate with rainfall amounts (fig. 13), but water levels collected from Boring \#2 indicate that almost complete saturation of the soil column occurs during normal rainfall, and drainage of the slope occurs at a moderately slow pace. Given the excessive rainfalls of 1983 , it is not difficult to envision greatly increased pore pressures and soil densities in the subsurface which serve to destabilize the slope. 
Topographic surveying was conducted for this investigation, using a theodolite and electric distance meter (EDM). An initial survey of the site was completed in the fall of 1988, to provide (1) a base data set for the generation of an accurate topographic map of the site and 2) an initial control data set for monitoring landslide movement. Re-surveying of several stations was conducted in December, 1989, providing data necessary to ascertain the current level of activity of the landslide.

\section{Prior Survey Work}

William Cotton \& Assöciates (personal communication, 1987) conducted a survey of the landslide, using a plane table and alidade, as part of their investigation in 1983. The survey resulted in an accurate topographic map (1:600 scale), based in part on elevations at over 200 locations that were sighted from nine instrument stations (A through $J$ ) around the perimeter of the landslide. Many of the locations were staked at the time of the survey, permitting continued monitoring of slide movement.

Initial (Round 1) Site Survey

When possible, instrument stations initially used by William Cotton \& Associates were re-occupied for this investigation to provide the greatest level of accuracy in measurements for comparison against the cotton data. Of the nine instrument stations used by cotton, four were found and 
utilized for this investigation (plate 1). At the locations of those that could not be found, new stations were added if necessary, as near to the mapped location as possible. A total of eight instrument stations were employed for this investigation.

An attempt was made to locate the 200 locations surveyed by Cotton, so that these points could be re-surveyed to estimate any movement that may have taken place since the Cotton survey. Only five of Cotton's original stations (16, $19,20,21$, and 36) could be located with certainty and found to be fully intact (plate 1). Several other cotton stations were located but not utilized because stakes had been removed, or broken, making accurate re-surveying impossible.

Approximately 75 additional locations were staked and surveyed specifically for this project (plate 1). Locations were selected to provide an overall definition of topography, and to provide detail on, and adjacent to, pressure ridges, and across fissures and fractures. Because the slide moved as an essentially solid mass with little or no disruption of topography, additional detail was provided in these areas where such movement would be more discernible. Tabulated survey data are presented in Appendix B.

Project Coordinate System

The survey data, in the form of azimuth, true horizontal distance, and true vertical offset were transformed into easting, northing, and elevation coordinates using a local rectangular coordinate system developed for this project. Such a coordinate system was made necessary for planned computer mapping and modeling activities, and to allow for accurate comparison of data pertaining to one location that may have been collected from more than one instrument 
station. The system was developed by first digitizing Instrument Station $A$, thus setting its location at an arbitrary $X$ and $Y$ location, and a known elevation (200 feet [see below]). Once Instrument Station $A$ was digitized, the easting and northing coordinates and elevations of all locations surveyed from that station, including Instrument Station BB, were computed, using a coordinate transformation program developed for this project that calculates coordinates of locations based on (1) a known easting and northing coordinate, and (2) the azimuth and distance of the locations relative to that coordinate. Easting, northing and elevation coordinates were then computed for locations surveyed from Instrument Station $\mathrm{BB}$, including Instrument Station $C$. The technique was applied to assign coordinates and elevations to each instrument station, and all locations surveyed from each station.

Survey Accuracy

Survey closure was obtained by averaging distances and azimuths measured between stations. Instrument Station A (plate 1) had earlier been used as the initial "base" station by Cotton, who located it as accurately as possible on the 200 foot contour at the northernmost extent of the pressure ridge. The station served an equal purpose for this investigation. Other instrument stations were located, directly or indirectly, relative to Instrument station A. Instrument Station BB, for instance, was accurately located based on averaging the distance and azimuth, as measured from Instrument station $\mathrm{A}$ to $\mathrm{BB}$, and from $\mathrm{BB}$ to $\mathrm{A}$. Instrument Station $C$ was then located by averaging measured distances and azimuths from $\mathrm{BB}$ to $\mathrm{C}$ and from $\mathrm{C}$ to $\mathrm{BB}$. This technique was conducted for all instrument stations around the 
perimeter of the site. Conversion of the survey data to the project coordinate system was completed after this activity.

Several locations were shot from more than one instrument location (Table 1), allowing for some comparison of derived locations, overall survey accuracy, and an

Table 1. Error in survey readings from multiple instrument stations.

\begin{tabular}{|c|c|c|c|c|c|c|c|}
\hline STATION & $\begin{array}{l}\text { FROM } \\
\text { STAUION } \\
\end{array}$ & $\begin{array}{l}\text { CALCULATED } \\
x-\infty O O R D .\end{array}$ & $\begin{array}{l}\text { CALCUIATED } \\
Y \text { YCOORO. }\end{array}$ & $\begin{array}{l}\text { ELEV. } \\
\text { MSL }\end{array}$ & $\begin{array}{l}\text { RANGE OF } \\
\text { X-COORDINATE } \\
\text { DIEEGERENGE }\end{array}$ & $\begin{array}{l}\text { RANGE OE } \\
\text { Y-COORDINATE } \\
\text { RIFEERREHCE }\end{array}$ & $\begin{array}{l}\text { RANGE OF } \\
\text { ELEVATION } \\
\text { DIFEERENCE } \\
\end{array}$ \\
\hline 010 & c & 144.29 & 565.08 & 261.85 & 0.31 & 0.11 & 0.16 \\
\hline 010 & D & 143.98 & 565.19 & 262.01 & & & \\
\hline 011 & 田 & 303.68 & 597.90 & 240.98 & 0.40 & 0.55 & 0.22 \\
\hline 011 & c & 303.92 & 598.16 & 240.77 & & & \\
\hline 011 & D & 303.55 & 598.45 & 240.90 & & & \\
\hline 016 & C & 328.46 & 729.14 & 224.69 & 2.92 & 0.26 & 0.04 \\
\hline 016 & D & 331.38 & 728.88 & 224.73 & & & \\
\hline 018 & $E E$ & 382.26 & 126.87 & 279.54 & 0.02 & 0.26 & 1.32 \\
\hline 018 & EF & 382.24 & 126.61 & 280.86 & & & \\
\hline 024 & $\mathrm{E}$ & 718.02 & 215.09 & 223.47 & 0.02 & 1.05 & 0.08 \\
\hline 024 & $H$ & 718.00 & 214.04 & 223.55 & & & \\
\hline 025 & $E$ & 709.50 & 164.86 & 224.21 & 0.34 & 0.06 & 0.01 \\
\hline 025 & $\mathrm{H}$ & 709.16 & 163.92 & 224.22 & & & \\
\hline 026 & $\bar{E}$ & 612.37 & 161.62 & 242.16 & 0.37 & 0.70 & 0.07 \\
\hline 026 & $F$ & 612.00 & 161.07 & 242.16 & & & \\
\hline 026 & $G G$ & 612.08 & 160.97 & 242.23 & & & \\
\hline 026 & $\mathrm{H}$ & 612.25 & 360.92 & 242.23 & & & \\
\hline 027 & EE & 619.24 & 239.59 & 242.76 & 0.08 & 0.79 & 0.10 \\
\hline 027 & $\mathrm{H}$ & 619.32 & 238.80 & 242.86 & & & \\
\hline 033 & $E E$ & 548.09 & 150.78 & 252.78 & 0.18 & 0.59 & 0.04 \\
\hline 033 & $\mathbf{F F}$ & 547.91 & 150.19 & 252.74 & & & \\
\hline 034 & $E$ & 474.64 & 153.52 & 267.33 & 0.18 & 0.40 & 0.01 \\
\hline 034 & $F$ & 474.46 & 153.12 & 267.32 & & & \\
\hline 045 & $G$ & 893.58 & 256.06 & 195.51 & 0.19 & 0.56 & 0.02 \\
\hline 045 & $\mathrm{H}$ & 893.77 & 255.50 & 195.53 & & & \\
\hline 07 & c & 235.41 & 464.41 & 269.72 & 0.99 & 0.38 & 0.00 \\
\hline 07 & D & 236.40 & 464.79 & 269.92 & & & \\
\hline 072 & c & 298.70 & 425.36 & 272.87 & 0.14 & 0.13 & 0.16 \\
\hline 072 & D & 298.56 & 425.49 & 273.03 & & & \\
\hline 074 & EB & 320.03 & 715.06 & 224.24 & 0.27 & 0.51 & 1.35 \\
\hline 074 & $c$ & 320.02 & 715.17 & 222.89 & & & \\
\hline 074 & D & 319.76 & 715.57 & 224.22 & & & \\
\hline 075 & B3 & 247.72 & 617.50 & 243.92 & 0.35 & 0.35 & 0.26 \\
\hline 075 & $c$ & 247.88 & 617.67 & 243.66 & & & \\
\hline 075 & $D$ & 247.53 & 617.85 & 243.83 &. & & \\
\hline 20 & BB & 188.75 & 422.91 & 285.84 & 0.23 & 0.24 & 0.67 \\
\hline 20 & $c$ & 188.98 & 423.02 & 286.40 & & & \\
\hline 20 & D & 188.96 & 423.15 & 285.73 & & & \\
\hline
\end{tabular}


appreciation for the confidence that should be placed on assessments of landslide movements following second round surveying. The minimum, maximum, and average variations in coordinate locations obtained from multipie instrument stations are presented in Table 2. These data suggest that landslide movement on the order of at least $0.15 \mathrm{~m}(0.5 \mathrm{ft}$. in the north-south or east-west direction (approximately 0.18 $m$ [0.6 ft] in the $\mathrm{N} 59 \mathrm{E}$ direction of landslide movement) would need to occur before it could be accurately determined during Round 2 surveying.

Table 2. Variation between Round 1 survey points located from multiple instrument stations.

\begin{tabular}{lccc}
\hline & $\begin{array}{c}\text { RANGE OF } \\
\text { MAXIMUM }\end{array}$ & $\begin{array}{c}\text { DIFFERENCE IN VALUES } \\
\text { MINIMUM }\end{array}$ & $\begin{array}{l}\text { (FT) } \\
\text { AVERAGE }\end{array}$ \\
\hline X COORDINATE & 2.92 & 0.02 & 0.47 \\
Y COORDINATE & 1.05 & 0.11 & 0.41 \\
ELEVATION & 1.59 & 0.00 & 0.36 \\
\hline
\end{tabular}

Round 2 site Survey

A second round of surveying was conducted in December 1989, approximately one year after Round 1, to determine if any movement had taken place. An attempt was made to find a representative number of Round 1 locations, and to survey them from the same instrument station that was used earlier. Although 30 locations were found; only four could be surveyed from the same instrument station used in Round 1 surveying 
because several of the instrument stations were destroyed or could not be found. This resulted in some loss of accuracy in the determination of possible landslide movement.

Table 3 presents a comparison of Round 1 and 2 coordinates and elevations for the 30 stations, and Table 4 presents minimum, maximum and average variances between Round 1 and Round 2 coordinates and elevations. On the average, the amount of change in northing, easting and elevation of surveyed locations was less than the error in surveying discussed previously, indicating the likelihood that no movement of the landslide has taken place in 1989.

Of the 30 stations re-surveyed during Round 2, 10 showed a change in northing or easting coordinate or elevation that exceeded $0.15 \mathrm{~m}(0.5 \mathrm{ft}$.$) , the approximate survey error$ discussed on page 38. All of these stations were surveyed from an instrument station in Round 2 that was different from that used in Round 1. Four of the stations $(020,021,065$, and 067) appeared to have been displaced horizontally or vertically greater than $0.3 \mathrm{~m}(1.0 \mathrm{ft.})$. The relative directions of movement (along the north-south, east-west and vertical axes) were determined to judge whether such displacements were due to error or to landslide movement. In general, movement of the landslide down the plane of the inferred failure surface (oriented N31W; 4.5NE) should result in the displacement of a point on the surface of the failed block that is expressed as (1) an increase in value of the northing coordinate, (2) a greater increase in value of the easting coordinate, and (3) a decrease in elevation. None of the 10 points showed apparent displacements in this manner. Minor topographic adjustments during landslide movement could result in variations of the above displacement trajectories. If displacement of all 10 points resulted from such 
Table 3. Comparison of data from Round 1 and Round 2 surveys.

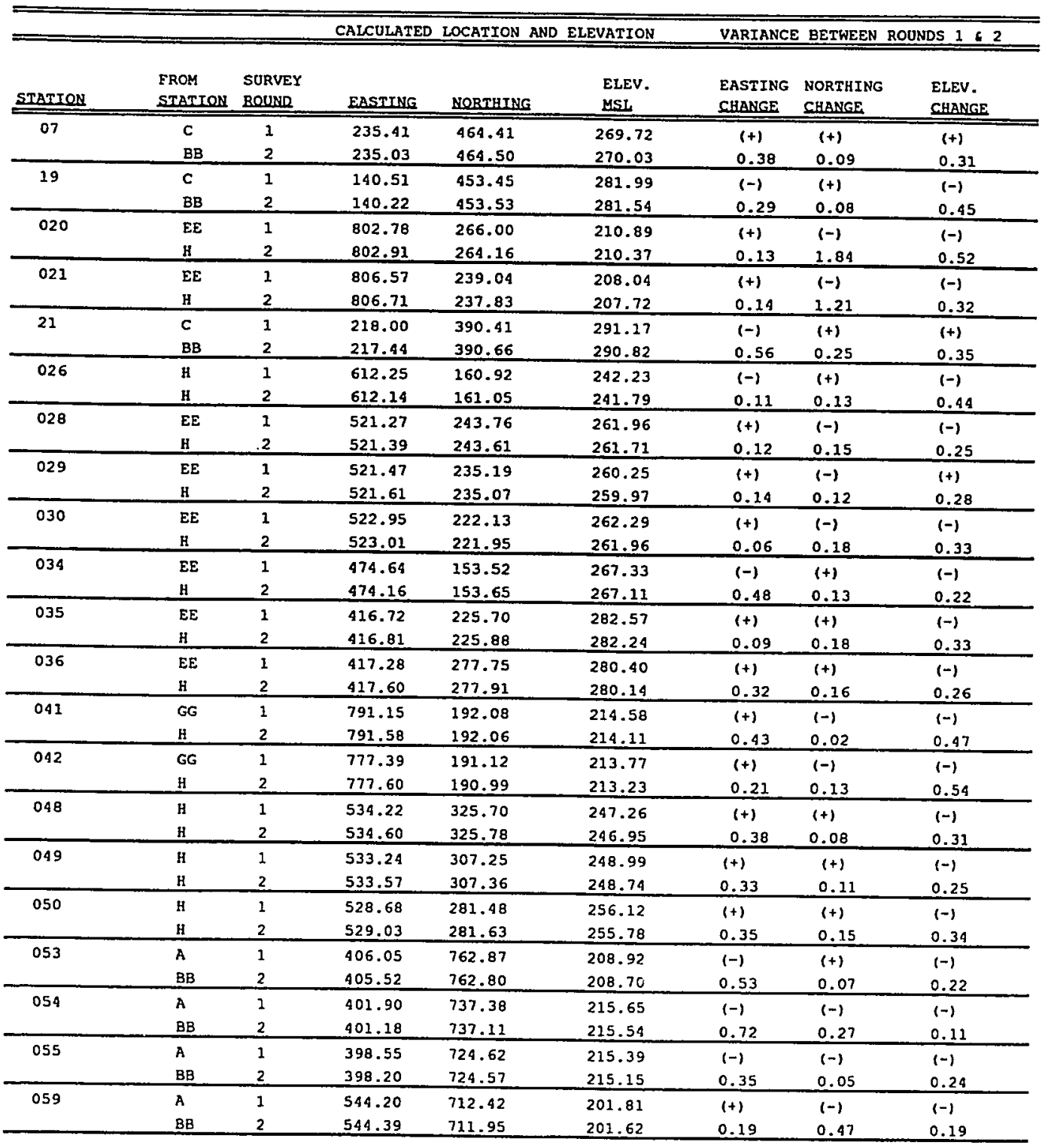

NOTES: - Round 1 survey completed September, 1988

- Round 2 survey completed December, 1989

- All measurements in feet

- Northing and easting measurements based on a local rectangular coordinate system developed for this project 
Table 3. Comparison of data from Round 1 and Round 2 surveys (continued from page 41).

\begin{tabular}{|c|c|c|c|c|c|c|c|c|}
\hline \multirow[b]{2}{*}{ STATION } & \multirow[b]{2}{*}{$\begin{array}{l}\text { FROM } \\
\text { STATION } \\
\end{array}$} & \multirow[b]{2}{*}{$\begin{array}{l}\text { SURVEY } \\
\text { BOIND } \\
\end{array}$} & \multirow{2}{*}{$\begin{array}{l}\text { CALCULATED } \\
\text { EASTING }\end{array}$} & \multirow{2}{*}{$\begin{array}{l}\text { LOCATION AND } \\
\text { NORTHING } \\
\end{array}$} & \multirow{2}{*}{$\begin{array}{l}\text { ELEVATION } \\
\text { ELEV. } \\
\text { USL }\end{array}$} & \multicolumn{3}{|c|}{ VARIANCE BETWEEN ROUNDS 162} \\
\hline & & & & & & $\begin{array}{l}\text { EASTING } \\
\text { CHANGE }\end{array}$ & $\begin{array}{l}\text { NORTHING } \\
\text { CHANGE }\end{array}$ & $\begin{array}{l}\text { ELEV. } \\
\text { CHANGE }\end{array}$ \\
\hline \multirow[t]{2}{*}{060} & A & 1 & 525.40 & 688.14 & 210.83 & $(-)$ & $(+)$ & $(-)$ \\
\hline & $\mathrm{BB}$ & 2 & 525.28 & 687.69 & 210.59 & 0.12 & 0.45 & 0.24 \\
\hline \multirow[t]{2}{*}{061} & A & 1 & 511.23 & 665.79 & 210.49 & $(-)$ & $(-)$ & $(-)$ \\
\hline & BB & 2 & 510.94 & 665.23 & 210.40 & 0.29 & 0.56 & 0.09 \\
\hline \multirow[t]{2}{*}{062} & A & 1 & 574.94 & 628.21 & 209.28 & $(-)$ & $(+)$ & $(-1)$ \\
\hline & BB & 2 & 574.56 & 627.43 & 208.89 & 0.38 & 0.78 & $0.3 \overline{9}$ \\
\hline \multirow[t]{2}{*}{063} & A & 1 & 590.92 & 656.51 & 211.00 & $(-)$ & $(+)$ & $(-)$ \\
\hline & $\mathrm{BB}$ & 2 & 590.63 & 655.84 & 210.66 & 0.29 & 0.67 & 0.34 \\
\hline \multirow[t]{2}{*}{064} & $A$ & 1 & 604.07 & 678.90 & 202.19 & $(-)$ & $(-)$ & $(+)$ \\
\hline & $\mathrm{BB}$ & 2 & 603.93 & 678.22 & 201.93 & 0.14 & 0.68 & 0.26 \\
\hline \multirow[t]{2}{*}{065} & A & 1 & 490.16 & 613.21 & 219.27 & $(+)$ & $(-)$ & $(+)$ \\
\hline & $\mathrm{BB}$ & 2 & 489.61 & 612.70 & 220.41 & 0.55 & 0.51 & 1.14 \\
\hline \multirow[t]{2}{*}{066} & A & 1 & 405.81 & 620.44 & 228.27 & $(-)$ & $(-)$ & $(-)$ \\
\hline & $\mathrm{BB}$ & 2 & 405.42 & 620.41 & 227.87 & 0.39 & 0.03 & 0.40 \\
\hline \multirow[t]{2}{*}{067} & $A$ & 1 & 444.42 & 488.28 & 237.48 & $(-)$ & $(-)$ & $(+)$ \\
\hline & $\mathrm{BB}$ & 2 & 443.54 & 487.93 & 238.92 & 0.88 & 0.35 & 1.44 \\
\hline \multirow[t]{2}{*}{072} & $D$ & 1 & 298.56 & 425.49 & 273.03 & $(-)$ & $(-)$ & $(-)$ \\
\hline & $\mathrm{BB}$ & 2 & 298.11 & 425.39 & 272.55 & 0.45 & 0.10 & 0.48 \\
\hline
\end{tabular}

NOTES: - Round 1 survey completed September, 1988

- Round 2 survey completed December, 1989

- All measurements in feet

- Northing and easting measurements based on a local rectangular coordinate system developed for this project

Table 4. Variation between Round 1 and Round 2 survey results.

DIEFERENCE IN

ROUND 1 LOCATION RELATIVE TO ROUND 2 (ET.)

MAXIMUM

0.88

1.84

1.14

ELEVATION
MINIMUM

0.06

0.02

0.09 AVERAGE

0.33

0.33

0.35 
topographic adjustments, however, then evidence of movement down the slope of the failure surface would be expected to appear elsewhere on the surface of the failed block. No such displacements at an amount greater than survey error are apparent in the data, suggesting that the landslide did not move during this time period and that variations in locations derived from survey Rounds 1 and 2 are due to error. 


\section{Computer Methodology}

A computer model of the Blucher Valley Landslide was developed, using Interactive Surface Modelling software (ISM; Dynamic Graphics, Inc., Berkeley, California), to gain improved visual understanding of landslide geometry and, most importantly, to provide a basis for the employment of a new technique of factor of safety analysis (page 50). The software utilizes geographically referenced data to generate a series of minimum-tension grid surfaces, which together form a three-dimensional geologic model of the site. In summary, the technique involves inputting $\mathrm{X}, \mathrm{Y}$, and elevation data, in the form of survey data files or digitized contours, followed by the generation of a computer grid (a uniformly spaced data set consisting of elevation values generated by interpolation of the data). Computer grids were generated for topography, the failure surface, and the water table (at high and low water). The software takes into consideration the apparent surface displacements in the vicinity of faults (e.g., the crown fissures and toe pressure ridges) during generation of topography and failure surface grids. Once generated, contour maps and perspective views can be created from any grid, or the grids can be used in combination to generate cross sections or three-dimensional bjock or fence diagrams, showing the entire geologic interpretation. An additional advantage in the use of such a system, lies in the ability to apply formulas (i.e., factor of safety equations) to one or more grids, thus taking into consideration the point-by-point values of elevation and thickness in producing a new grid that contains results of the equation at each 
point. Additional detail on the development of geologic models is presented in Romie (1985).

Topography

A topographic grid was developed from the $X$ (easting), $Y$ (northing) and $\mathrm{z}$ (elevation) data obtained from the initial site survey (page 35). The data were hand contoured and then digitized (contours and survey data) in an effort to constrain the gridder and obtain a result that most accurately reflected true topography. Additional data employed were digitized lines depicting the outline of the crown fissures and toe pressure ridges which served as areas of abrupt change in surface slope. Some editing of the initial topography grid was necessary, due to the topographic complexities in the vicinity of the fissures and pressure ridges. The resulting grid was then used to generate a topographic contour map (plate 2) and contour perspective of the landslide (plate 3). The perspective view allows for increased understanding of the slide by providing a threedimensional depiction as one would see it from the air. While visible on the topographic map, the perspective view presents a more convincing depiction of topographic high to the northeast, immediately below the pressure ridge, which may have served as a buttress that ceased movement of the iandslide.

Failure Surface

A failure surface grid was created by inputting three points that define the plane $N 31 W ; 4.5 N E$, and then generating a first order trend surface through those points. The resultant grid depicted a plane surface which was then adjusted in elevation to match the elevation of failure (sheared casing) at the location of Boring \#2. 
Groundwater Elevation

Groundwater elevation grids were developed to reflect seasonal low water (water level at or below the failure surface) and high water. The low water elevation grid was created by adding $0.3 \mathrm{~m} \mathrm{(1} \mathrm{ft.)} \mathrm{to} \mathrm{the} \mathrm{failure} \mathrm{surface} \mathrm{grid}$ (setting low water equal in elevation to the failure surface would result in zero-devide problems during later factor-ofsafety analyses). The high water grid represents only an approximation of high water elevations, developed by digitizing and then gridding contours that were drawn based on: (1) water levels observed in Boring \#2, (2) observations of water depth in the fissures and, (3) areas of seepage following heavy rainfalls.

Geologic Cross Sections

Geologic cross sections at low and high water are presented in figure 17. Both cross sections follow the same trace ( $A-A^{\prime}$ [plate 1]) down the slope of the failure surface. The cross sections together show portions of all four of the initial grids which make up the geologic model, and were used for determination of factor of safety, using standard infinite slope hand calculation (Appendix C). 

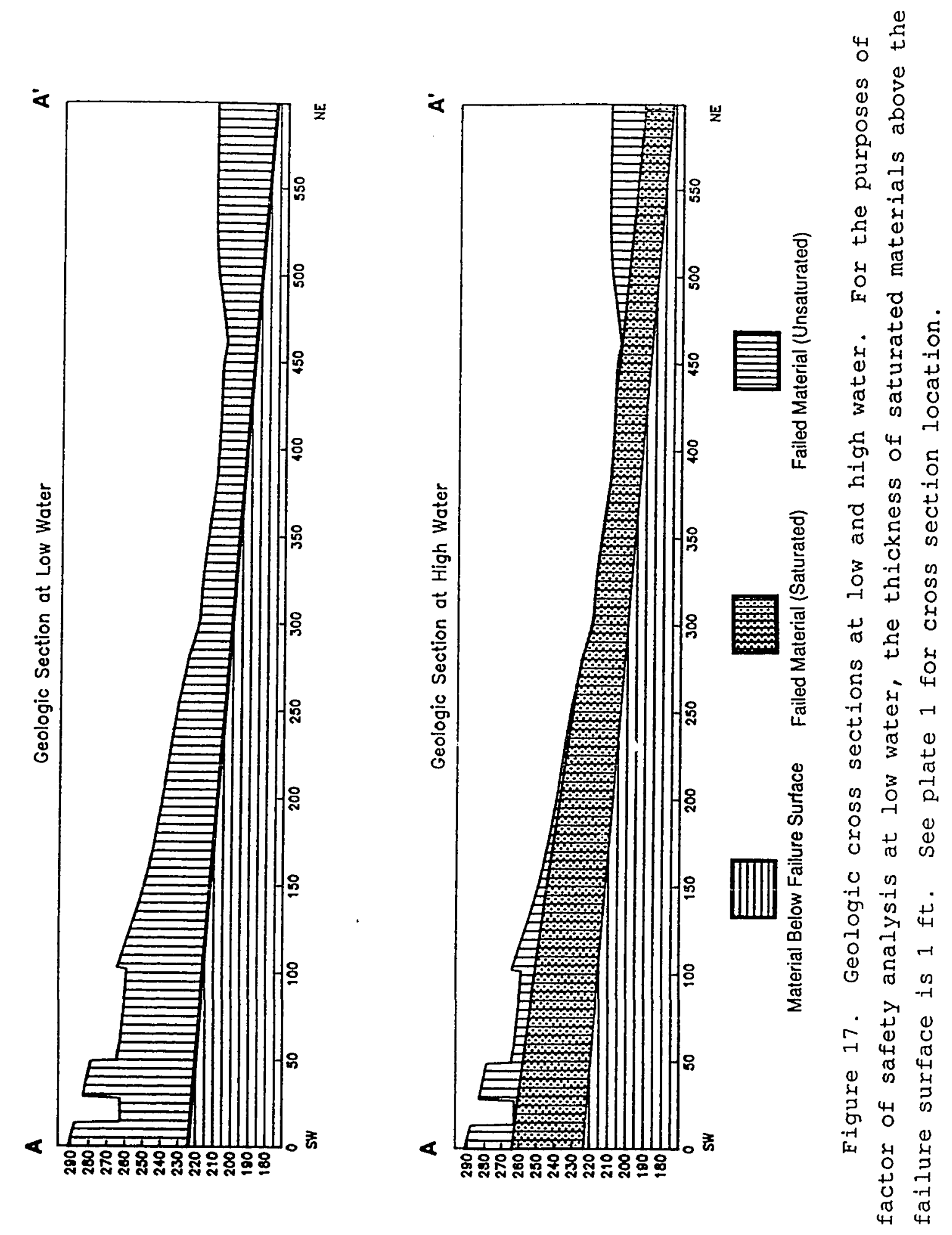
FACTOR OF SAFETY ANAIYSIS

\section{Analysis Type}

Because the Blucher Valley Landslide moved as an essentially solid mass down a planar failure surface, with little disruption of the failed mass, it has been classified as a translational rock block slide. The analysis used in this case is an extension of the stability of a rigid block on an inclined plane. Chowdhury (1978) presents equations for determining the factor of safety of such failures, based on soil unit weights, and the slope, cohesion and friction angle at the failure surface (fig. 18). The typical

procedure for factor of safety analysis involves selecting a representative cross section, oriented parallel to the direction of movement, and calculating the factor of safety based on average depths to the water table and failure surface. The methodology bases the determination of safety factor on the landslide geometries presented in only one or several of these representative slices. It is likely, however, that the majority of block slides have failure surfaces and water tables that vary in depth from point to point, due to intricacies in the configuration of topography and water tables. Such variations exist at the Blucher Valley Landslide (fig. 17) because (1) the landslide is located on the nose of a spur ridge, where topographic aspect, dip, and therefore depth to the failure surface, vary over the extent of the slide; (2) the topographic slope generally exceeds the dip of the failure surface, resulting in decreasing depth to the failure surface from crown to toe, and; (3) the water table likely does not parallel the plane of the failure surface (especially in the current landslide configuration of crown fissures and pressure ridges). These 


\section{Factor of Safety by Infinite Slope Method}

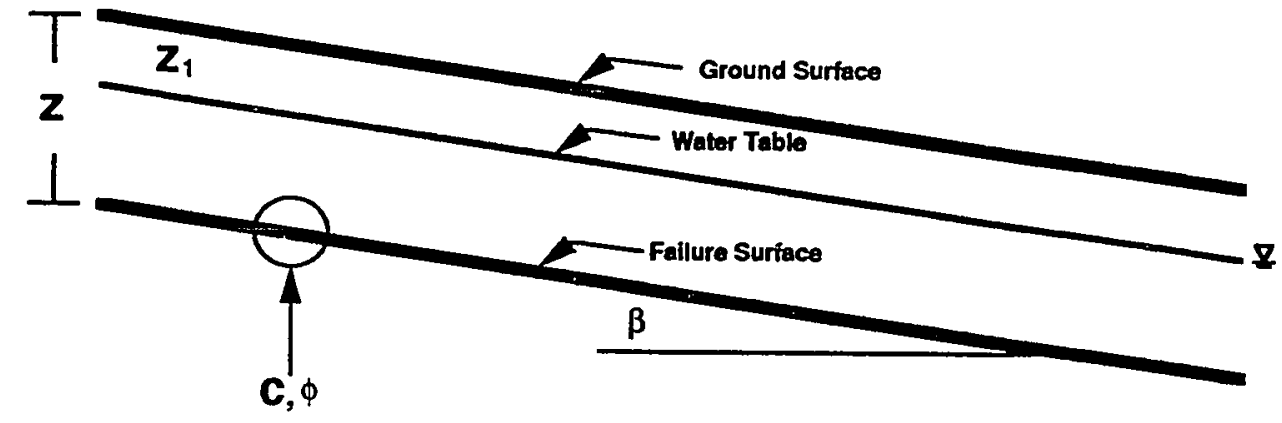

$$
\mathbf{F}=\frac{\mathbf{c}}{\left[\gamma_{1} z_{1}+\gamma\left(\mathbf{z}-\mathbf{z}_{1}\right)\right] \sin \beta \cos \beta}+\frac{\frac{z_{1}}{\mathbf{z}-\mathbf{z}_{1}} \gamma_{1}+\gamma^{\prime}}{\frac{\mathbf{z}_{1}}{\mathbf{z}-\mathbf{z}_{1}} \gamma_{1}+\gamma} \frac{\tan \phi}{\tan \beta}
$$

Where:

$$
\begin{aligned}
& \mathbf{F}=\text { Factor of Safety } \\
& \gamma_{1}=\text { Soil unit weight above seepage line (water table) } \\
& \gamma=\text { Soil saturated unit weight } \\
& \gamma^{\prime}=\text { Soil submerged unit weight } \\
& \phi=\text { internal friction angle at failure surface } \\
& \mathbf{C}=\text { Cohesion at failure surface } \\
& \beta=\text { Slope of the failure surface }
\end{aligned}
$$

Figure 18. Factor of safety determination by the infinite slope method (Chowdhury, 1978) 
intricacies do not lend themselves to qualitative estimations of factor of safety based on the above representative slice method.

A new method of slope stability analysis was developed during this investigation which takes into consideration the variations in topographic and water table configurations that are expressed in the geologic model. While the method does not replace standard techniques (it does not provide an estimate of stability of the entire failed mass), it allows for a detailed examination of the variation in factor of safety over the extent of the landslide that results from subtle variations in the configuration of the ground surface and water table. The understanding of these variations can then aid in determining the probable causes of failure.

The stability analysis methodology used for this investigation involves the following steps (fig. 19):

1) A failed material thickness grid is generated by subtracting the failure surface grid from the topography grid (each node of the failure surface grid is subtracted from the corresponding node of the topographic grid, yielding the failed mass thickness at that location);

2) An unsaturated material thickness grid is generated by subtracting the water table elevation grid from the topography grid, and;

3) Interactive Formula Processor software (IFP - Dynamic Graphics, Berkeley, California) is utilized to perform the calculation presented in figures 18 and 19. 


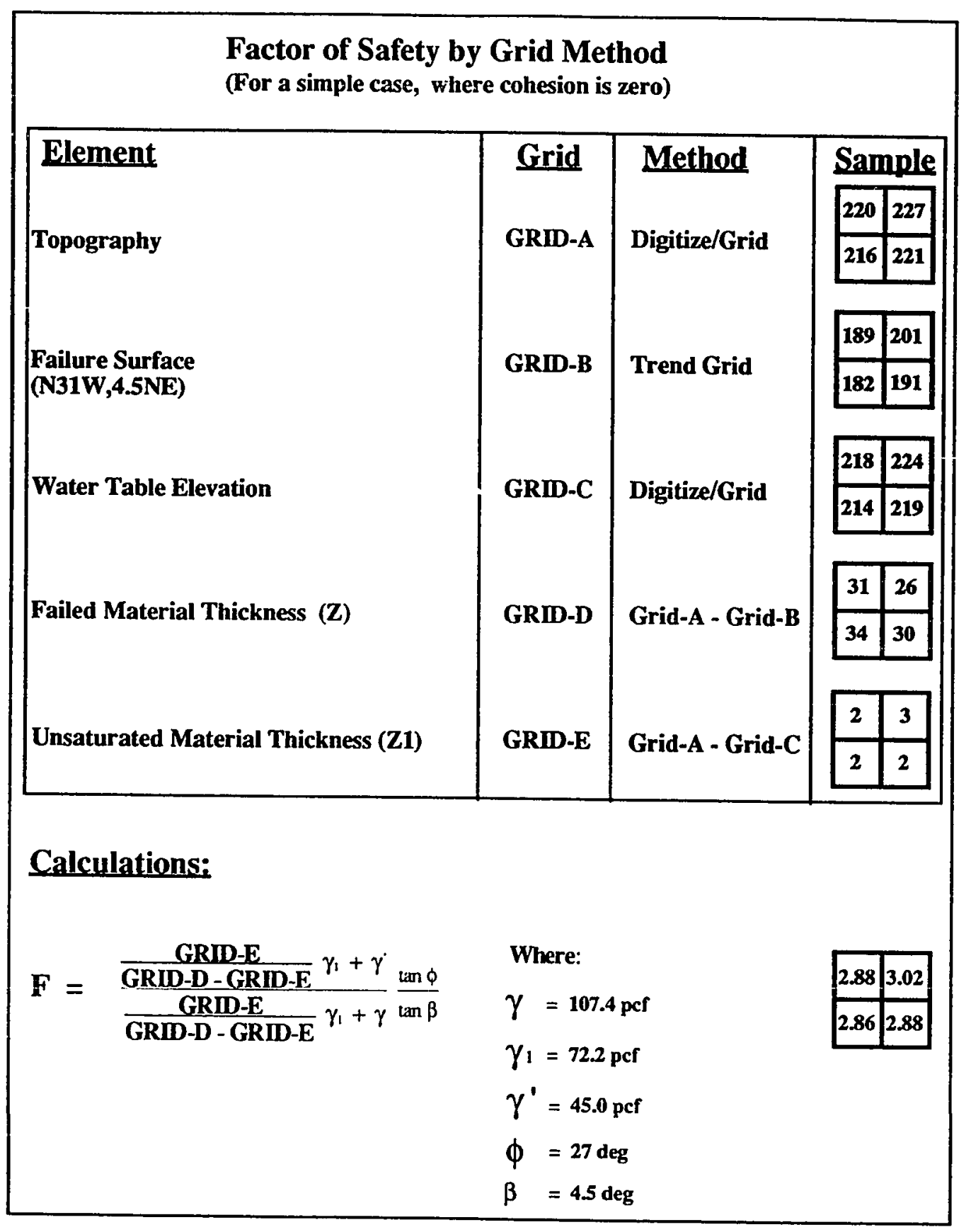

Figure 19. A method of factor of safety determination that takes into consideration information in the geologic model. 
Each of the 8200 nodes of the resultant grid contains a value of the factor of safety that is based on saturated and unsaturated material thicknesses at that node. The factor of safety grid can then be contoured to assess the variation of factor of safety, and to attempt a determination of landslide causes that may be suggested by these variations.

Results

The above factor of safety methodology was conducted several times, in an attempt to assess the variations in factor of safety under different conditions of water level, friction angle $(\phi)$, and cohesion (C) at the failure surface. The results of each run of the calculation are presented below, followed by a discussion of results as they pertain to landslide causes. The factor of safety was also calculated manually, by the infinite slope method (page 48; Chowdhury, 1978), to provide a comparison of contoured results with results of the standard calculation methodology. The calculations, performed for a unit slice along cross section $A-A^{\prime}$ (fig. 17), are presented in Appendix B, and results are noted in the following sections.

During site surveying activities, and generation of the geologic model of the Blucher valley Landslide, the U.S. Customary system of measurement was used for both the coordinate reference system, and topographic elevations. The conversion of this data to the Metric system during the course of stability analysis would involve additional computer manipulations and would result in confusion between the units of measure presented in the model, and and those presented in the following sections. For this reason, the U.S. Customary system is employed in discussions of the results of stability analyses. 
Low Water Level, $\phi=27$ degrees, $C=0$ psf

Figure 20 depicts factor of safety contours at low water (fig. 17), using the 27 degree friction angle determined from laboratory soils analysis (page 26), and assuming a cohesion

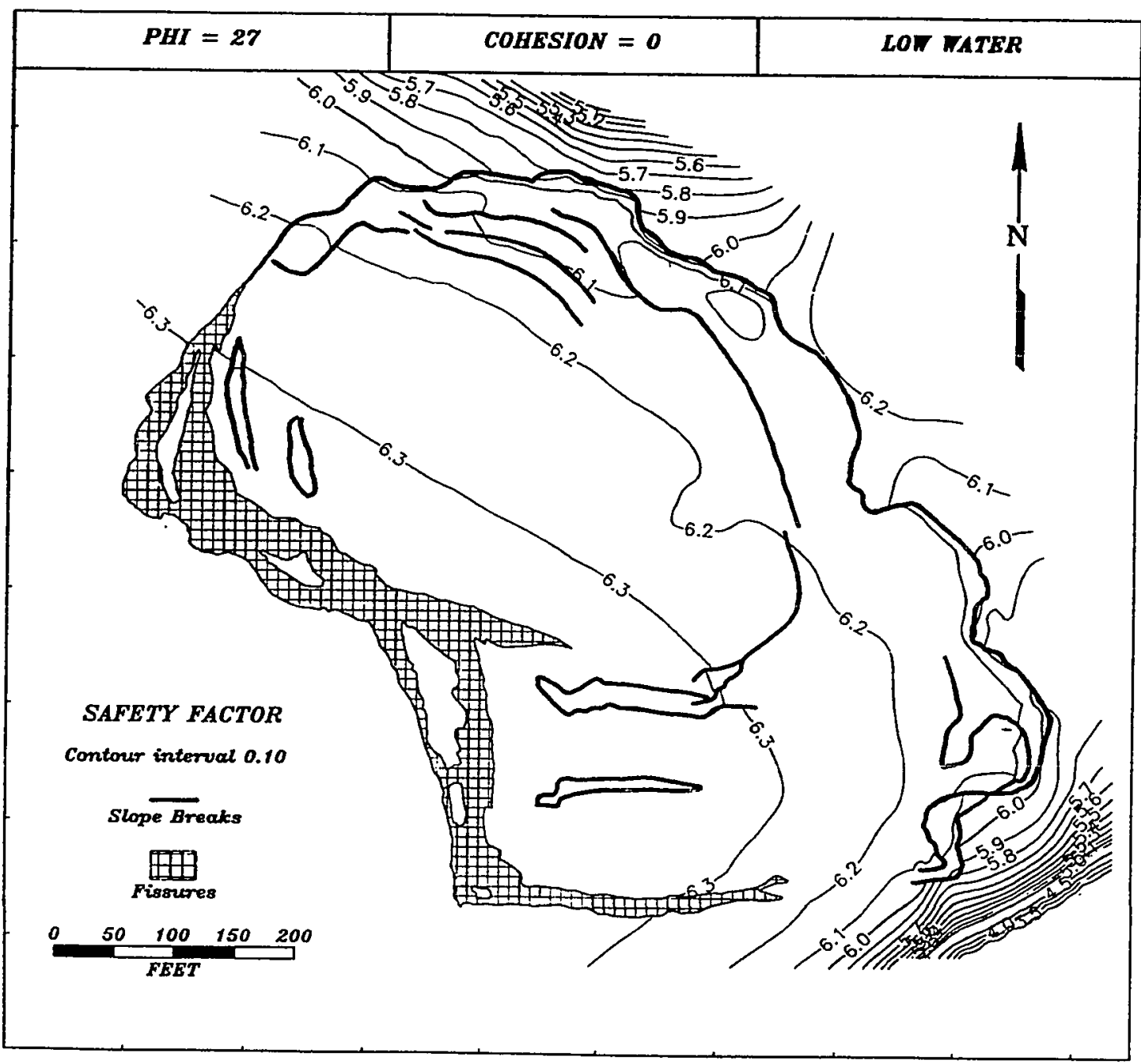

Figure 20. Factor of safety contours under conditions of low water, where $\phi=27 \mathrm{deg}$, and $c=0$ psf. 
intercept of 0 psf. The resultant factors of safety vary from less than 3.5 to more than 6.3. The factor of safety increases from the toe of the slide, where the failed material thickness is low, to the crown, where the failed material thickness is greatest. At low failed material thicknesses, the factor of safety is more dependent on the ratio between soil submerged unit weight (45 pcf) and the saturated unit weight (107.4 pcf) (fig. 18). By increasing the failed material thickness (e.g., near the crown) the ratio becomes less of a factor, and the factor of safety also increases. The contour pattern is similar to that of topography, which is largely responsible for the above thickness differences. To the north and southeast of the slide, the factor of safety drops off sharply, again due to a reduction in thickness of the failed mass. Both locations are near where the failure surface would be expected to daylight. Manual calculations for a slice along cross section $A-A^{\prime}$ (Appendix $C$ ) indicate a safety factor of 6.3 for the entire slope. At low water, with a 27 degree friction angle and a 0 cohesion intercept, the landslide is most stable.

High Water Level, $\phi=27$ degrees, $C=0$ psf

Using the above soil properties, and raising the water table to a level approaching the maximum high observed in the field (fig. 17), results in factors of safety which vary between 2.8 and 4.0 (fig. 21). The contour pattern also follows topography, but is much more dramatic. At lower topographic elevations, the saturated thickness of failed materials is greatest, resulting in lower factors of safety. As the topographic elevation increases, the difference between the total failed mass and unsaturated thicknesses 


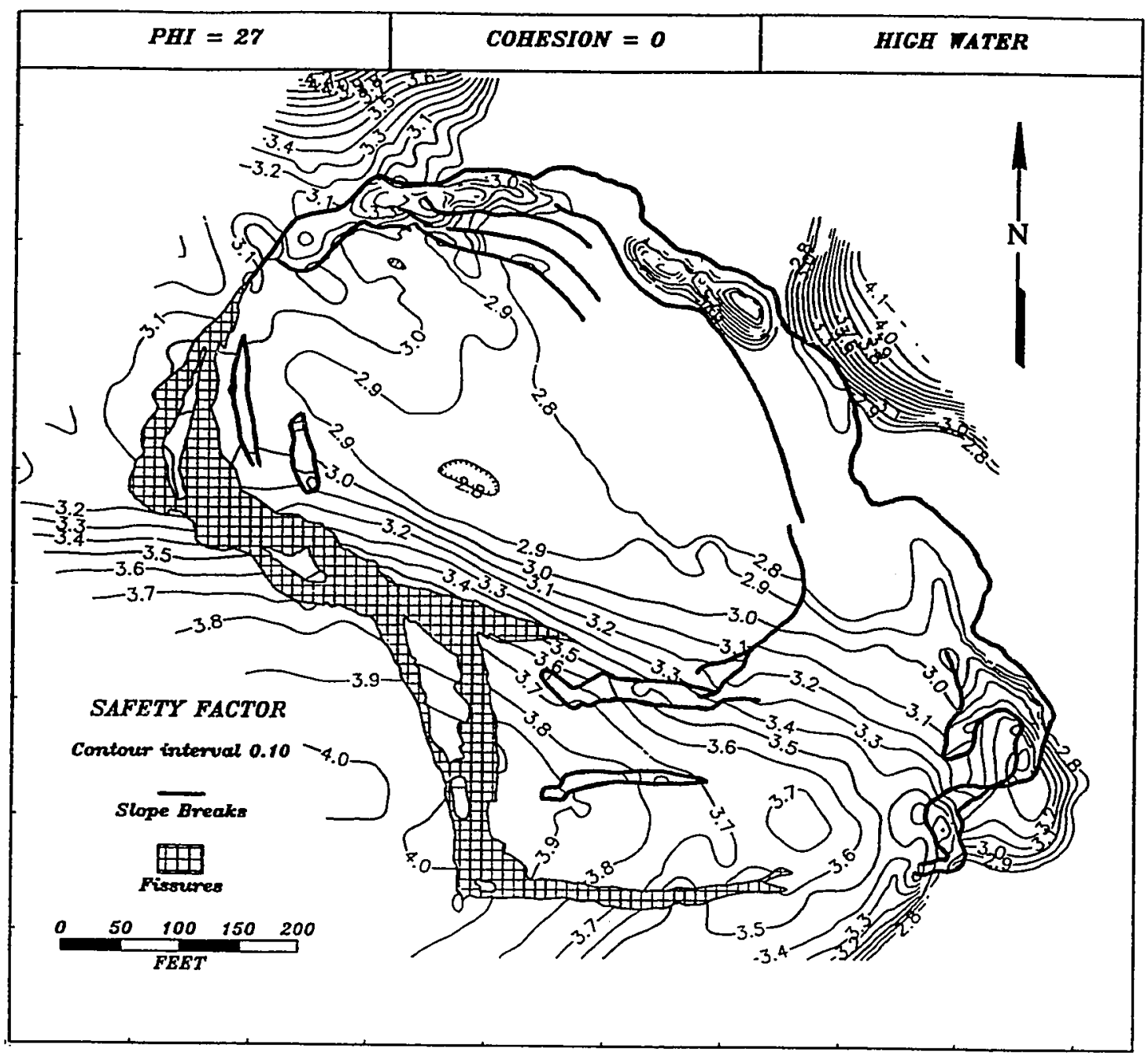

Figure 21. Factor of safety contours under conditions of high water, where $\phi=27 \mathrm{deg}$. and $\mathrm{C}=0 \mathrm{psf}$.

increases, causing marked increases in safety factor. The buttressing effect of the topographic high discussed on page 45 becomes noticeable, causing an increase in the factor of safety at the northeast edge of the slide. 
Manual calculations (Appendix $C$ ) indicate a factor of safety of 3.3 for the entire slope under the above conditions. This value, and the contours in figure 21, indicate that the landslide remains stable at high water, with a 27 degree friction angle and cohesion intercept of 0 psf.

High Water Level, $\phi=13$ degrees, $c=0$ psf

Additional factors of safety contour maps were generated by varying the friction angle and cohesion intercept of materials along the failure surface. Because there is no solid information on material properties at the failure surface, and because the slope certainly reached a state of instability at the time of failure, attempts were made to alter these soil properties until such a state of instability was attained. The first such change was made by altering the friction angle to a value of 13 degrees (at high water, with $\mathrm{C}=0$ psf), well within the range that might be expected of a plastic clay. The resultant contour map (fig. 22) again depicts contours that follow topography. The variation in factor of safety resulting from this analysis is between 1.3 and 1.8, again increasing from the toe to the crown of the slide. By decreasing the friction angle, however, the changes in factor of safety become less dramatic, because the results of the equation are less affected by $\tan \phi / \tan \beta$ (where $\beta$ is the slope of the failure surface), which becomes less as $\phi$ is reduced. Manual calculations of safety factor under these conditions yield a value of 1.5 along cross section A$A^{\prime}$, indicating a stable slope. 


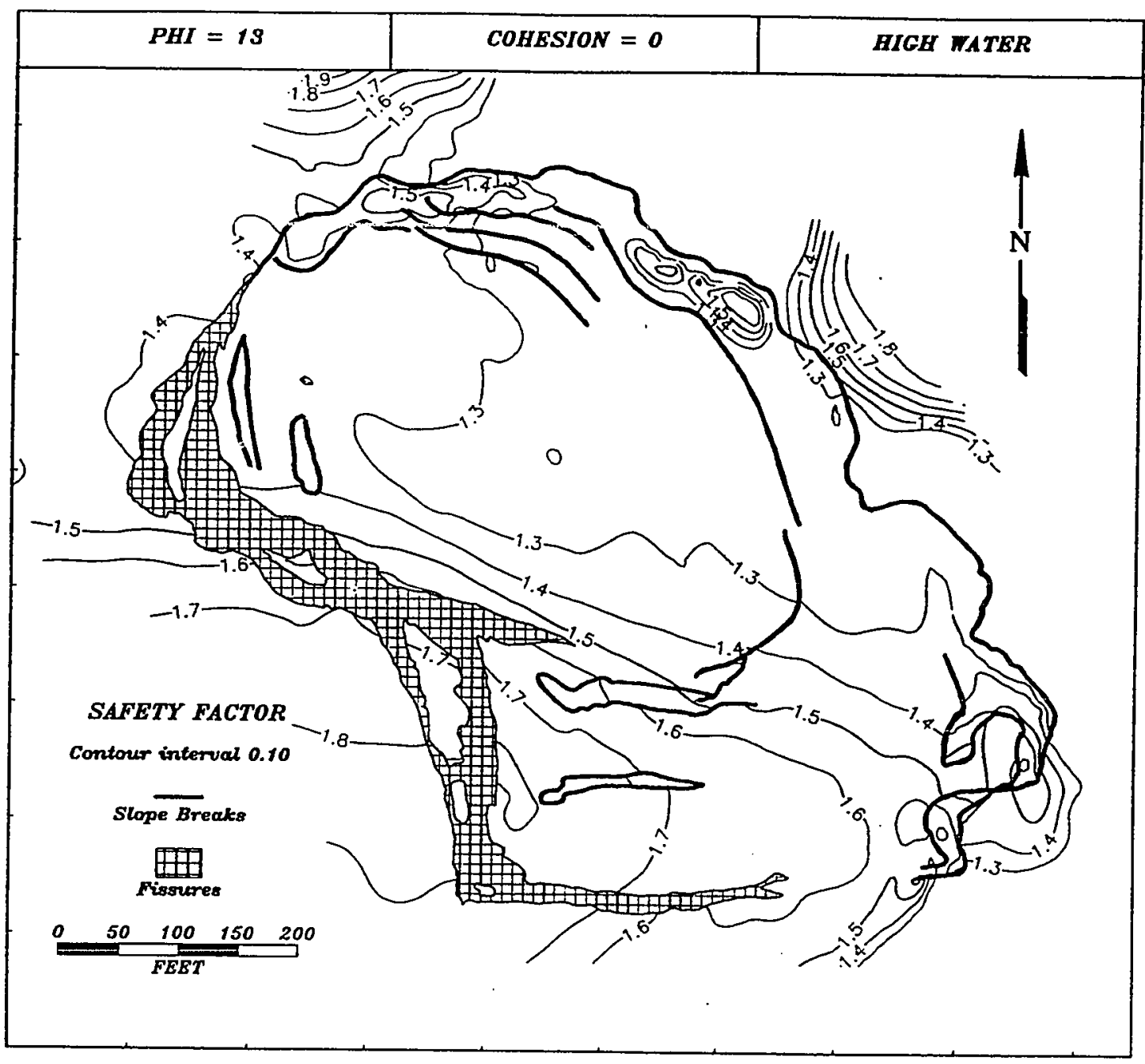

Figure 22. Factor of safety contours under conditions of high water, where $\phi=13 \mathrm{deg}$, and $\mathrm{C}=0 \mathrm{psf}$.

High Water Level, $\phi=7$ degrees, $C=0$ psf

Reducing the friction angle to a value of 7 degrees results in the entire slope becoming unstable (factor of safety less than 1), with factor of safety values varying between 0.7 and 0.9 (fig. 23). The variation in safety 


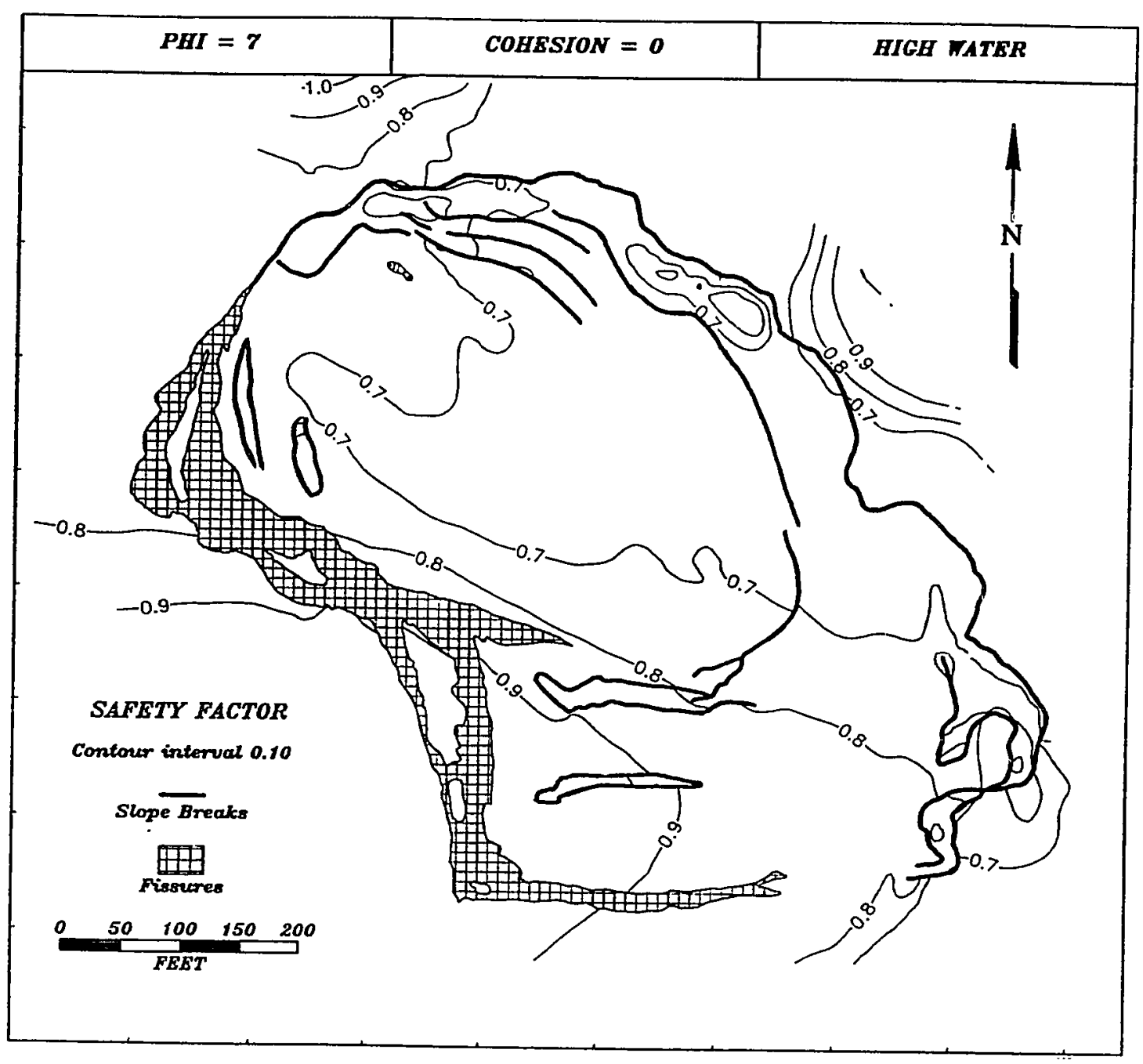

Figure 23. Factor of safety contours under conditions of high water, where $\phi=7 \mathrm{deg}$. and $c=0$ psf.

factor again decreases, as the dependency on $\tan \phi / \tan \beta$ becomes less. This reduced variation in factor of safety approaches what would be expected for a block failure, wherein the entire (or great majority) of the slope approaches instability at once. The morphology of failure suggested by the contours, however, does not indicate that 
failure would take place as it did (e.g., a break-away with the same orientation as the crown fissures). Manual calculations of the factor of safety under these conditions yield a result of 0.8 , also indicating instability.

High Water Level, $\phi=0$ degrees, $C=200$ psf

A separate run of the calculation was performed by setting $\phi$ at 0 degrees, and increasing the cohesion intercept to 200 psf. The resultant factor of safety (fig 24) varies between 0.5 and 5.0, with contours that again mimic topography. In this case, however, the factor of safety increases from the crown to the toe of the landslide. This suggests that thicker (and therefore heavier) failed material thicknesses create stresses which overcome the cohesion of materials, while a thinner section of failed materials does not have enough weight to overcome cohesion. It is possible however, that failure of the thick section near the present crown may induce failure at lower elevations, resulting in a block failure. While manual calculations of factor of safety indicate instability $(F=0.9)$ the pattern of contours depicted in figure 24 does not suggest failure along the existing crown fissures.

High Water Level, $\phi=7$ degrees, $C=200$ psf

To satisfy the equation for factor of safety where both $\phi$ and $C$ are greater than zero (fig. 18), the factor of safety grids from the two prior runs $(\phi=7, C=0$, and $\phi=0, C=200$ psf) were added together. The resultant contour map (fig. 25) depicts factor of safety contours at high water, where $\phi$ $=7$ degrees, and $\mathrm{C}=200 \mathrm{psf}$. Under these conditions, the slope remains stable, with factors of safety ranging from 1.5 to 5.0 (manual calculations yield a value of 1.6 ). The 


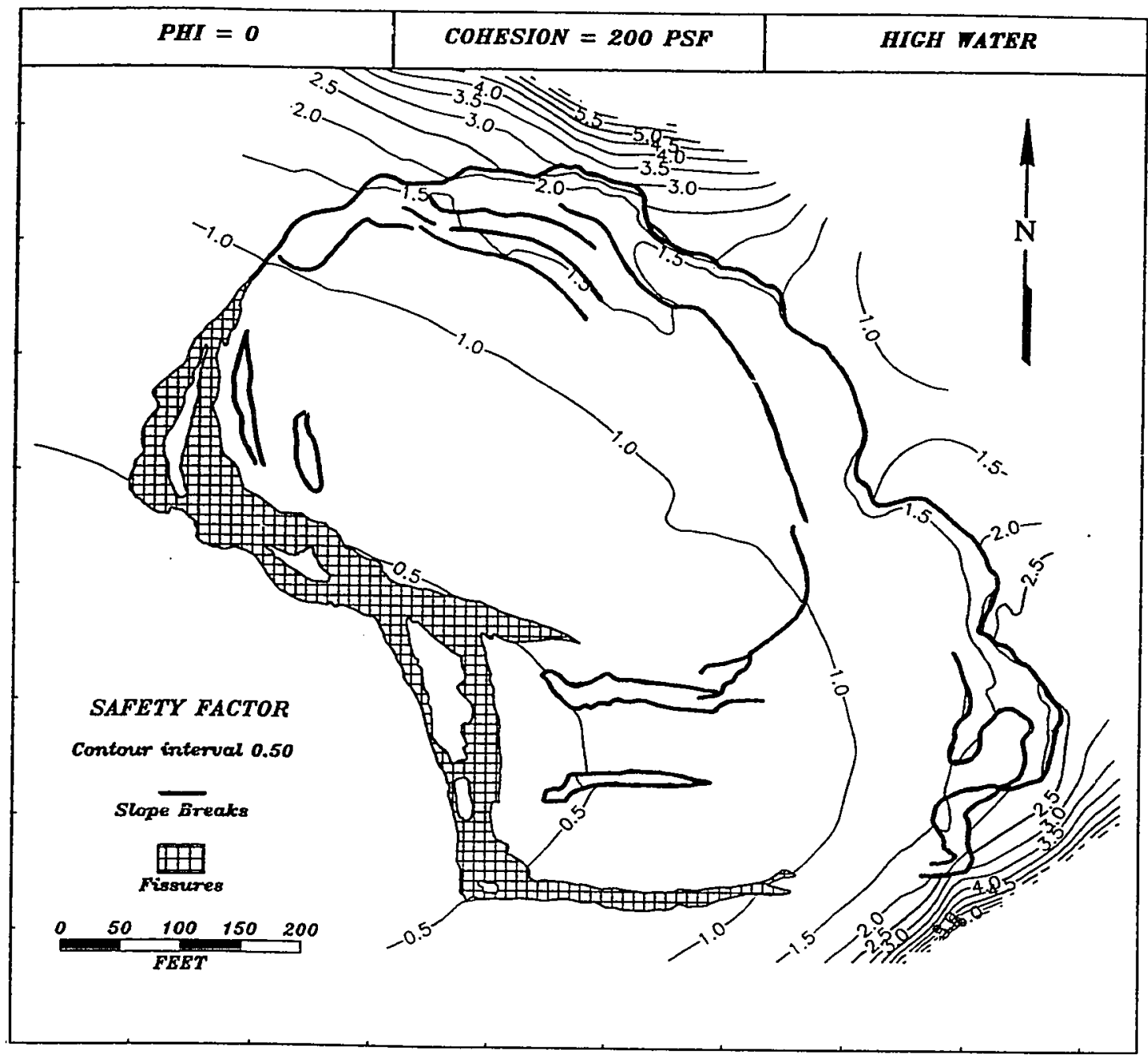

Figure 24. Factor of safety contours under conditions of high water, where $\phi=0$ deg. and $C=200$ psf.

safety factor again increases from crown to toe, due to the effects of increasing cohesion. 


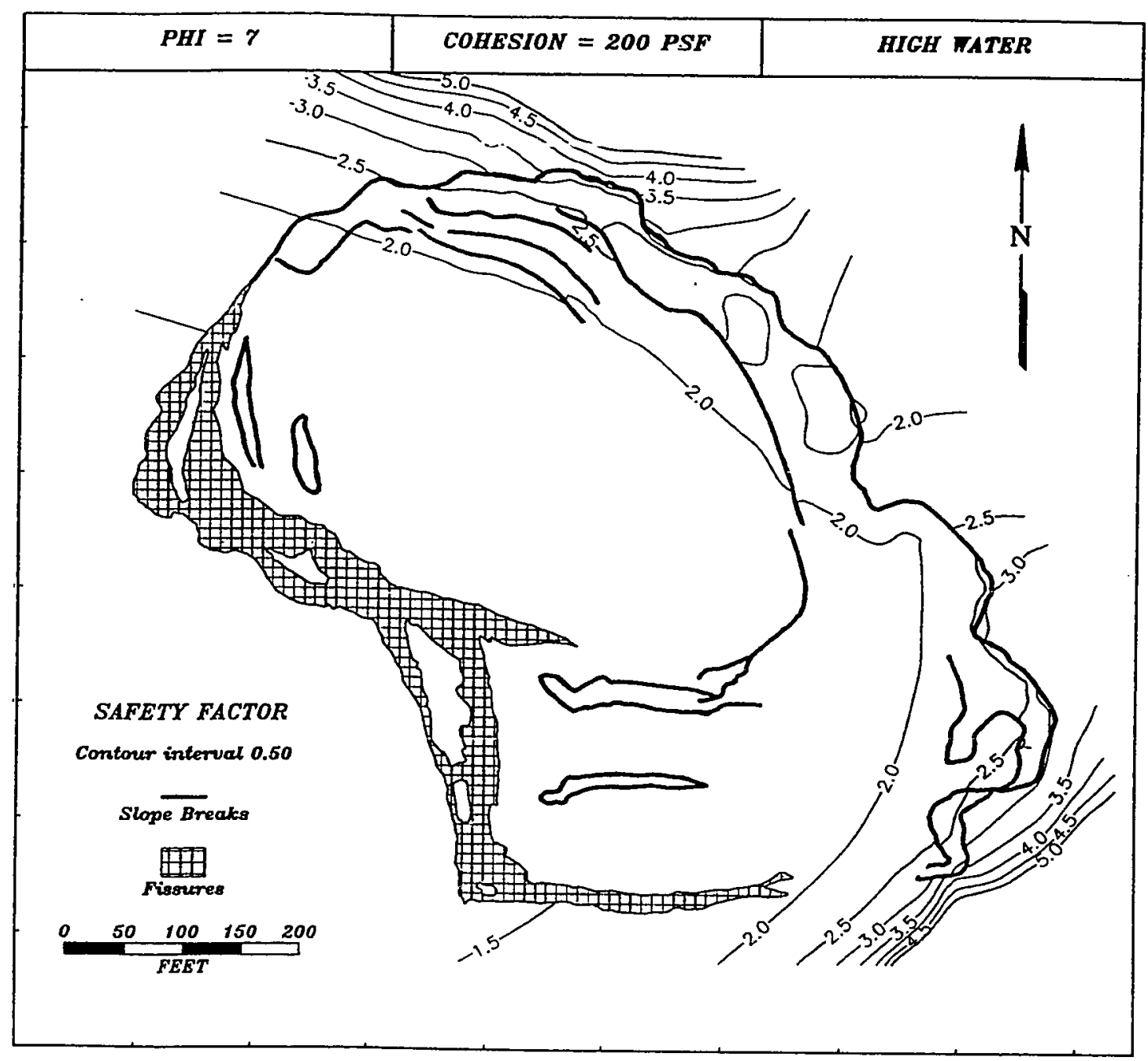

Figure 25. Factor of safety contours under conditions of high water, where $\phi=7 \mathrm{deg}$. and $c=200$ psf. .

Discussion

The above calculations, performed both manually and by the grid method, indicate that the Blucher Valley Landslide is stable urder the current drought conditions. Even at low values of $\phi$ ( 7 deg.), the slope remains stable at low water 
levels resulting from limited rainfall $(F=1.5)$. As the water level is raised to elevations observed in the field after heavy rains, the above calculations indicate that the slope becomes unstable under conditions of low $\phi$ and zero $C$, or $C=200$, with zero $\phi$.

Two interesting conclusions can be drawn from the results of stability analysis by the grid method. First, little evidence suggests that failure should have occurred as it did (i.e., a block glide failure) rather than as a progressive upslope failure from toe to crown. Although the contour spacings depicted in figures 20 through 25 indicate that a block mode of failure is approached as the value of $\phi$ is reduced, in none of the results did instability of the entire slope occur at once, as would be expected in a block failure. As the water level is raised, instability first cccurs at the toe of the landslide. Continued increase in water level causes instability to progress upslope from the toe to the crown of the landslide. This progressive instability would be expected to result in a progressive block failure as opposed to a block failure of the entire mass at once.

A second conclusion that can be drawn from the above calculations is that the crown fissures should not necessarily have opened in the geometry that is present. Because a factor of safety value of approximately 1.0 is considered to be transitional between a stable and unstable slope, failure of the slope should occur in all areas where the factor of safety is less than approximately 1.0, and failure should not occur in areas where the factor of safety is greater than 1.0. Some departure from this rule is acceptable because of localized variations in topography and landslide geometry which result in localized variations in 
safety factor that are negated by the overall resisting or driving forces. In general, however, failure along a factor of safety contour of approximate value 1.0 would be expected because this marks the transition from stability to instability. Examination of figures 20 through 25 suggests that the orientation of the crown fissures is independent of the location of the 1.0 factor of safety contour, suggesting the likelihood that other forces were in part responsible for causing the Blucher Valley Landslide.

\section{Wedge Failure Analysis}

The orientation of the crown fissures suggests that the two orthogonal joint sets described on pages 1 and 15 may have played a role in the development of the landslide. Hoek and Bray (1977) present a method of calculating the factor of safety of a rock slope based in part on the the locations of water filled fractures. The wedge failure analysis method (fig. 26) takes into consideration the wedging force provided by increased water levels in joints and fractures. The wedging caused by greatly increased water pressures actually acts to push the failed mass down the slope. Although use of the method is generally limited to rock slopes, it was employed on the Blucher Valley Landslide because the competence of the materials here results in similar properties to many rock slopes. The wedge failure analysis calculation was performed for a $\phi$ value of $13 \mathrm{deg}$. (the middle of the three $\phi$ values employed in the infinite slope method), and varying levels of water and cohesion. The results (fig. 26) indicate a strong possibility that wedging of water filled fractures was partly responsible for initial movement of the Blucher Valley Landslide. Such wedging would help to explain the orientation of the crown fissures, and 


\section{Analysis as a Wedge Failure}

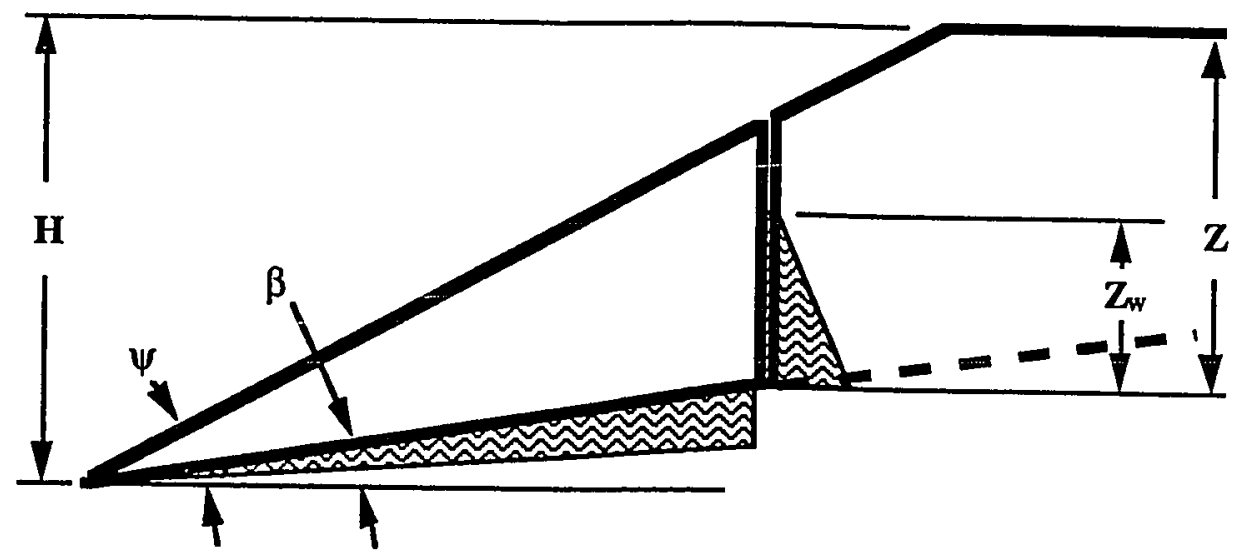

$\mathbf{F}=\frac{(2 \mathrm{c} / \gamma \mathbf{H}) \mathbf{P}+(\mathbf{Q} \operatorname{Cotan} \beta-\mathbf{R}(\mathbf{P}+\mathbf{S})) \operatorname{Tan} \phi}{\mathbf{Q}+\mathbf{R S C O t a n} \beta}$

Where

$P=(1-Z / H) \operatorname{Cosec} \beta$

$\mathrm{Q}=\left((1-\mathrm{Z} / \mathbf{H})^{2} \operatorname{Cos} \beta(\operatorname{Cotan} \beta \operatorname{Tan} \psi-1)\right)$

$\mathbf{R}=\frac{\gamma_{w}}{\gamma} \frac{Z_{w}}{\mathbf{Z}} \frac{\mathbf{Z}}{\mathbf{H}}$

$S=\frac{Z_{\mathrm{W}}}{\mathbf{Z}} \mathbf{Z} \operatorname{Sin} \beta$

\begin{tabular}{|c|c|c|c|}
\hline$Z_{w}$ & $\phi$ & $c$ & $F$ \\
\hline 1 & 13 & 0 & 0.98 \\
\hline 40 & 13 & 0 & 0.42 \\
\hline 1 & 13 & 200 & 2.3 \\
\hline 40 & 13 & 200 & 1.0 \\
\hline
\end{tabular}

Figure 26. Analysis as a wedge failure (Hoek and Bray, 1977).

the fact that failure occurred as a block, rather than as a progressive slump failure. 
Assumptions and Limitations

The methodologies employed herein for the determination of factor of safety cesult in useful approximations of slope stability, and the variation in stability throughout the landslide. They are, however, based on techniques and data that may impart errors in the final results and in the understanding of results. Such potential errors may be attributed to the quantity and quality of data utilized in the geologic model, and the the methods whereby those data are employed in factor of safety analyses.

The Geologic Model

Although this investigation has utilized an extensive data set, several of the parameters used to formulate an estimate of geometry, stability, and causes of the Blucher Valley Landslide are based partially on assumptions, including the following:

1) The material properties of the failed block were determined from samples taken from the walls of the crown fissures, and as such represent values only at that location. The resultant values, however, are reasonable when compared to other materials of similar Iithology.

2) Because data on the true material properties on the failure surface are sparse, it was necessary to assume, for the sake of stability analysis, that the material properties are similar to those of clays that are present in the crown fissure. The factor of safety analyses performed, however, also considered other reasonable material properties that may exist at the 
failure surface. Higher friction angles, with or without moderate cohesion, could be associated with stiffer clays or tuff. These properties result in higher factors of safety. Lowering the friction angle to values representing material such as weak clays, however, greatly reduces the factor of safety. In all of the stability analyses performed, however, the same indications resulted (e.g., failure due to high pore pressures at the failure surface, augmented by wedging of water filled fractures).

3) The location and orientation of the failure surface, assumed to be a plane which follows structural dip, has been approximated based on the orientation of bedding in the crown fissures, and on the location of sheared casing in boreholes. Although an improved understanding of failure mechanisms and stability would be realized through better knowledge of failure surface geometry, the location and orientation used fits well with available data and probably is a close approximation of the true failure surface configuration.

4) Groundwater levels at high water were extrapolated based on limited information provided by one monitoring well, and the areas where apparent seepage took place during and after heavy rainfall. The use of additional data (e.g., acquired from several monitoring wells that could be installed) would allow for more accurate results.

The above assumptions were made necessary due to the lack of data from below ground level. All of these assumptions, however, are within ranges that would be expected in similar structural, lithologic, and geographic settings. 
Factor of Safety Analysis

The computer methodology described (page 50) and used for this investigation presents the variation in factor of safety over the extent of the landslide. The method cannot be employed as a replacement of standard (infinite slope or method of slices) techniques. The reason for this is that the method takes into consideration only those properties that exist in the soil column at the location of each grid cell. In fact, a valid methodology for the determination of factor of safety of the entire landslide must consider not only the safety factor at the point in question, but also that of adjacent locations (grid cells). The stability at each cell is at least partially dependant on the safety factor of adjacent cells in the upslope and downslope directions. An extreme example would be one in which a cell with a calculated factor of safety of 0.5 occurs immediately upslope of one in which the factor of safety is calculated as 10.0: In ail likelihood, the very low stability in the upslope cell would be increased by that of the downslope cell. In most cases, however, differences in slope stability from cell to cell of the Blucher Valley Landslide geologic model are much less than 0.1 , and the resultant contour maps depict factors of safety that are reasonably accurate. Although this method does not supply one value of slope stability for the landslide, it is a valuable tool for the understanding of the range in slope stability, and factors which result in such ranges.

Another assumption employed in this investigation is that the present configuration of the landslide is the same as that which existed prior to initial movement. All factor of safety analyses performed have taken into consideration 
the configuration of the landslide as it exists at present. The final analysis represents the safety factor of the landslide which includes the effect of the crown fissures and toe pressure ridges. While these features affect, to some degree, the stability of the landslide, these effects are minor. Given the block glide mode of failure, and the very limited disruption of the failed material and topography (which would be much greater in the case of a rotational failure, or debris flow), the factor of safety calculations are representative of those that existed under similar conditions before or during movement.

Lastly, all stability calculations performed take into consideration a circumstance in which the soil column is dry above the water table, and 100\% saturated below the water table. This is not likely to have been the case during failure, because little if any of the soil above the water table would have been dry following the levels of rainfall that had occurred. In all likelihood, the soil above the water table would have varied in saturation from $100 \%$ to a lesser percentage that is still well above zero. Because of this, the factors of safety presented are probably somewhat greater than what would exist under real conditions.

Increasing soil weights in the unsaturated zone would result in the same general conclusion with respect to causes of the block failure. 


\section{CONCLUSIONS}

\section{The Landslide}

The Blucher Valley Landslide is a translational block glide that was likely caused by increased pore pressures along the failure surface. These destabilizing forces were likely augmented by the wedging of water filled fractures at the crown of the slide. A probable chain of events in the formation of the landslide is as follows:

1) abnormally heavy rains during the 1981-82 and 198283 seasons saturated near-surface materials (the present failed block), including a thin clay layer along the present failure surface of the slide, resulting in increased driving forces and decreased resisting forces;

2) as a direct result of over $23.7 \mathrm{~cm}(9.35 \mathrm{in.})$ of rain falling over a period of 7 days, the water levels within the orthogonal joint set in the Wilson Grove formation caused wedging which opened the crown fissure by pushing the failed mass down slope;

3) initial movement of the failed material by wedging probably further reduced the strength of clays along the failure surface, allowing for continued movement over a period of several weeks;

4) movement of the landslide probably ceased due to a combination of drainage of the slope and fissures, 
and the buttressing effect of a topographic high at the toe of the landslide.

The shape of the crown fissures of the landslide are a result of the orientation of the two orthogonal joint sets in the wilson Grove formation at this locality. The topographic high at the toe of the slide, along with the orientation of the failure surface and geometry of the failed mass, is probably responsible for the shape of the toe pressure ridges, which were caused by the buckling of materials along the margins of the failed mass.

In current drought conditions, the landslide is stable and inactive. Topographic monitoring suggests that movement has not occurred in the last 2 years, and probably has not occurred since several months after initial movement. The topographic high that is present at the toe of the landslide probably acts as a buttress that assists in curtailing future movement.

The Analysis Methodology

This investigation has resulted in the the introduction of a new means of investigating and understanding the geometry, stability, and causes of slope failures. The grid method factor of safety analysis presented allows for a detailed examination of the variation of factor of safety over the landslide that results from variations in topography, geometry, and water levels. The method does not replace standard slope stability methods. Standard methods serve to provide a stability of the entire slope. The grid method, however, augments the analysis by directing attention to variations in stability, and the possible causes of such variations. The capability of applying formulas to the grids that make up a geologic model allows for such methods to be 
applied in numerous landslide situations, using the analysis method that applies best to the landslide of interest. 
REFERENCES CITED

Bartow, J.A., Sarna-Wojcicki, A.M., Addicott, W.O., and LaJoie, K.R., 1973, Correlation by tephrochronology: American Association of Petroleum Geologists, Bulletin,
v.57, no.4.

Bedrossian, T.I., 1982, Geology and slope stability, west Sebastopol area: California Geology, Vol. 35, No. 4, pp. 71-79.

Chowdhury, R.N., 1978, Slope analysis: Amsterdam, The Netherlands, Elsevier Scientific Publishing Company $423 \mathrm{p}$.

Compton, R. R., 1962, Manual of field geology: New York, John Wiley \& Sons, $378 \mathrm{p}$.

Cotton, W.C. and Associates, 1983, Preliminary report, engineering geologic investigation, Blucher Valley landslide, Sebastopol, California: Unpublished report to landowners P. Johnson and B. Aita, $6 \mathrm{p}$.

Fox, K.F., 1983, Tectonic setting of Late Miocene, Pliocene, and $P$ leistocene rocks in part of the Coast Ranges north of San Francisco, California: U.S. Geological Survey Professional Paper 1239, $33 \mathrm{p}$.

Hoek, E., and Bray, J.W., 1977, Rock slope engineering: London, Institute of Mining and Minerals, $402 \mathrm{p}$.

Lambe, W.T., and Whitman, R.V., 1969, Soil mechanics: New York, John Wiley \& Sons, $553 \mathrm{p}$.

Mooney, H.M., 1984, Handbook of engineering geophysics: Minneapolis, Minnesota, Bison Instruments, Inc., pp. 5-1 $-5-3$.

Romie, J.E. 1986, Use of a geographic information system for geologic site characterization studies in the Paradox Basin, Southeastern Utah, in Opitz, B.K., ed., Geographic information systems in government, vol 1 , Hampton, Virginia, A. Deepak Publishing, pp. 379-402.

Sarna-Wojcicki, A.M., 1976, Correlation of Late Cenezoic tuffs in the Central Coast Ranges of California by means of trace- and minor element chemistry: U.S. Geological Survey Professional Paper 972, p. 27. 
Smith, T.C., 1986, Landslide hazards in the southern part of the Petaluma Dairy Belt, Sonoma County, California: California Division of Mines and Geology, Open-File Report 86-5 SE, 4 plates.

Smith, T.C., and Hart, E.W., 1982, Landslides and related storm damage, January 1982, San Erancisco Bay Region: California Geology, V. 35, No. 7, July, 1982, pp. 139152 .

Spittler, T.E., 1983, Blucher Valley translational landslide: California Geology, Vol. 36, No. 8, pp. 175-180.

Travis, R.B., 1952, Geology of The Sebastopol Quadrangle, California: California Division of Mines, Bulletin 162, $33 \mathrm{p}$.

Personal Communications

Anderson, T., 1987, Department of Geology, Sonoma State University, California

Fowler, B,.1987, William Cotton \& Associates, Los Gatos, California

Koons, W., 1989, Sonoma County Water Agency, Santa Rosa, California

Olsborg, E., 1987, Field Engineering Associates, Inc., Santa Rosa, California 
APPENDIX A

Lab Determination of Soil Properties 


\title{
ATTERBERG LIMITS DETERMINATION
}

\author{
SITE: Blucher Valley Landslide LOCATION: Sebastopol, CA
}

SAMPLE INFORMATION: Collected with split spoon sampler. Sample located on wall of island within crown fissure. approximately 5 feet above base of fissure (approximate map coordinates: $X=250, Y=420$ ). Sample is grav clay, veny plastic when saturated.

\section{LIQUID LIMIT:}

\begin{tabular}{|l|c|c|c|c|c|c|}
\hline CAN NUMBER & M-3 & D-59 & M-13 & D-54 & D-92 & F-9 \\
\hline WET SOIL + CAN (gm.) & 65.6 & 58.5 & 70.1 & 62.8 & 58.1 & 73.7 \\
\hline DRY SOIL + CAN (gm.) & 59.4 & 50.7 & 61.4 & 53.5 & 50.6 & 65.1 \\
\hline CAN (gm.) & 51.4 & 40.9 & 50.4 & 42.6 & 41.4 & 55.0 \\
\hline DRY SOIL (gm.) & 8.0 & 9.8 & 11.0 & 10.9 & 9.2 & 10.1 \\
\hline MOISTURE (gm) & 6.2 & 7.8 & 8.7 & 9.3 & 7.5 & 8.6 \\
\hline WATER CONTENT (\%) & 77.5 & 79.6 & 79.1 & 85.3 & 81.5 & 85.2 \\
\hline BLOWS & 54 & 39 & 41 & 18 & 26 & 16 \\
\hline
\end{tabular}

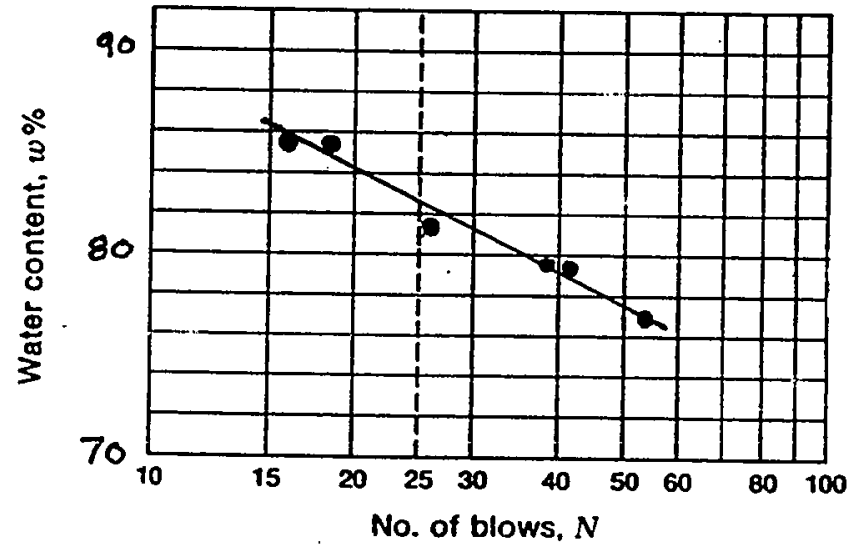

Liquid Limit:

Plastic Limit:

Plasticity Index:
82.5

45.2

37.3

PLASTIC LIMIT:

\begin{tabular}{|l|c|c|c|}
\hline CAN MUMBER & D-97 & D-14 & F-8 \\
\hline WET SOIL + CAN (gm.) & 48.9 & 47.7 & 62.4 \\
\hline DRY SOIL + CAN (gm.) & 46.7 & 45.6 & 58.9 \\
\hline CAN (gm.) & 41.6 & 41.0 & 51.4 \\
\hline DRY SOIL (gm.) & 5.1 & 4.6 & 7.5 \\
\hline MOISTURE (gm.) & 2.2 & 2.1 & 3.5 \\
\hline WATER CONTENT (\%) & 43.1 & 45.7 & 46.7 \\
\hline
\end{tabular}




\section{MOISTURE CONTENT - DRY DENSITY SPECIFIC GRAVITY}

SITE: Blucher Valley Landslide LOCATION: Sebastopol, CA

SAMPLE INFORMATION: Cellected with split speen sampler (1.5 in , 1,D.). Sample located in fissure wall. approximately 6 feet above base of fissure (approximate map coordinates: $X=485, Y=350$ ). Light brown silty fine sand at top of capillary fringe.

\section{MOISTURE CONTENT}

Sample Length (in.) $\quad 4.0$

Cup + wet soil (gm.) 261.7

Cup + dry soil (gm.) 241.9

Moisture loss (gm.) 19.8

Cup (gm.) 107.6

Dry Soil (gm.) $\quad 134.3$

Moisture Content (\%) 14.74

Dry Density (pcf) 72.2

\section{SPECIFIC GRAVITY}

\begin{tabular}{|c|c|c|c|}
\hline & & $\begin{array}{l}\text { Sample } \\
\# 1\end{array}$ & $\begin{array}{r}\text { Run } \\
\# 2\end{array}$ \\
\hline $\begin{array}{l}\text { Tempurature (Water/Soil, deg C) } \\
\text { Dry Soil (gm.) }\end{array}$ & $\begin{array}{l}T \\
W_{S}\end{array}$ & $\frac{23}{100.0}$ & 93.6 \\
\hline Flask + Water (gm.) & $\mathbf{w}_{\text {bw }}$ & 671.9 & 667.2 \\
\hline$W_{s}+W_{b} w$ & & 771.9 & 760.8 \\
\hline Flask+water+immersed soil (gm.) & $W_{\text {bws }}$ & 734.2 & 725.7 \\
\hline Correction Factor (temp. dependent) & $\mathbf{K}$ & 0.9993 & 0.9993 \\
\hline$G=\left(W_{s} K\right) /\left(W_{s}+W_{b w}-W_{b w s}\right)$ & & 2.65 & 2.66 \\
\hline
\end{tabular}




\section{DETERMINATION OF SOIL UNIT WEIGHT UNDER SATURATED CONDITIONS}

Total unit weight of a soil $(\eta)$ is defined as follows:

$$
\begin{array}{lll}
\gamma=\frac{\mathbf{G}+\mathbf{S e}}{\mathbf{1}+\mathbf{e}} \gamma_{\mathbf{W}} & \text { Where: } & \mathbf{G}=\text { Specific Gravity } \\
& \mathbf{S}=\text { Percent saturation } \\
& \mathbf{e}=\text { Void Ratio } \\
& \gamma_{\mathbf{w}}=\text { Unit weight of water }
\end{array}
$$

Void Ratio (e) is defined as follows:

$$
e=\left(G x_{w} V / w_{s}\right)-1 \text { Where }
$$

$$
\begin{aligned}
& \mathbf{V}=\text { Volume of material } \\
& \mathbf{W}_{\mathbf{S}}=\text { Weight of solids }
\end{aligned}
$$

Fine silty sands (failed material) at the Blucher Valley Landslide have the following properties under saturated conditions:

Void Ratio

$$
\mathrm{e}=((2.65(62.4 \mathrm{pcf})(1 \mathrm{cf})) / 72 \mathrm{pcf})-1 \quad \underline{1.29}
$$

Saturated unit weight

$$
\gamma=\frac{(2.65+(100 \%)(1.29))}{1+1.29}(62.4 \mathrm{pcf})=\underline{107.4 \mathrm{pcf}}
$$

Submurged unit weight

$$
\begin{aligned}
\left(\gamma^{\prime}\right) & =\gamma-\gamma_{\mathrm{w}} \\
& =107.4 \mathrm{pcf}-62.4 \mathrm{pcf}=45.0 \mathrm{pcf}
\end{aligned}
$$


APPENDIX B

Tabulated Survey Data for Round 1 Survey 
TABULATED SURVEY DATA FOR ROUND 1 SURVEY

BLUCHER VALLEY LANDSLIDE

EXPLANATION OE THEODOLITE AND EDM SURVEY COMPUTATION TABLES

Station Number:

- Alpha characters denote instrument stations. Where instrument stations are expressed as single digits, the station is the same as that used during prior work by William Cotton \& Associates. Those expressed as double digits (BB) are specific to this investigation.

- "C-12" denotes a measurement from instrument station $C$ to survey station 12 . The station was initially surveyed by William Cotton \& Associates.

- "C-012" denotes measurement from instrument station $C$ to survey station 012 , and the station is specific to this investigation.

\section{G.I to Theodolite:}

- The distance, in inches, from the ground surface to the theodolite optical center at the instrument station. 
GI to Prism:

- The distance, in inches, from the ground surface to the center of the prism assembly at the survey station.

Azimuth:

- Compass direction from the instrument station to the survey station, expressed as DD.MMSS (DD = degrees, $\mathrm{MM}=$ minutes, $\mathrm{SS}=$ seconds).

Theodolite Vertical Angle:

- The vertical angle read from the theodolite, where 90 degrees is horizontal.

EDM Hypotenuse:

- The straightline distance from the EDM to the prism assembly.

Corrected Hypotenuse:

- The straightline distance from the EDM to the prism assembly, corrected to account for slight difference in elevation between Theodolite and EDM (Romie, 1987).

True Horizontal Distance:

- The horizontal distance from theodolite/EDM to the prism assembly, with the above correction taken into consideration.

True Vertical offset:

- The difference in elevation between the theodolite/EDM and the prism assembly. 


\begin{abstract}
Ground Level Slevation Change:
- The corrected ground level elevation change between instrument and survey stations, based on true vertical offset, GI to theodolite, and GL to prism.
Calculated Elevation:
- Calculation based on the knowr elevation of the instrument station, and the ground level elevation change.

\begin{abstract}
REFERENCE
Romie, J, 1987, SURVEY.BAS and SURVEY,WK1, Two MS-DOS

Programs for the correction of combined EDM and Theodolite

Survey Data, unpublished independent research report

submitted to San Jose State University, Department of Geology, December, 1987.
\end{abstract}




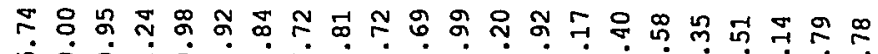

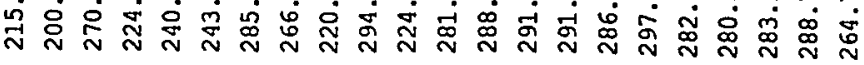

ธสํํำ

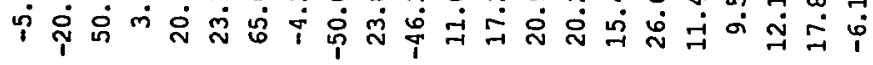

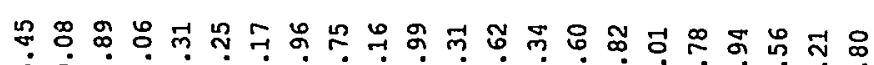

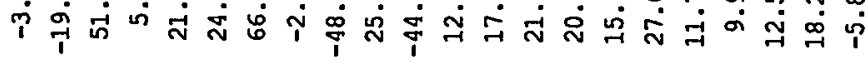

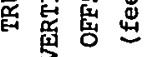

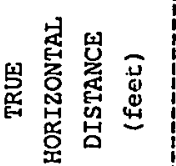

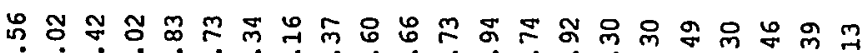

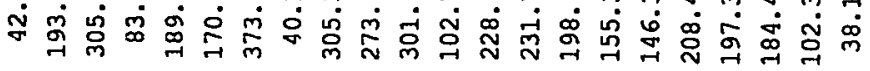

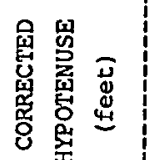

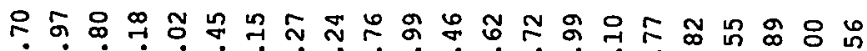
ฟ

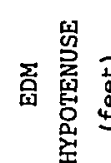

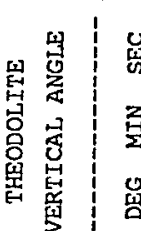

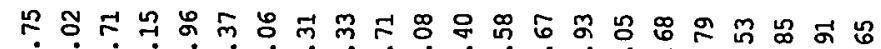
ฟ

0.000 .0000000 .00000000

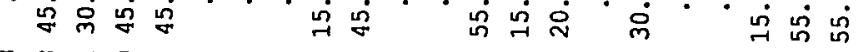

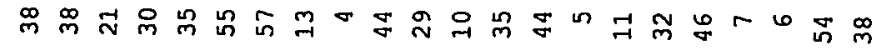
హำ

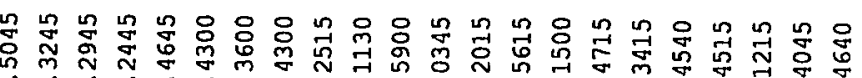

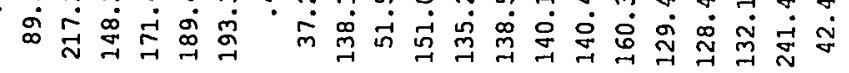

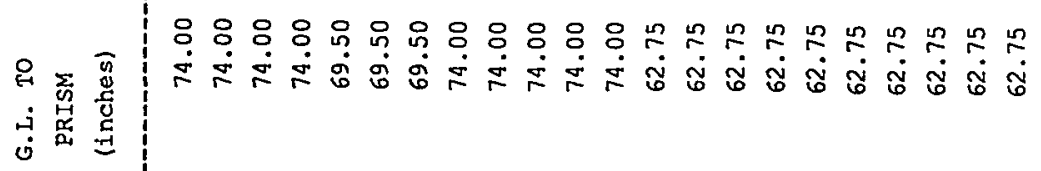

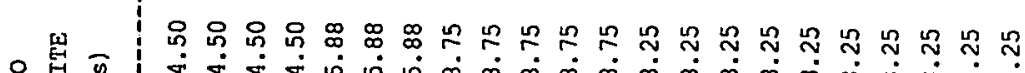
每率 总罳

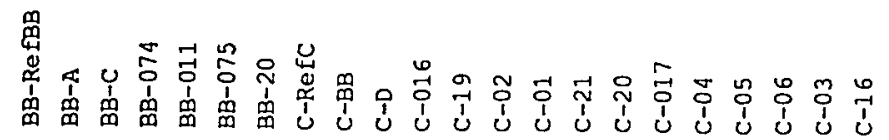




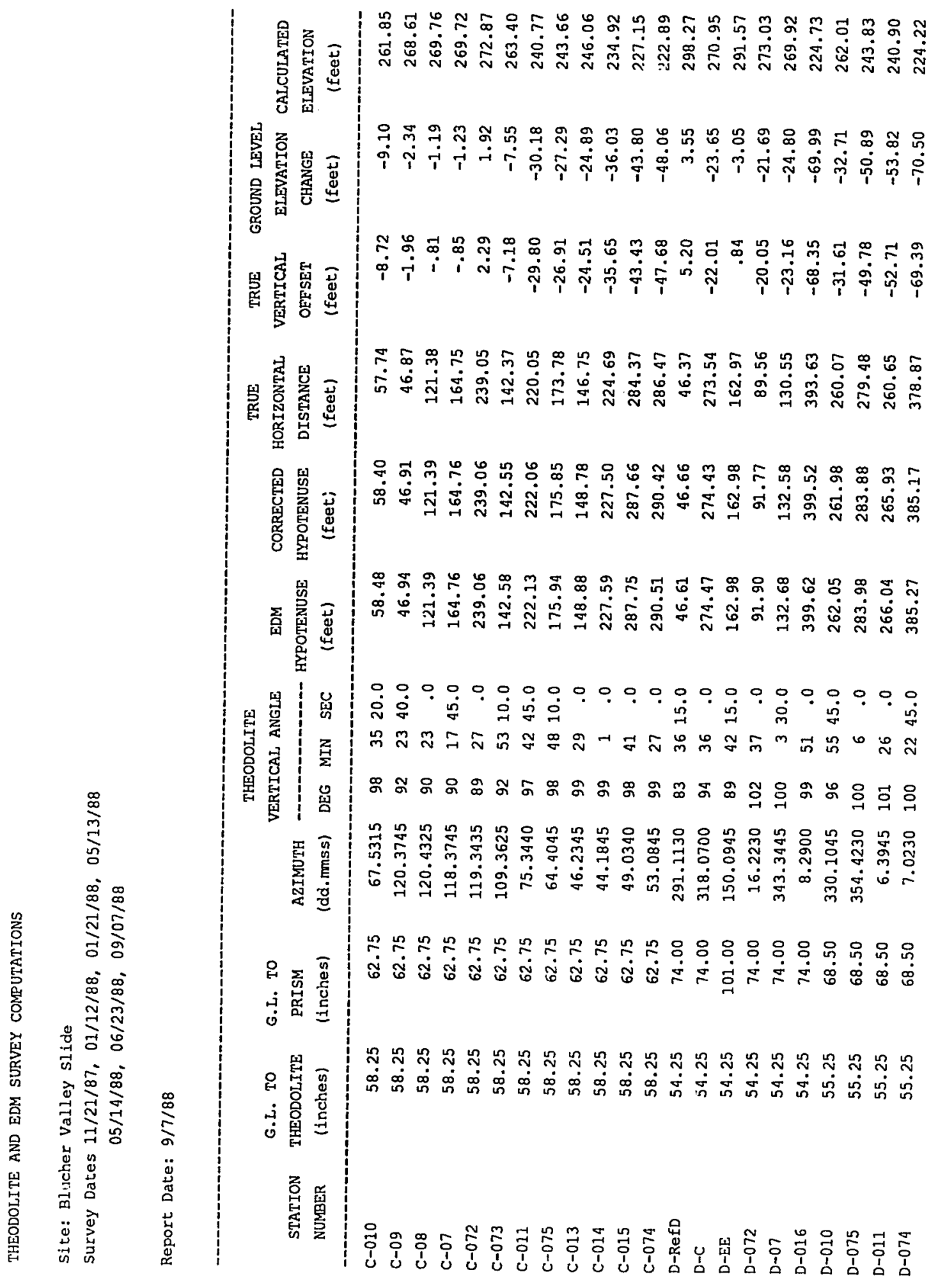




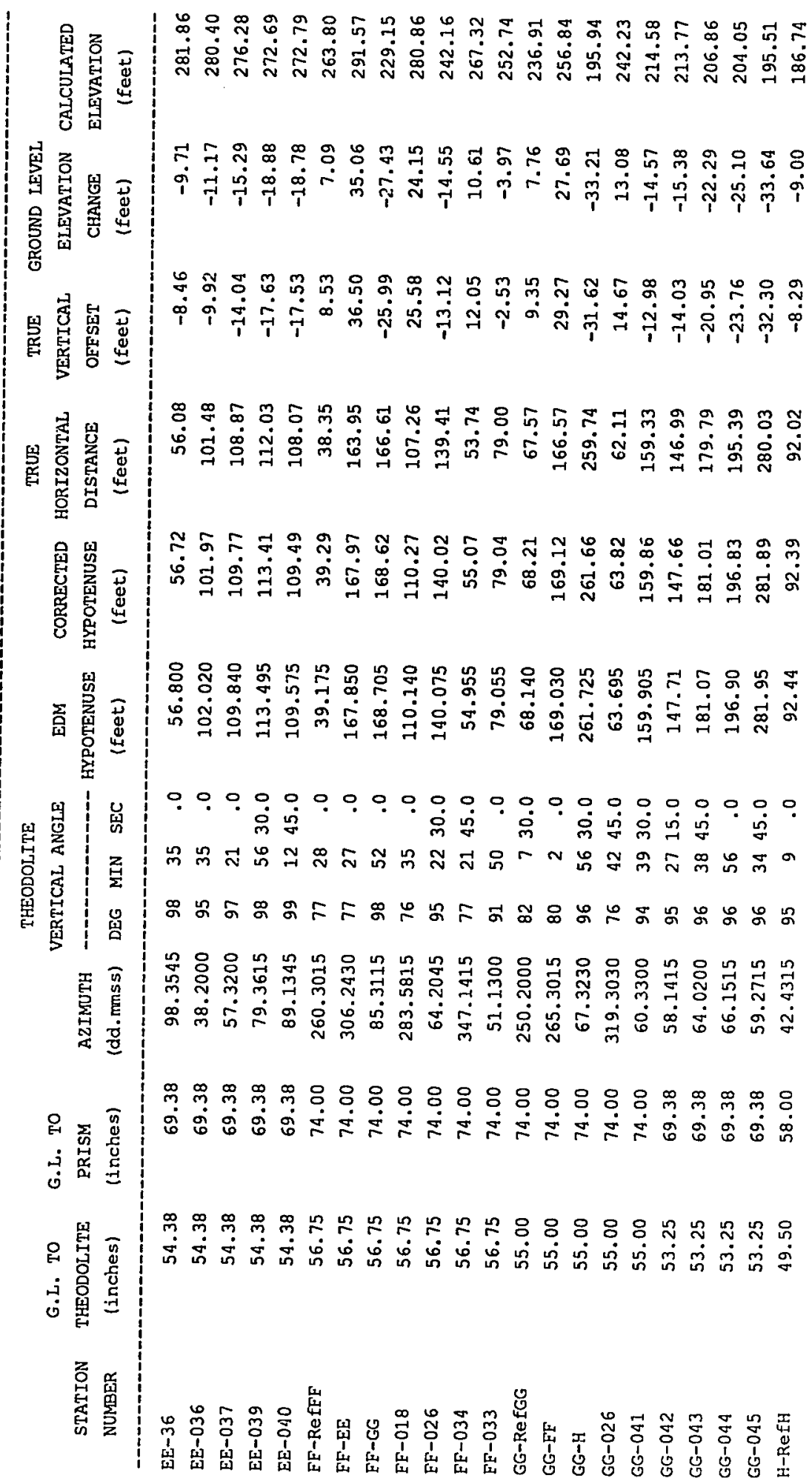




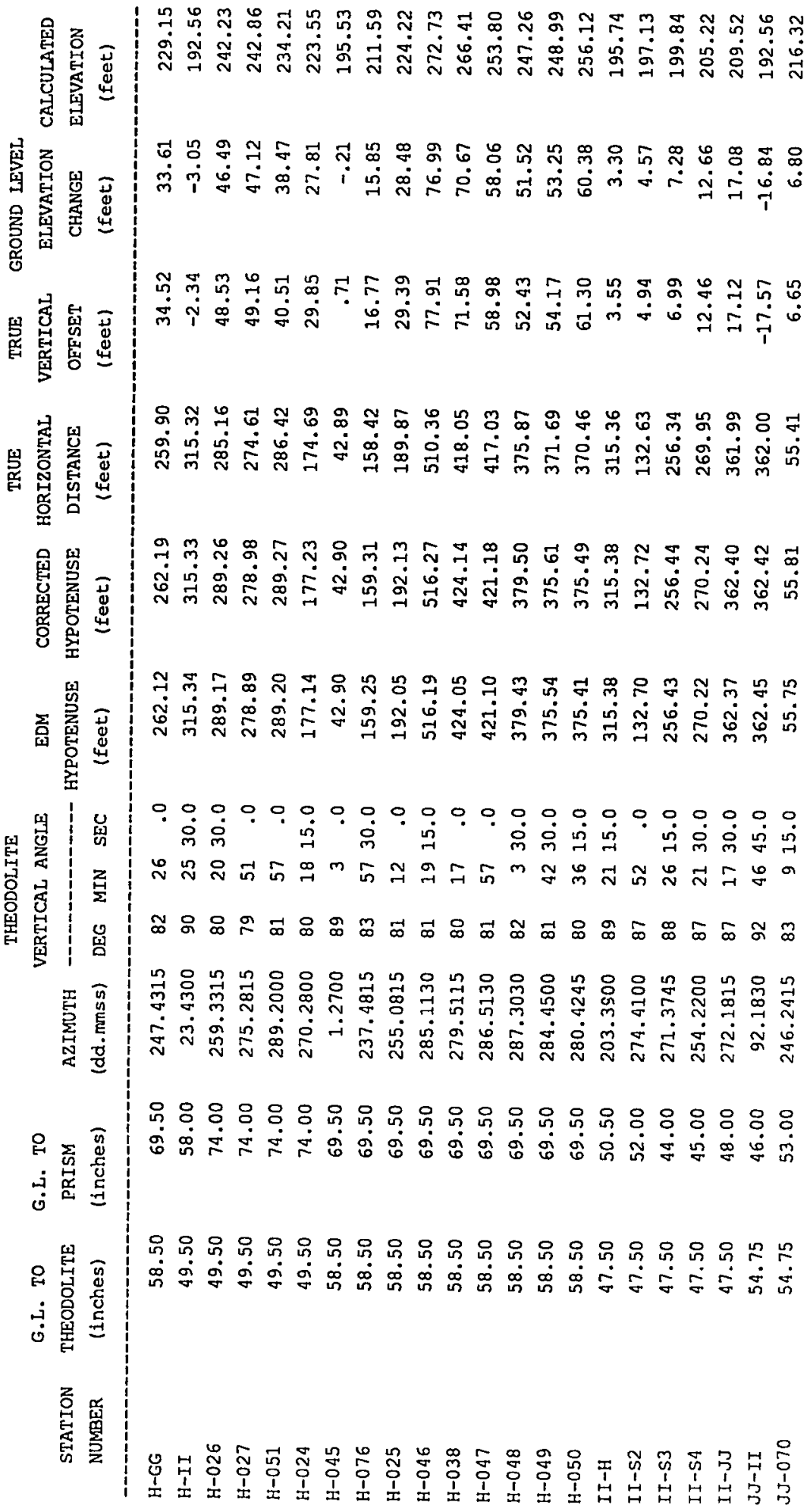




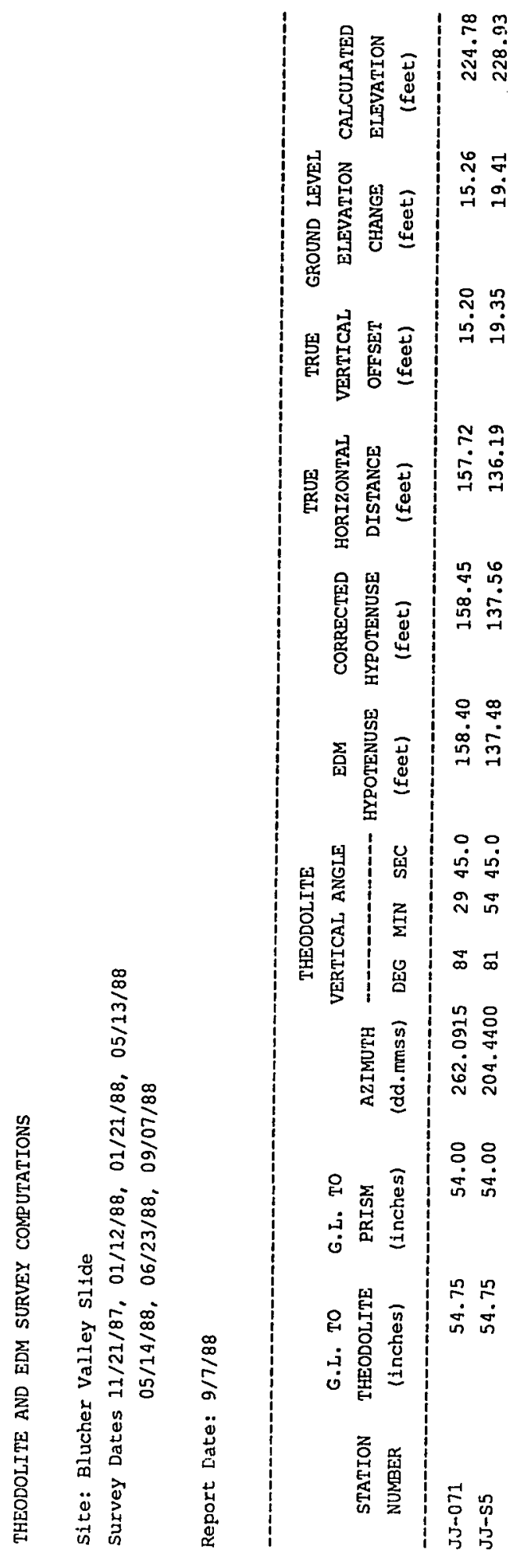


SURVEY STATION MAP COORDINATES AND ELEVATIONS

BLUCHER VALLEY LANDSLIDE

\begin{tabular}{|c|c|c|c|}
\hline Station & Easting & Northing & Elevation MSL \\
\hline 01 & 243.03 & 368.62 & 291.92 \\
\hline 010 & 144.29 & 565.08 & 261.85 \\
\hline 011 & 303.92 & 598.16 & 240.77 \\
\hline 013 & 197.06 & 644.56 & 246.06 \\
\hline 014 & 247.76 & 704.12 & 234.92 \\
\hline 015 & 305.62 & 729.68 & 227.15 \\
\hline 016 & 328.46 & 729.14 & 224.69 \\
\hline 017 & 139.47 & 405.38 & 297.58 \\
\hline 018 & 382.26 & 126.87 & 279.54 \\
\hline 019 & 860.81 & 258.24 & 204.97 \\
\hline 02 & 251.73 & 380.51 & 288.20 \\
\hline 020 & 802.78 & 266.00 & 210.89 \\
\hline 021 & 806.57 & 239.04 & 208.04 \\
\hline 022 & 790.93 & 266.39 & 209.98 \\
\hline 023 & 715.05 & 288.20 & 220.94 \\
\hline 024 & 718.00 & 214.04 & 223.55 \\
\hline 025 & 709.16 & 163.92 & 224.22 \\
\hline 026 & 612.08 & 160.97 & 242.23 \\
\hline 027 & 619.24 & 239.59 & 242.76 \\
\hline 028 & 521.27 & 243.73 & 261.96 \\
\hline 029 & 521.47 & 235.19 & 260.25 \\
\hline 03 & 0.67 & 494.78 & 288.79 \\
\hline 030 & 522.95 & 222.13 & 262.29 \\
\hline 031 & 563.87 & 233.12 & 253.27 \\
\hline 032 & 530.41 & 193.26 & 259.90 \\
\hline 033 & 547.91 & 150.19 & 252.74 \\
\hline 034 & 474.46 & 153.12 & 267.32 \\
\hline 035 & 416.72 & 225.70 & 282.57 \\
\hline 036 & 417.28 & 277.75 & 280.40 \\
\hline 037 & 446.19 & 256.59 & 276.28 \\
\hline 038 & 480.80 & 284.17 & 266.41 \\
\hline 039 & 464.53 & 218.37 & 272.69 \\
\hline 04 & 251.07 & 410.00 & 282.35 \\
\hline 040 & 462.40 & 199.60 & 272.79 \\
\hline 041 & 791.15 & 192.08 & 214.58 \\
\hline 042 & 777.39 & 191.12 & 213.77 \\
\hline 043 & 814.05 & 192.46 & 206.86 \\
\hline 044 & 831.26 & 192.42 & 204.05 \\
\hline
\end{tabular}

Northing and easting coordinates based on local rectangular coordinate system, in feet. 
SURVEY STATION MAP COORDINATES AND ELEVATIONS

BLUCHER VALLEY LANDSLIDE

\begin{tabular}{|c|c|c|c|}
\hline Station & Easting & Northing & Elevation MSL \\
\hline 045 & 893.77 & 255.50 & 195.53 \\
\hline 046 & 400.15 & 346.36 & 272.73 \\
\hline 047 & 493.57 & 333.56 & 253.80 \\
\hline 048 & 534.22 & 325.70 & 247.26 \\
\hline 049 & 533.24 & 307.25 & 248.99 \\
\hline 05 & 244.66 & 419.84 & 280.51 \\
\hline 050 & 528.68 & 281.48 & 256.12 \\
\hline 051 & 622.41 & 307.44 & 234.21 \\
\hline 052 & 354.55 & 755.02 & 215.01 \\
\hline 053 & 406.05 & 762.87 & 208.92 \\
\hline 054 & 401.90 & 737.38 & 215.65 \\
\hline 055 & 398.55 & 724.62 & 215.39 \\
\hline 056 & 446.42 & 716.82 & 211.56 \\
\hline 057 & 450.71 & 737.39 & 210.97 \\
\hline 058 & 455.13 & 767.38 & 203.27 \\
\hline 059 & 544.20 & 712.42 & 201.81 \\
\hline 06 & 227.44 & 419.43 & 283.14 \\
\hline 060 & 525.40 & 688.14 & 210.83 \\
\hline 061 & 511.23 & 665.79 & 210.49 \\
\hline 062 & 574.94 & 628.21 & 209.28 \\
\hline 063 & 590.92 & 656.51 & 211.00 \\
\hline 064 & 604.07 & 678.90 & 202.19 \\
\hline 065 & 490.16 & 613.21 & 219.27 \\
\hline 066 & 405.81 & 620.44 & 228.27 \\
\hline 067 & 444.42 & 488.28 & 237.48 \\
\hline 068 & 476.46 & 456.44 & 237.44 \\
\hline 069 & 368.86 & 475.40 & 247.58 \\
\hline 07 & 235.41 & 464.41 & 269.72 \\
\hline 070 & 606.86 & 493.77 & 216.32 \\
\hline 071 & 501.40 & 494.42 & 224.78 \\
\hline 072 & 298.70 & 425.36 & 272.87 \\
\hline 073 & 224.91 & 495.58 & 263.40 \\
\hline 074 & 320.03 & 715.06 & 224.24 \\
\hline 075 & 247.88 & 617.67 & 243.66 \\
\hline 076 & 758.62 & 128.21 & 211.59 \\
\hline 08 & 195.14 & 481.34 & 269.76 \\
\hline 09 & 131.13 & 519.47 & 268.61 \\
\hline
\end{tabular}

Northing and easting coordinates based on local rectangular coordinate system, in feet. 
SURVEY STATION MAP COORDINATES AND ELEVATIONS

BLUCHER VALLEY LANDSLIDE

$\begin{array}{lrrr}\text { Station } & \text { Easting } & \text { Northing } & \text { Elevation MSI } \\ \text { I6 } & & & \\ \text { 19 } & 116.70 & 571.34 & 264.78 \\ 20 & 140.51 & 453.45 & 281.99 \\ 21 & 188.98 & 423.02 & 286.40 \\ \text { 36 } & 218.00 & 390.41 & 291.17 \\ \text { A } & 409.79 & 189.77 & 281.86 \\ \text { BB } & \text { 469.62 } & 787.58 & 200.00 \\ \text { C } & 276.54 & 785.78 & 220.81 \\ \text { D } & 90.80 & 543.35 & 270.95 \\ \text { EE } & 273.31 & 339.56 & 294.72 \\ \text { FF } & 354.34 & 198.15 & 291.57 \\ \text { GG } & 486.33 & 100.71 & 256.71 \\ \text { H } & 652.41 & 113.74 & 229.15 \\ \text { II } & 892.68 & 212.62 & 195.74 \\ \text { JJ } & 1019.35 & 501.40 & 192.56 \\ \text { S1 } & 657.64 & 515.95 & 209.52 \\ \text { S2 } & 579.20 & 881.22 & 179.41 \\ \text { S3 } & 887.16 & 512.23 & 197.13 \\ \text { S4 } & 763.11 & 508.69 & 199.84 \\ \text { S5 } & 759.39 & 428.65 & 205.22 \\ & 600.66 & 392.25 & 228.93\end{array}$

Northing and easting coordinates based on local rectangular coordinate system, in feet. 


\section{APPENDIX C}

Factor of Safety Calculations

Along A Representative Slice (Cross Section A-A') 


\section{Explanation of Calculations Utilized in Factor of Safety Spreadsheets}

(Calculation Along A Representative Slice - Cross Section A-A')

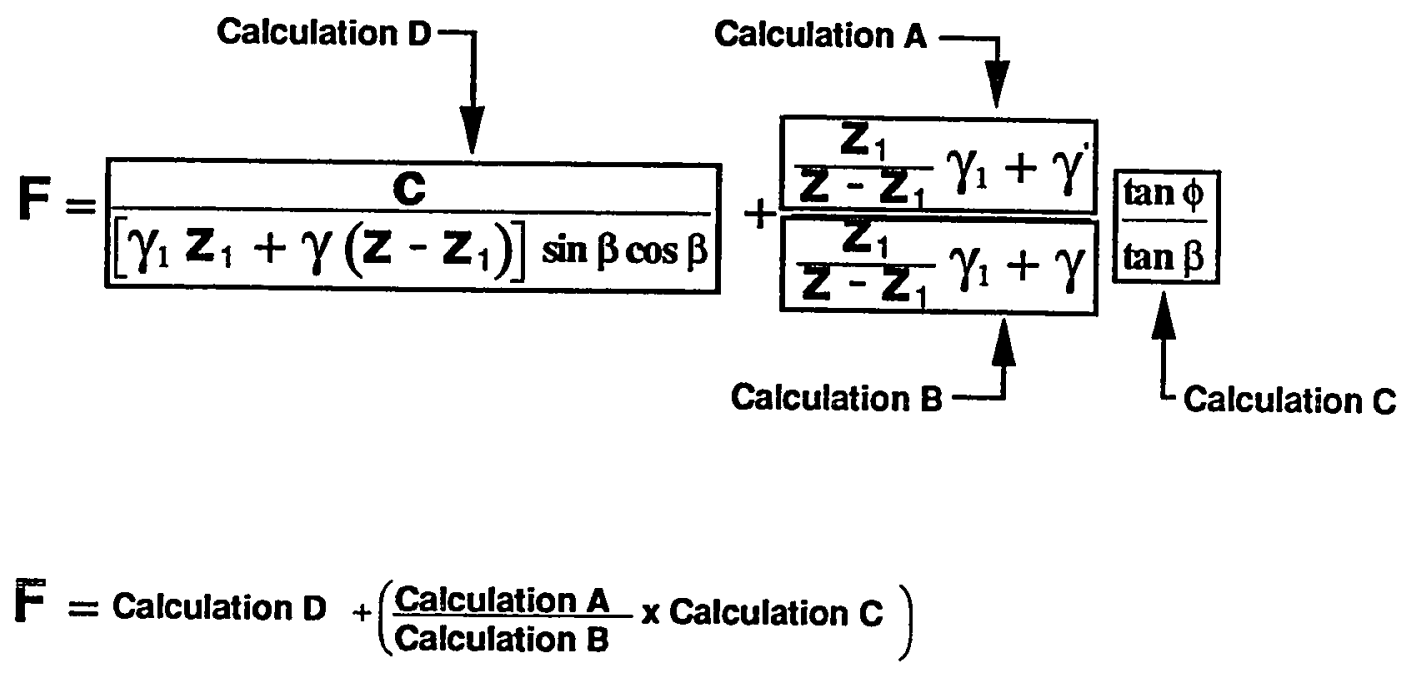

Given that:

$\gamma_{1}=$ GAMMA1, Soil unit weight above seepage line (water table) (pcf)

$\gamma=$ GAMMA, Soil saturated unit weight (pcf)

$\gamma^{\prime}=$ GAMMAp, Soil submerged unit weight (pcf)

$\phi \quad=\mathrm{PHI}$, Internal friction angle at failure surface (deg)

C = COHESION, Cohesion at failure surface (psf)

$\beta=$ BETA, Slope of the failure surface (deg)

$\mathbf{Z}=$ Thickness of failed material (ft.)

$Z_{1}=$ Thickness of failed material above the seepage line (ft.) 

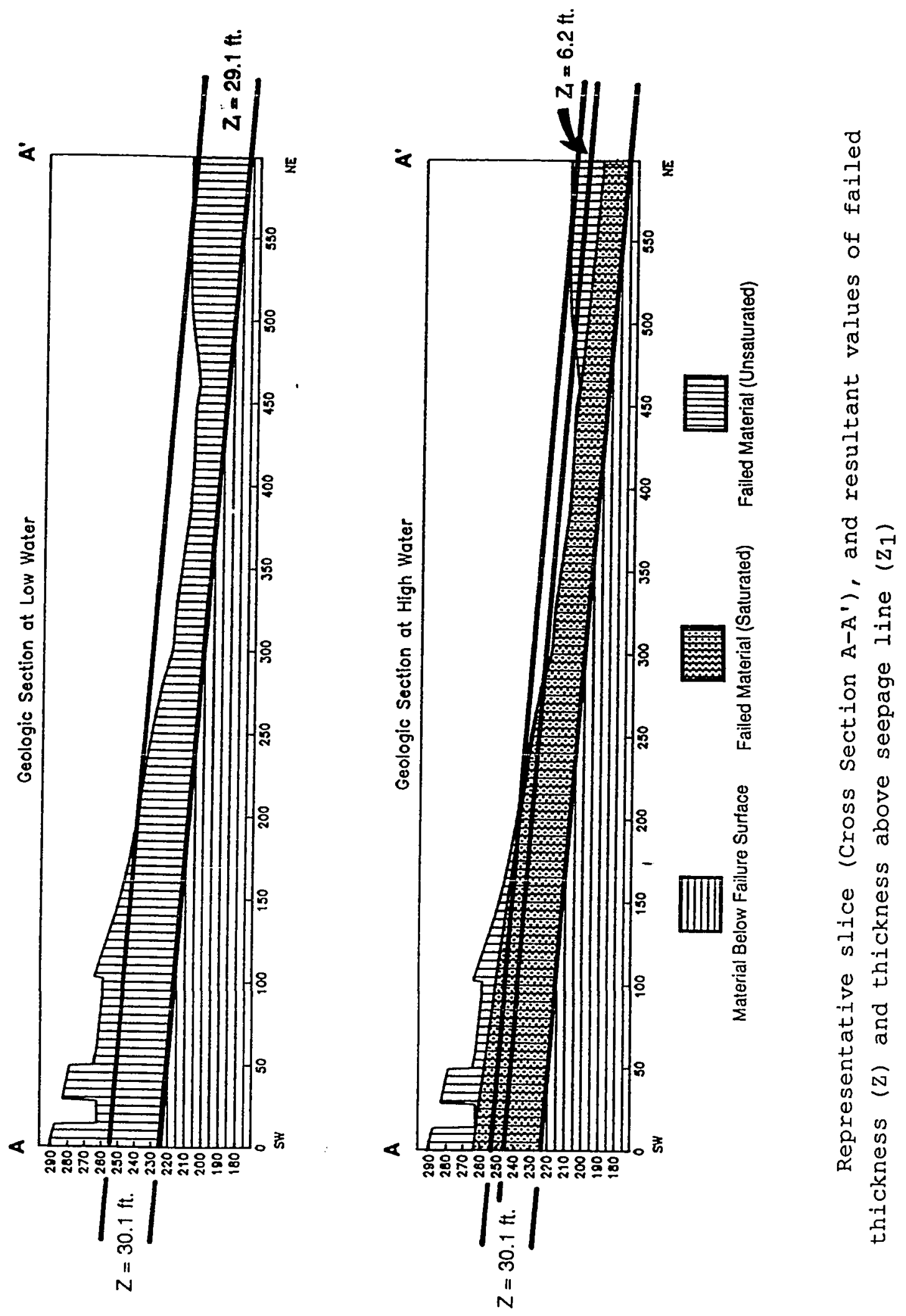
SLOPE STABILITY BY INFINITE SLOPE METHOD CALCULATED FOR A UNIT SLICE ALONG CROSS SECTION A-A'

CONDITIONS: WATERLEVEL: LOW WATER BETA: 4.5 PHI: 27.0

COHESION: 0.0

GAMMA: 107.4

Z: $\quad 30.1$

Z1: 29.1

GAMMA1: 72.2

GAMMAp: 45.0

CALCULATIONS: A) 2146.0

B) 2208.4

C) 6.5

D) 0.0

EACTOR OF SAFETY $-\cdots \quad 6.29$

CONDITIONS: WATERLEVEL: HIGH WATER PHI: 27.0

COHESION: $\quad 0.0$

GAMMA: 107.4

GAMMA1: 72.2

GAMMAp: 45.0

CALCULATIONS: A) 63.7

B) 126.1

C) 6.5

D) 0.0

FACTOR OF SAFETY -..--> $\quad 3.27$ 
SLOPE STABILITY BY INFINITE SLOPE METHOD

CALCULATED FOR A UNIT SLICE ALONG CROSS SECTION A-A'

CONDITIONS: WATER LEVEL: HIGH WATER BETA: 4.5

COHESTI: 13.0

GAMMA: 107.4

Z: $\quad 30.1$

GAMMA1: 722

GAMMAP: 45.0

CALCULATIONS: A) 63.7

B) 126.1

C) 2.9

D) 0.0

FACTOR OF SAFETY $-\ldots \quad 1.48$

CONDITIONS: WATERLEVEL: HIGH WATER PHI: 7.0

COHESION: $\quad 0.0$

GAMMA: 107.4

GAMMA1: 72.2

GAMMAP: 45.0

Z1: 6.2 
SLOPE STABILITY BY INFINITE SLOPE METHOD

CALCULATED FOR A UNIT SLICE ALONG CROSS SECTION A-A'

CONDITIONS: WATER LEVEL: HIGH WATER

PHI: 0.0

COHESION: 200.0

GAMMA: 107.4

GAMMA1: 72.2

GAMMAp: $\quad 45.0$

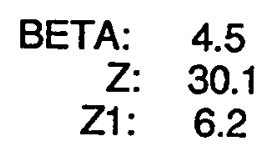

CALCULATIONS:
A) 63.7
B) 126.1
C) 0.0
D) 0.8

FACTOR OF SAFETY - - $>\quad 0.85$

CONDITIONS: WATER LEVEL: HIGH WATER PHI: 7.0

COHESION: 200.0

GAMMA: 107.4

GAMMA1: 72.2

GAMMAp: 45.0

\section{BETA: $\quad 4.5$ \\ Z: $\quad 30.1$ \\ $\mathrm{Z1}: \quad 6.2$}

CALCULATIONS:
A) 63.7
B) 126.1
C) 1.6
D) 0.8

EACTOR OF SAFETY $\cdots \quad 1.64$ 
SLOPE STABILITY BY IAFFNITE SLOPE METHOD CALCULAT동 FOR A UNIT SLICE ALONG CROSS SECTION A-A'

CONDITIONS: WATER LEVEL: LOW WATER

PHI: 7.0

COHESION: 0.0

GAMMA: 107.4

GAMMA1: 72.2

GAMMAp: 45.0

CALCULATIONS:
A) 2146.0
B) 2208.4
C) 1.6
D) 0.0

BETA: $\quad 4.5$

$Z: \quad 30.1$

$Z 1: \quad 29.1$

FACTOR OF SAFETY -...- $\quad 1.52$ 


\section{PLEASE NOTE:}

Oversize maps and charts are filmed in sections in the following manner:

\section{LEFT TO RIGHT, TOP TO BOTTOM, WITH SMALL OVERLAPS}

The following map or chart has been refilmed in its entirety at the end of this dissertation

(not available on microfiche). A xerographic reproduction has been provided for paper copies and is inserted into the inside of the back cover.

Black and white photographic prints (17" $\left.\times 23^{\prime \prime}\right)$ are available for an additional charge.

University Microfilms International 



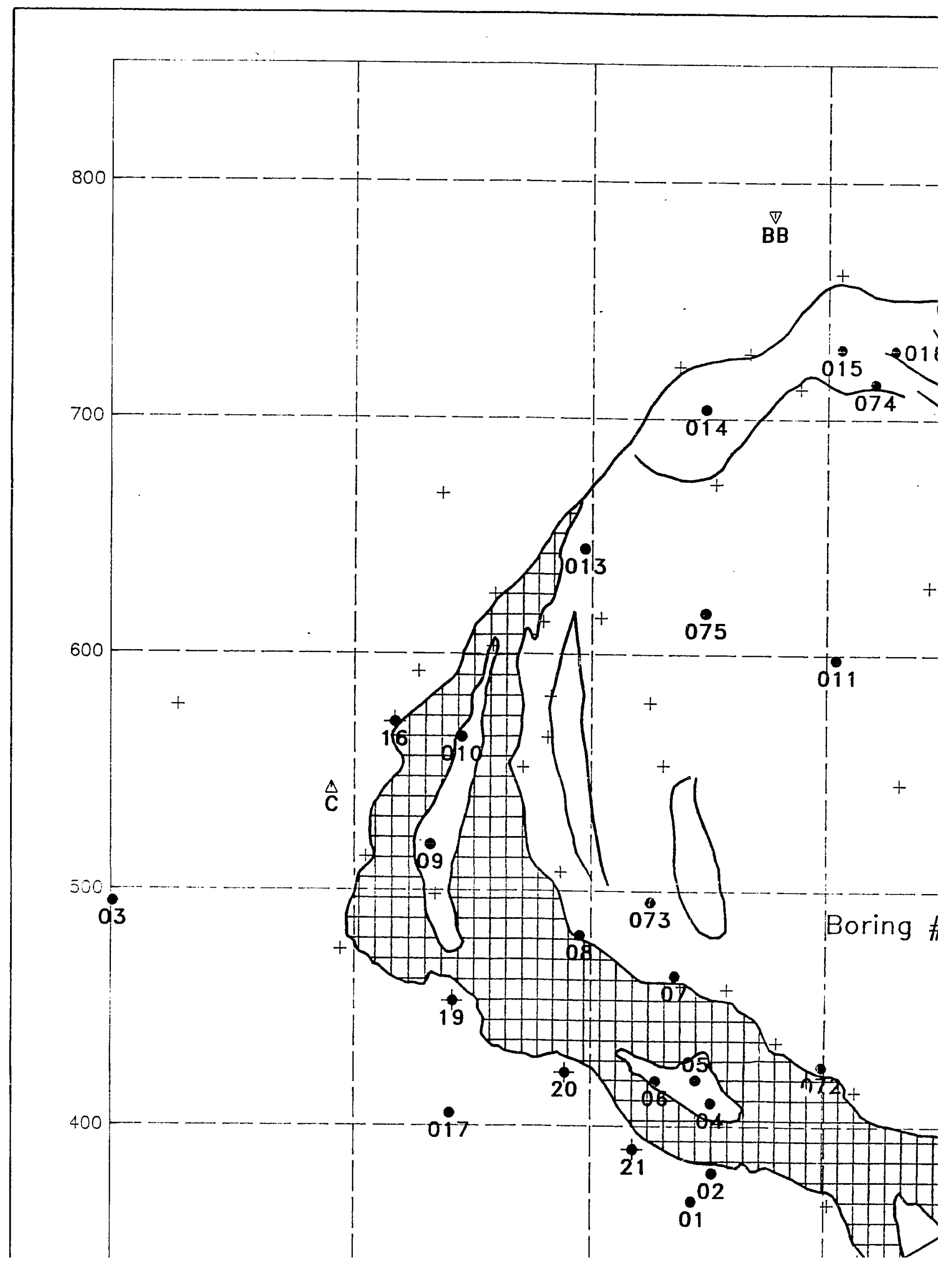




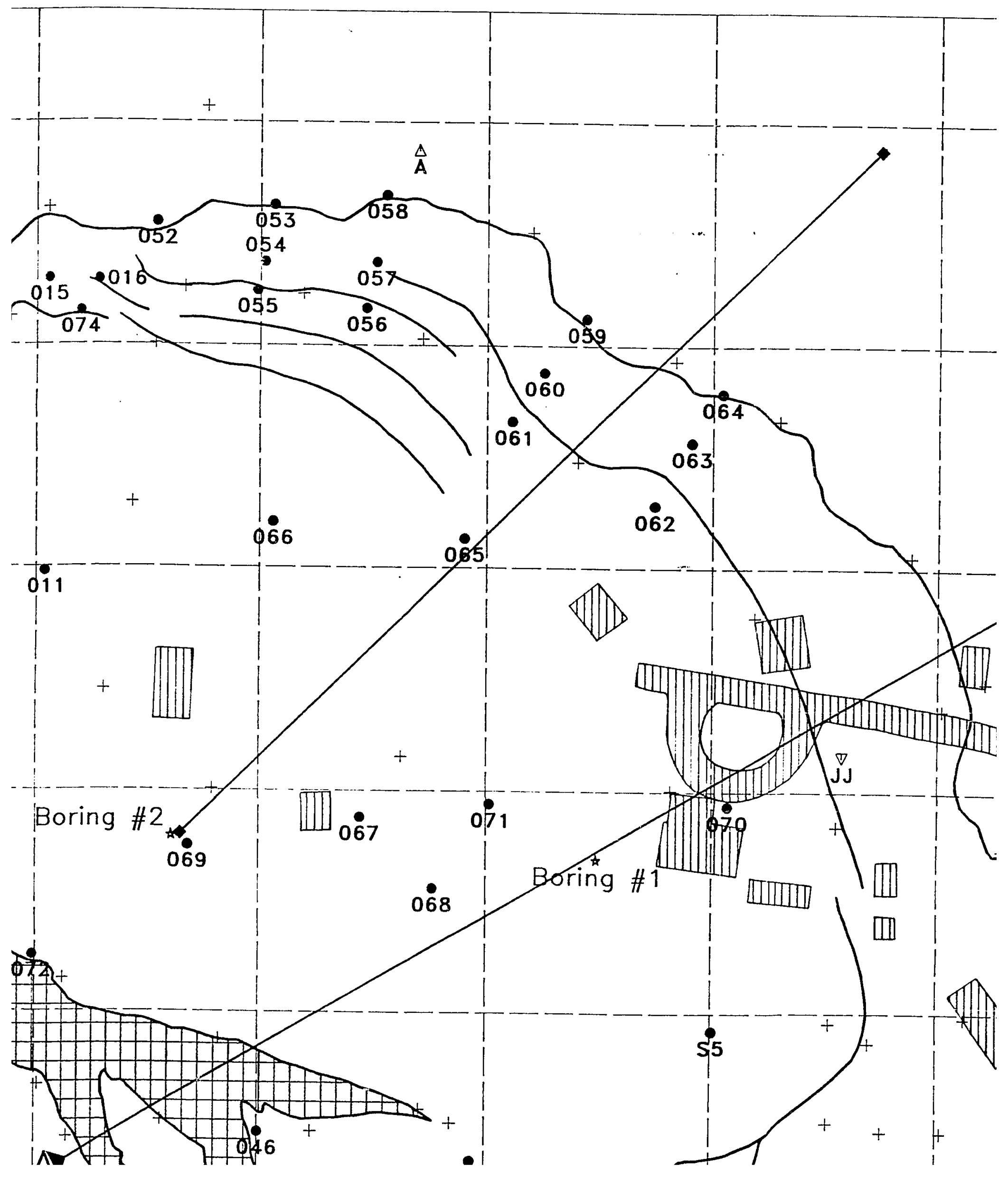




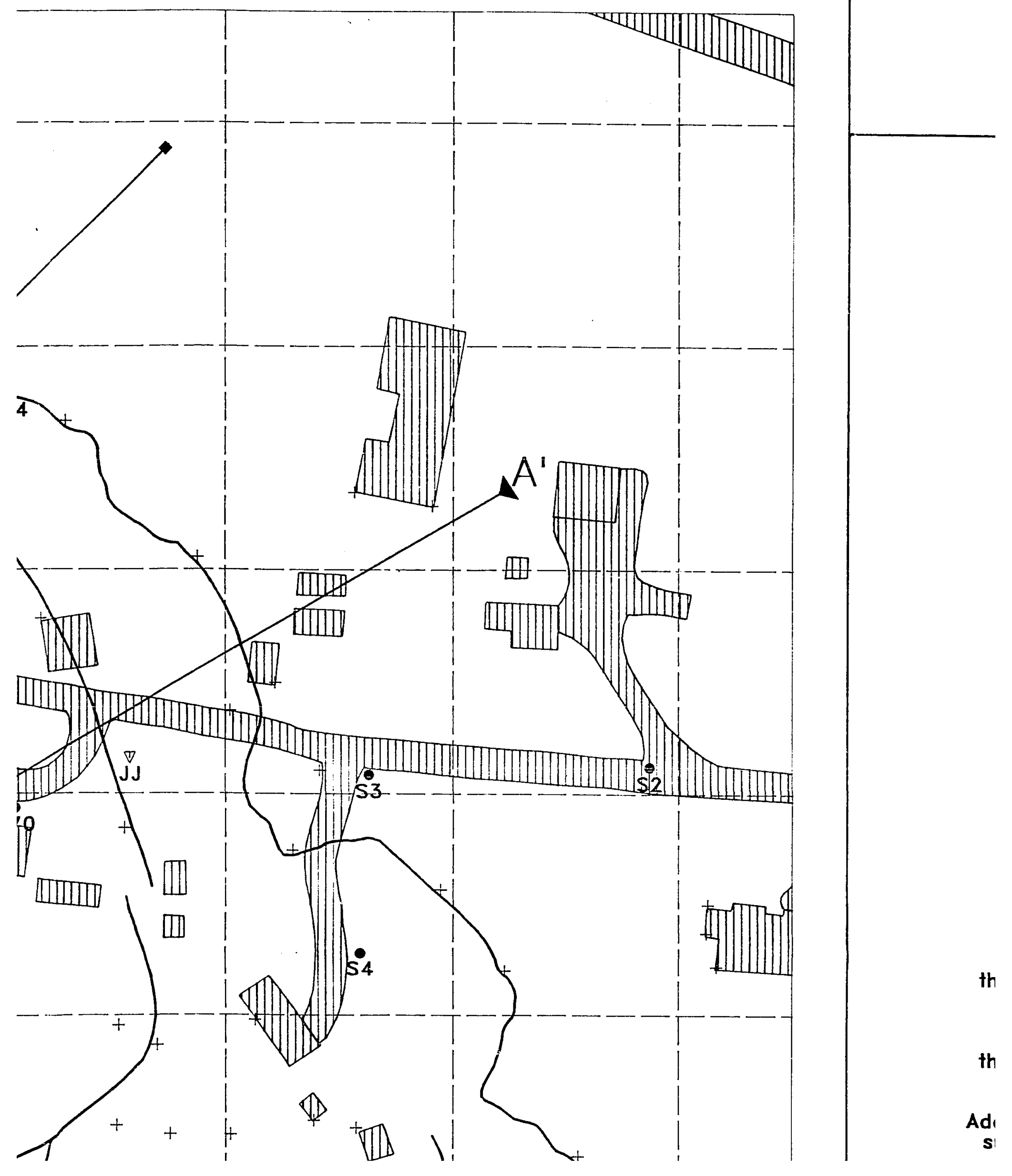




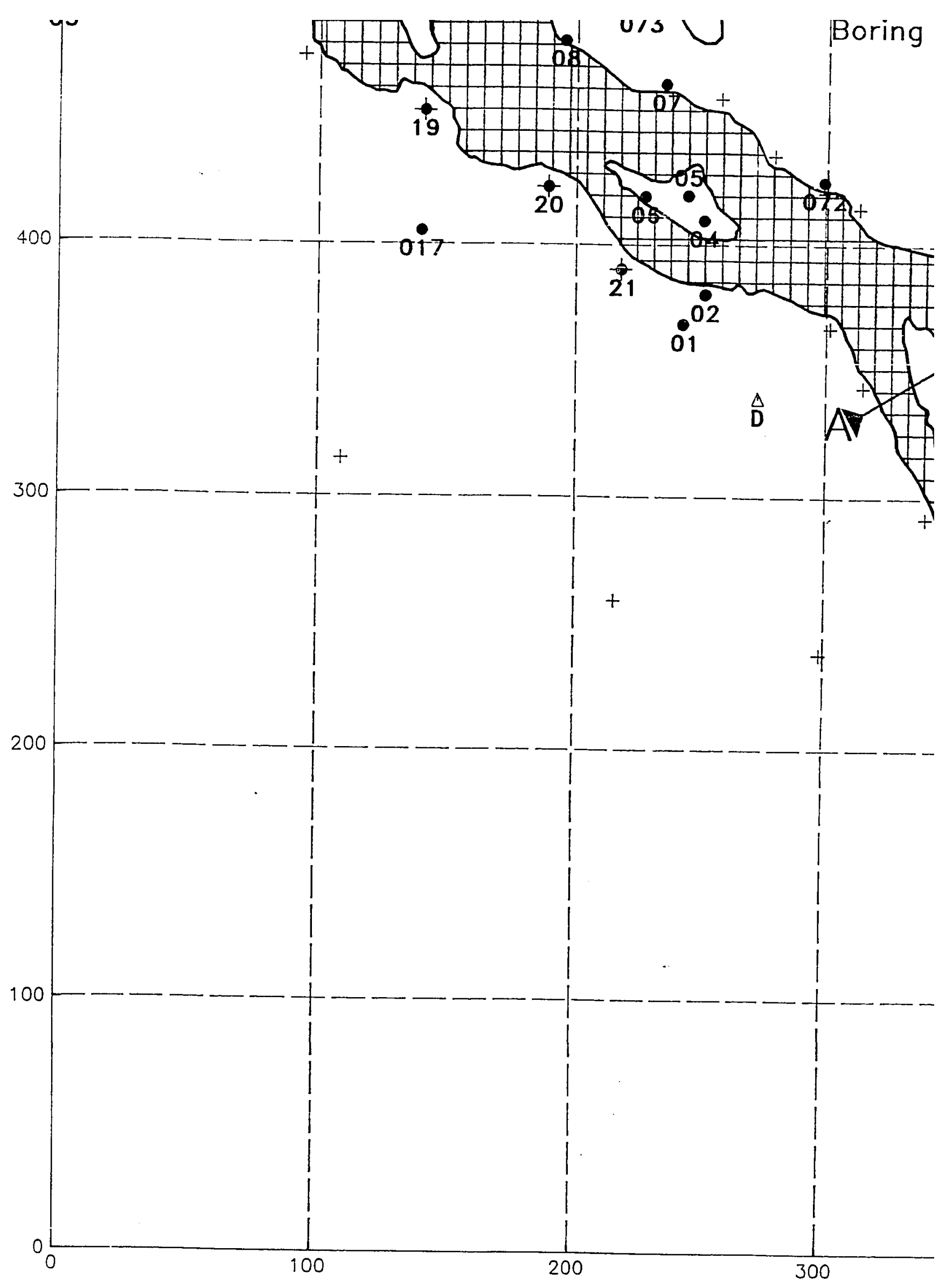




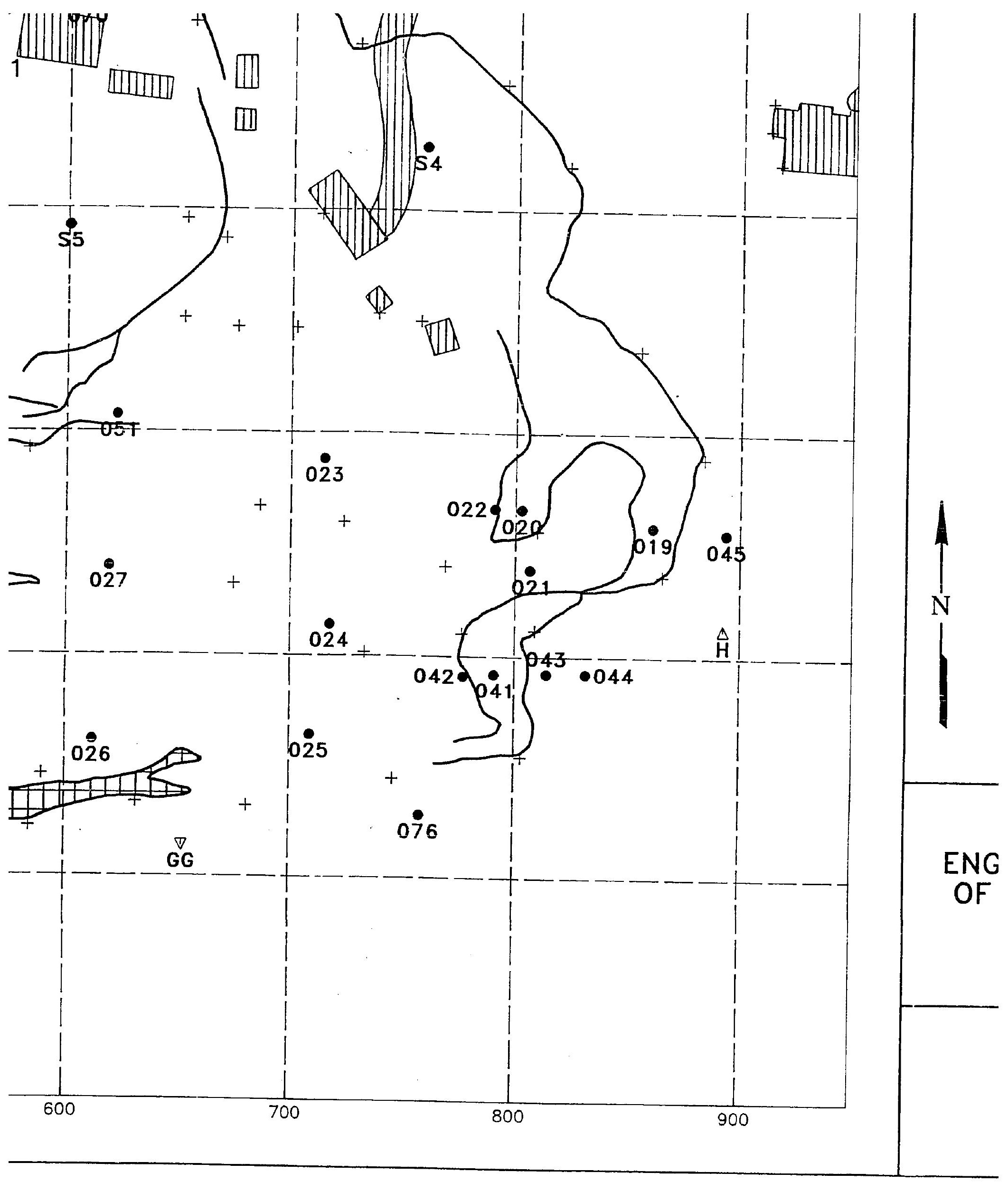




\section{PLEASE NOTE:}

tversize maps and charts are filmed in sections in the following manner:

\section{LEFT TO RIGHT, TOP TO BOTTOM, WITH SMALL OVERLAPS}

The following map or chart has been refilmed in its entirety at the end of this dissertation (not available on microfiche). A xerographic reproduction has been provided for paper copies and is inserted into the inside of the back cover.

Black and white photographic prints (17" $\left.\times 23^{\prime \prime}\right)$ are available for an additional charge. 



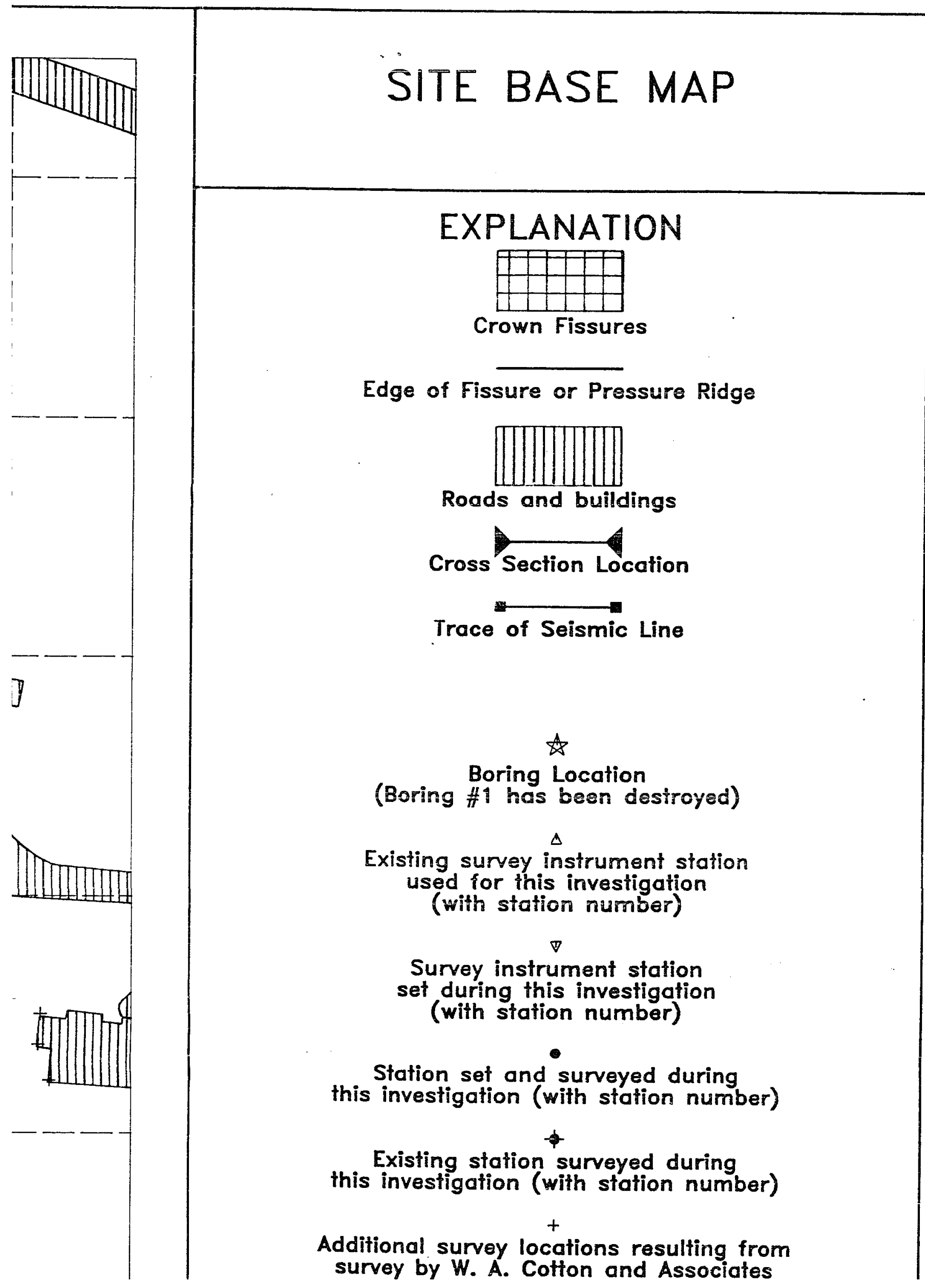




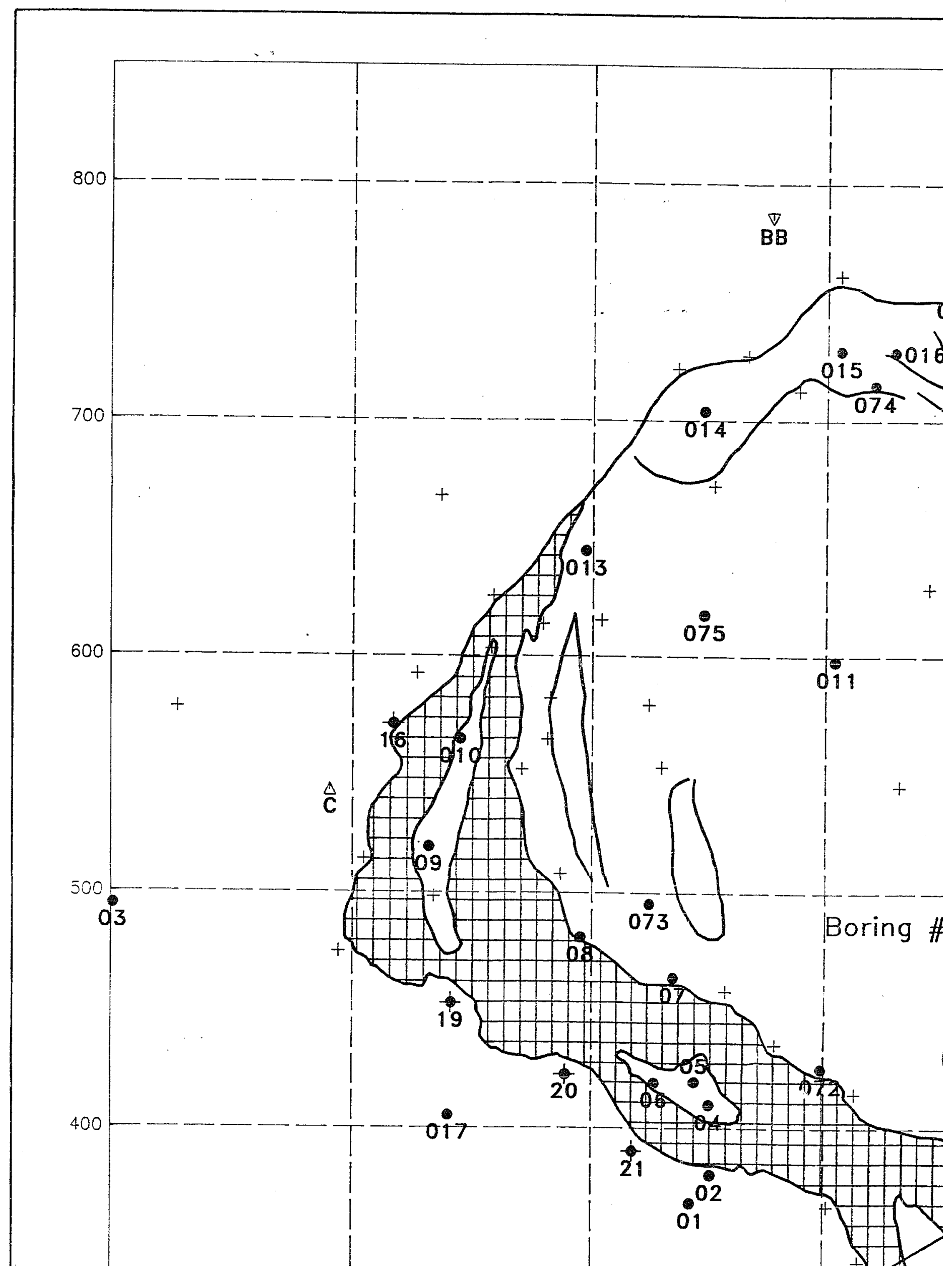




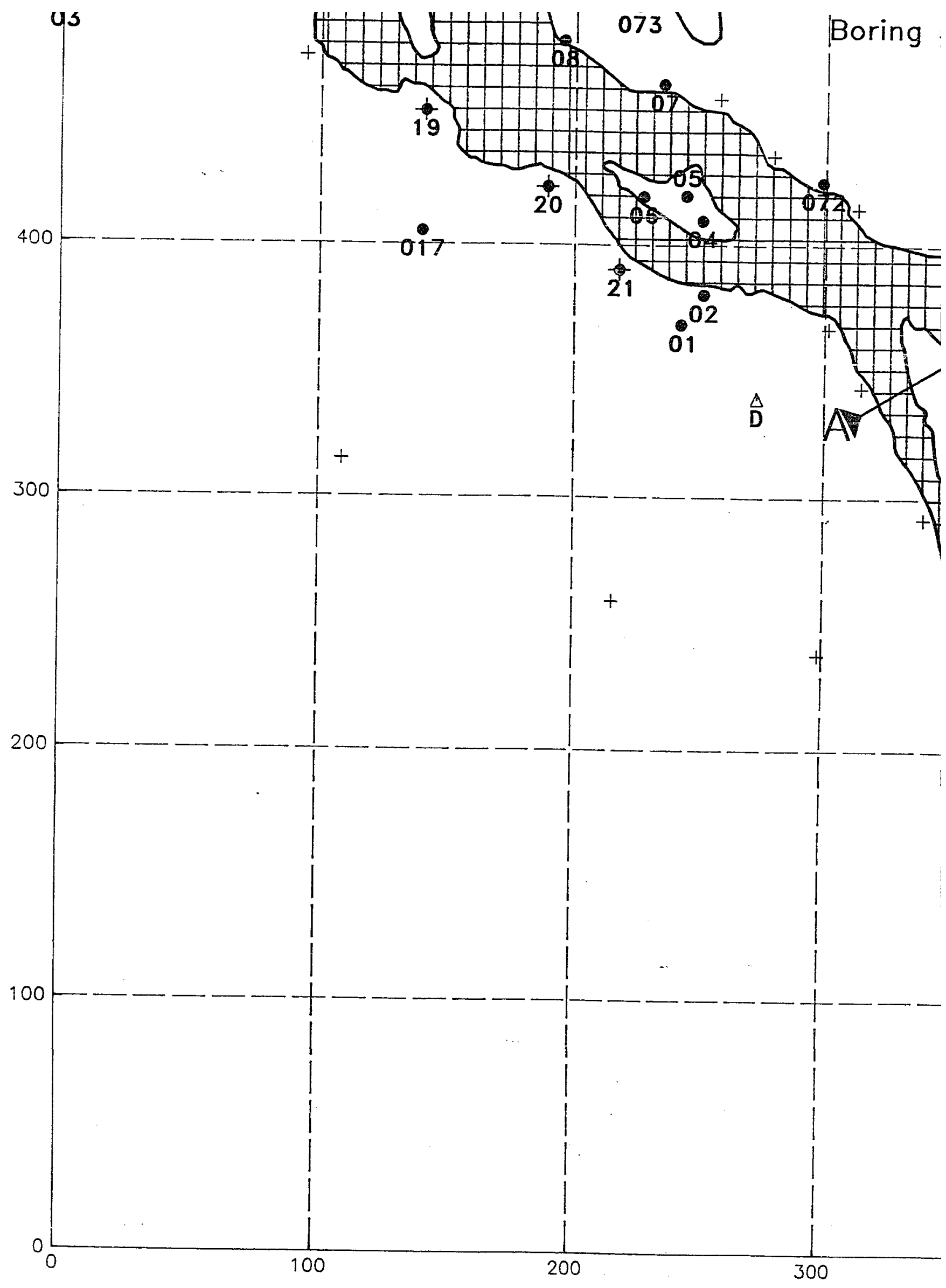




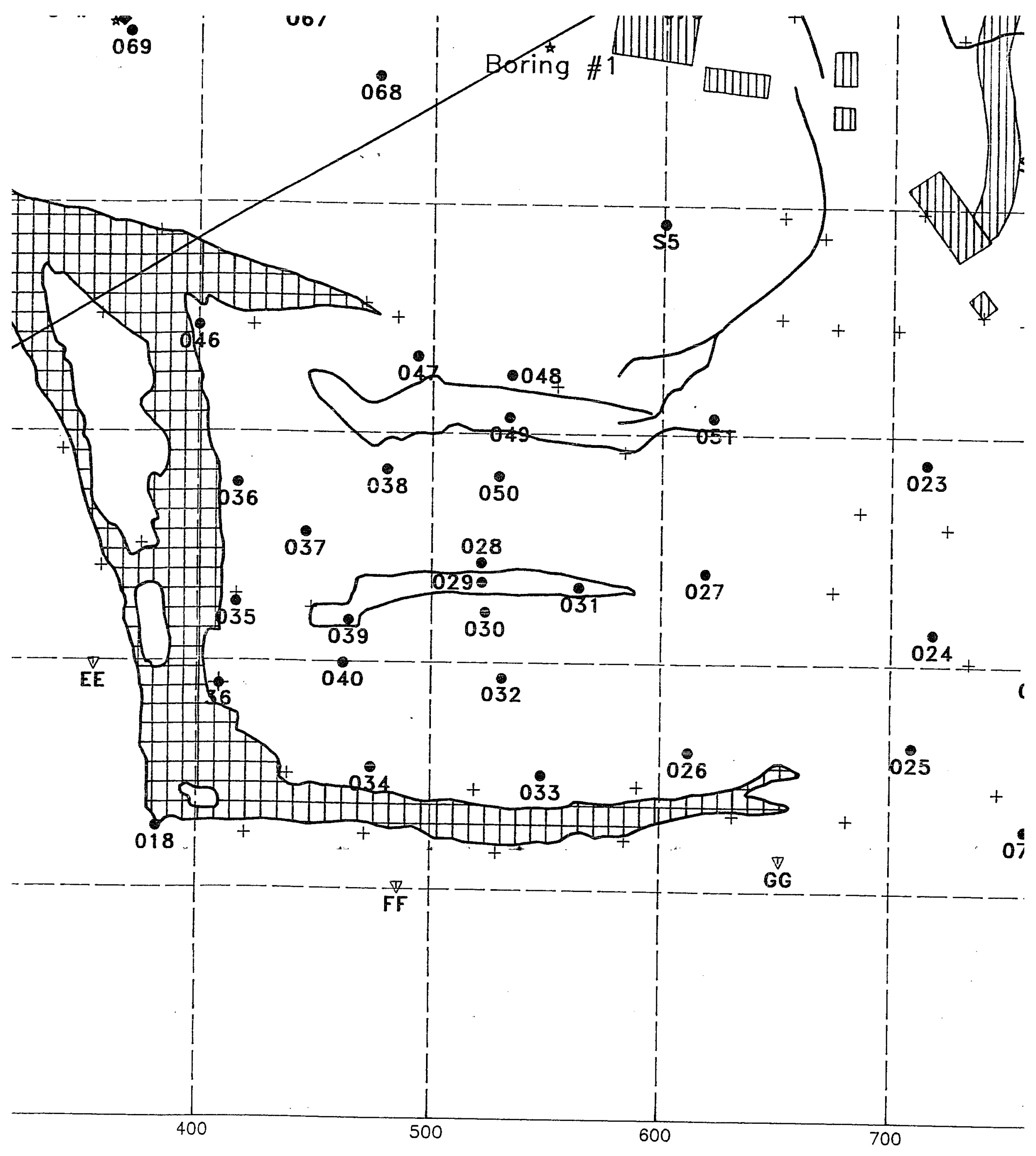




\section{PLEASE NOTE:}

versize maps and charts are filmed in sections in the following manner:

\section{LEFT TO RIGHT, TOP TO BOTTOM, WITH SMALL OVERLAPS}

The following map or chart has been refilmed in its entirety at the end of this dissertation (not available on microfiche). A xerographic reproduction has been provided for paper copies and is inserted into the inside of the back cover.

Black and white photographic prints (17" $\times 23 ")$ are available for an additional charge. 



\section{SITE TOPOGRAPHY}

\section{EXPLANATION}

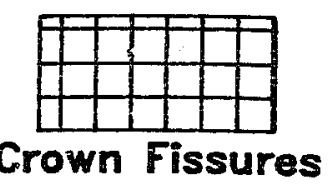

Edge of Fissure or Pressure Ridge

Topographic contours based on survey data obtained during this investigation, and during a prior investigation by W. A. Cotton and Associates. Contours were hand drawn from these data, digitized, and gridded with a five foot cell size.

SOURCES:

Fowler, 1987, Personal Communication

Field work completed during this investigation 
Topographic contours based on survey data obtained during this investigation, and during a prior investigation by W. A. Cotton and Associates. Contours were hand drawn from these data, digitized, and gridded with a five root cell 'size.

\section{SOURCES:}

Fowler, 1987, Personal Communication

Field work completed during this investigation
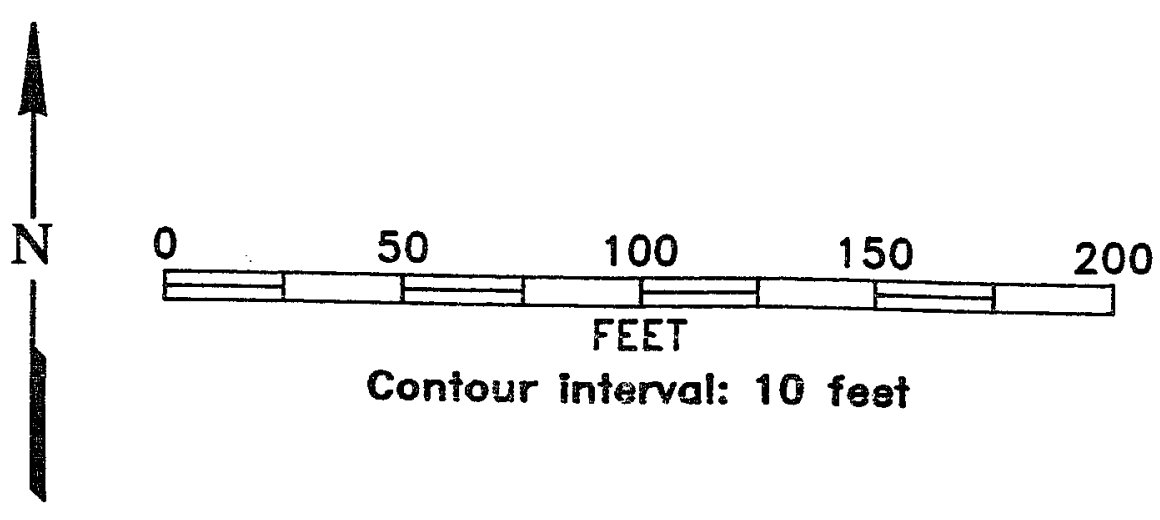

Contour inferval: 10 feet

A COMPUTER ASSISTED

ENGINEERING GEOLOGIC INVESTIGATION OF THE BLUCHER VALLEY LANDSLIDE, SEBASTOPOL, CALIFORNIA

JOHN E. ROMIE 1990 


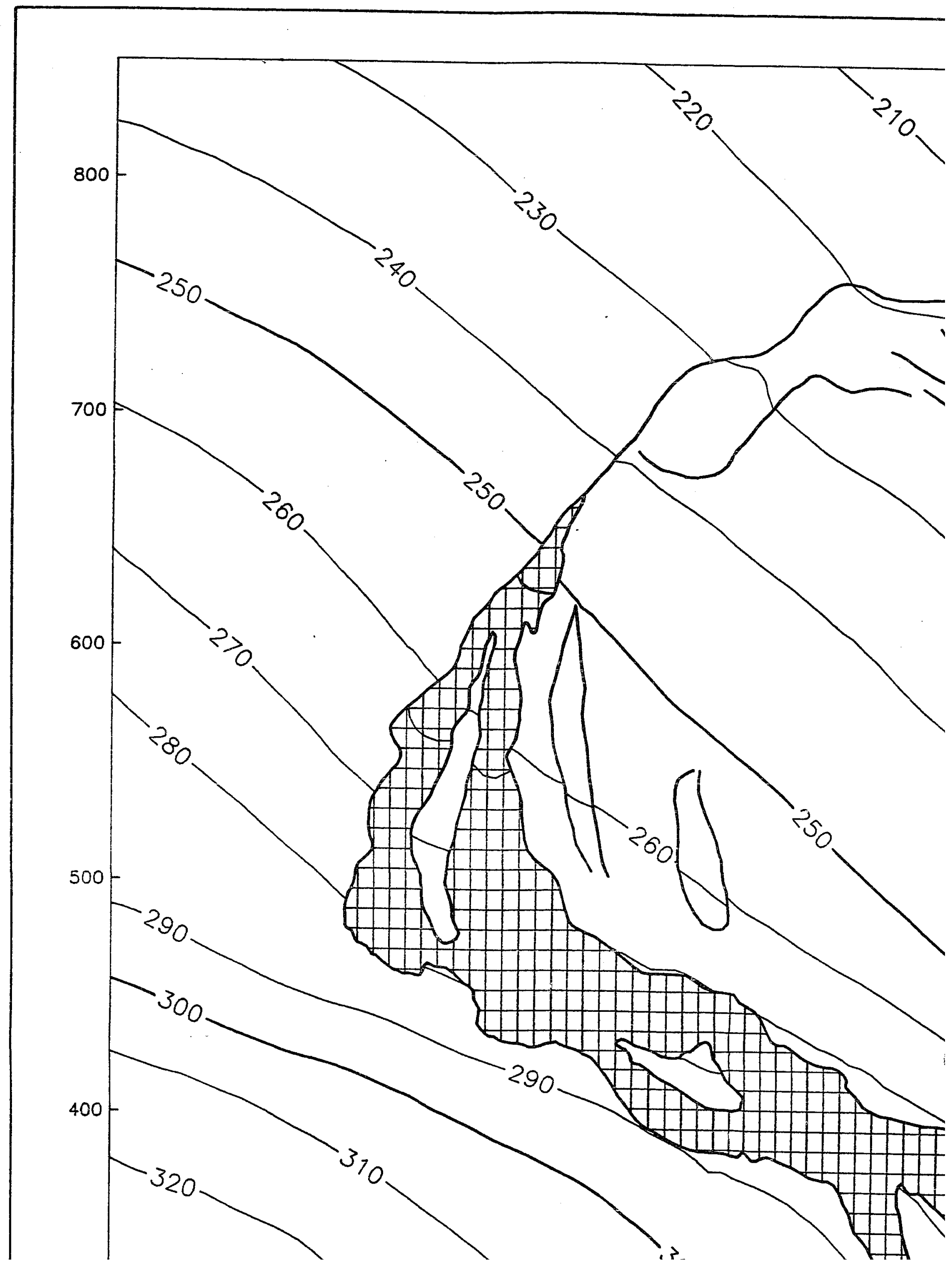




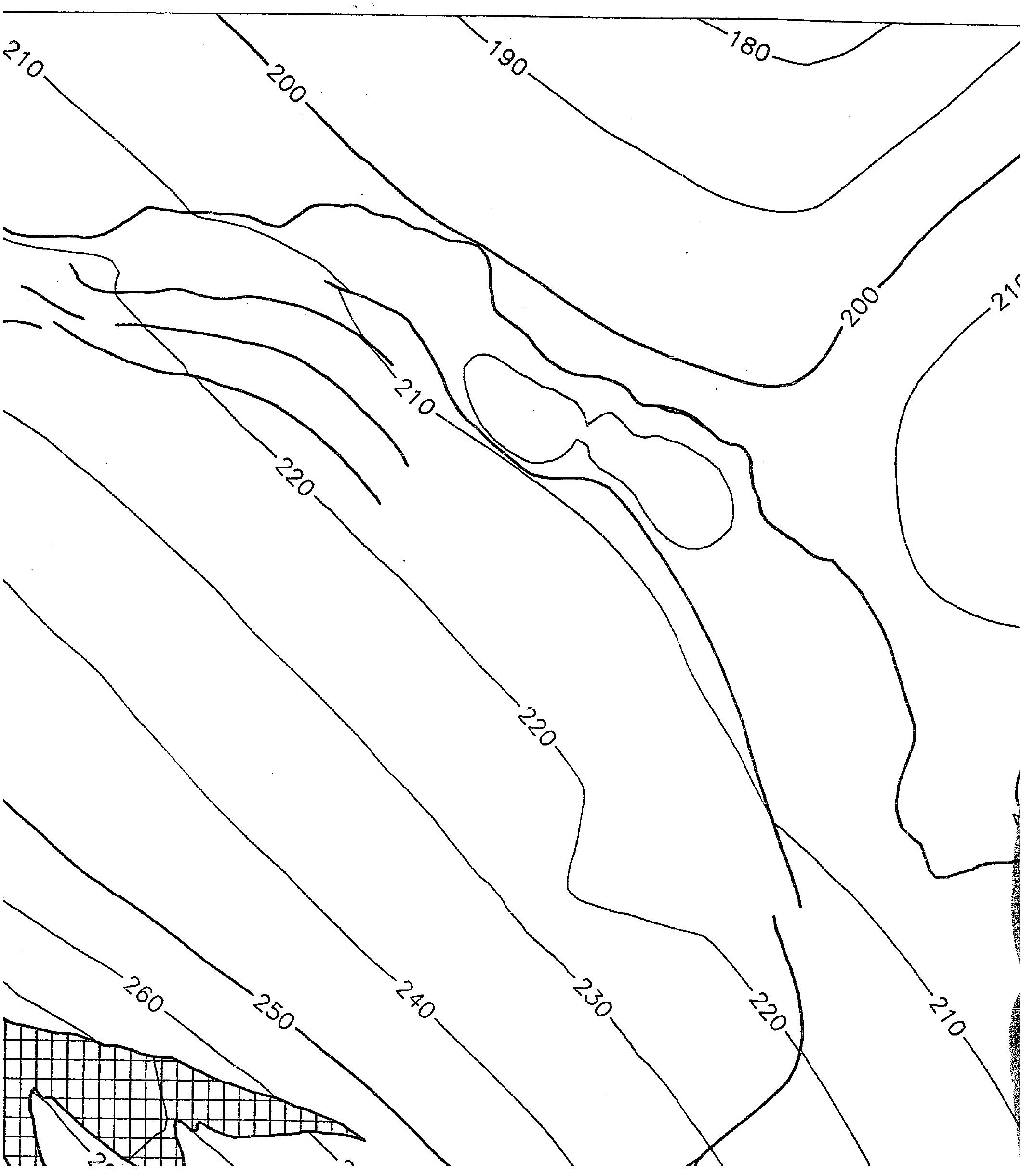




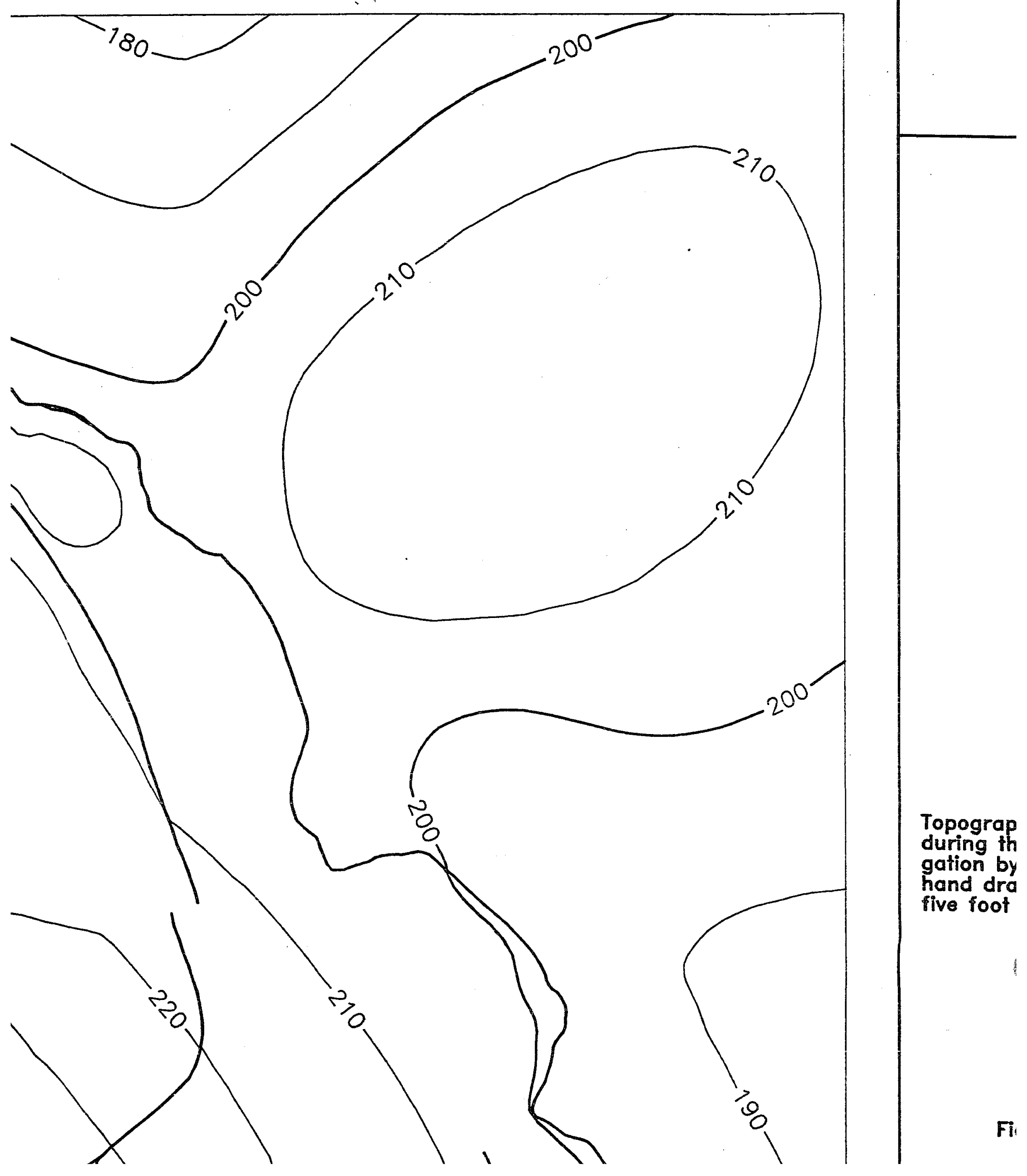




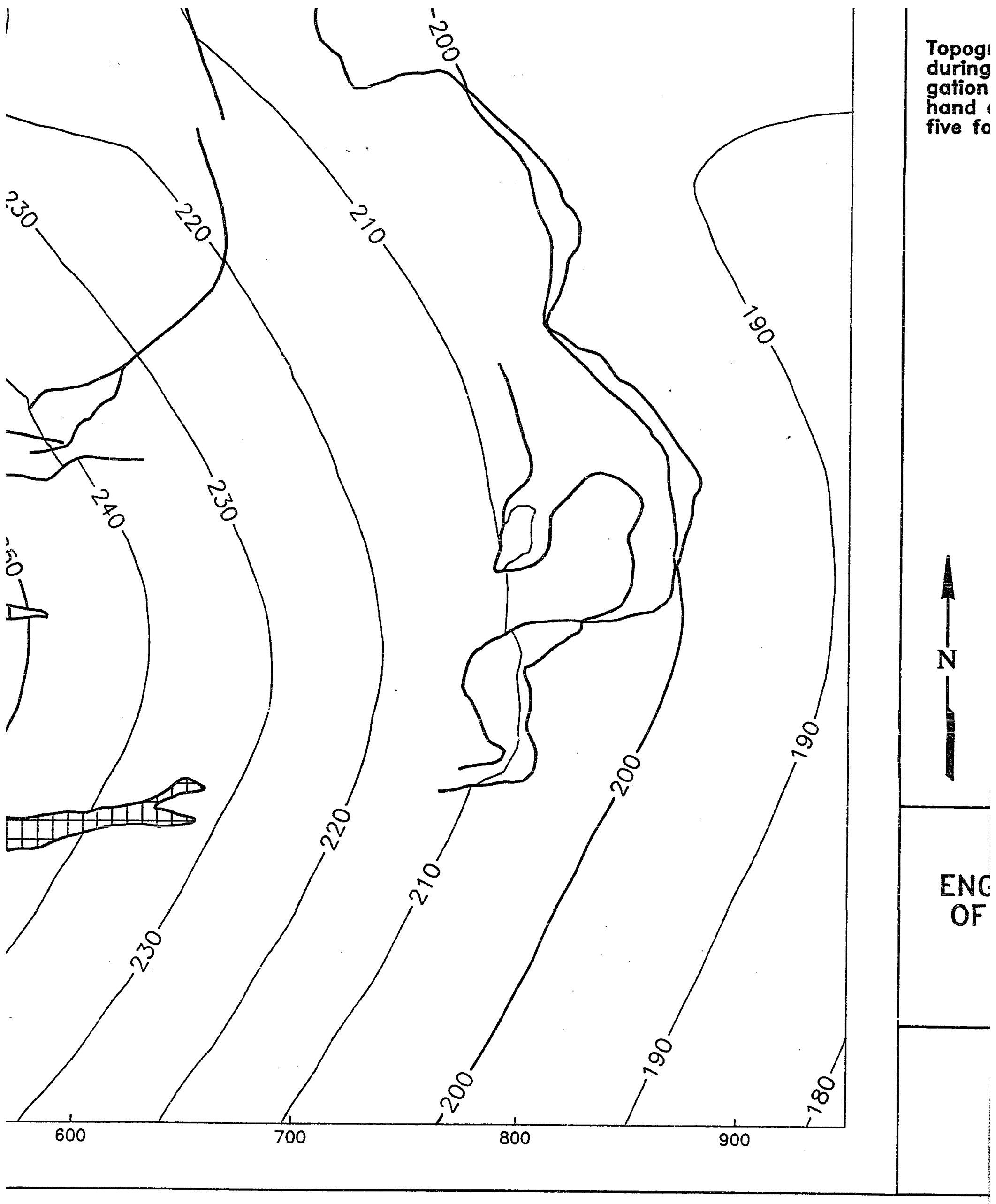




\section{PLEASE NOTE:}

Oversize maps and charts are filmed in sections in the following manner:

\section{LEFT TO RIGHT, TOP TO BOTTOM, WITH SMALL OVERLAPS}

The following map or chart has been refilmed in its entirety at the end of this dissertation (not available on microfiche). A xerographic reproduction has been provided for paper copies and is inserted into the inside of the back cover.

Black and white photographic prints (17" x 23") are available for an additional charge. 


\section{TOPOGRAPHIC PERSPECTIVE}

EXPLANATION

VIEW PARAMETERS:

Viaw diraction fro: $155 E$

Inclination angl 20 degrees

Topographic contours based on survey data obtained during this investigation, and during a prior investigation by W. A. Cotton and Associates. Contours were hand drawn from these data, digifized, and gridded with a five foot cell size.

SOURCES:

Fowler, 1987, Personal Communication

Field work completed during this investigation 


\section{SOURCES:}

Fowler, 1987, Personal Communication

Field work completed during this investigation

Contour interval: 10 feet

\section{A COMPUTER ASSISTED ENGINEERING GEOLOGIC INVESTIGATION OF THE BLUCHER VALLEY LANDSLIDE, SEBASTOPOL, CALIFORNIA \\ JOHN E. ROMIE 1990}

PLATE 3 


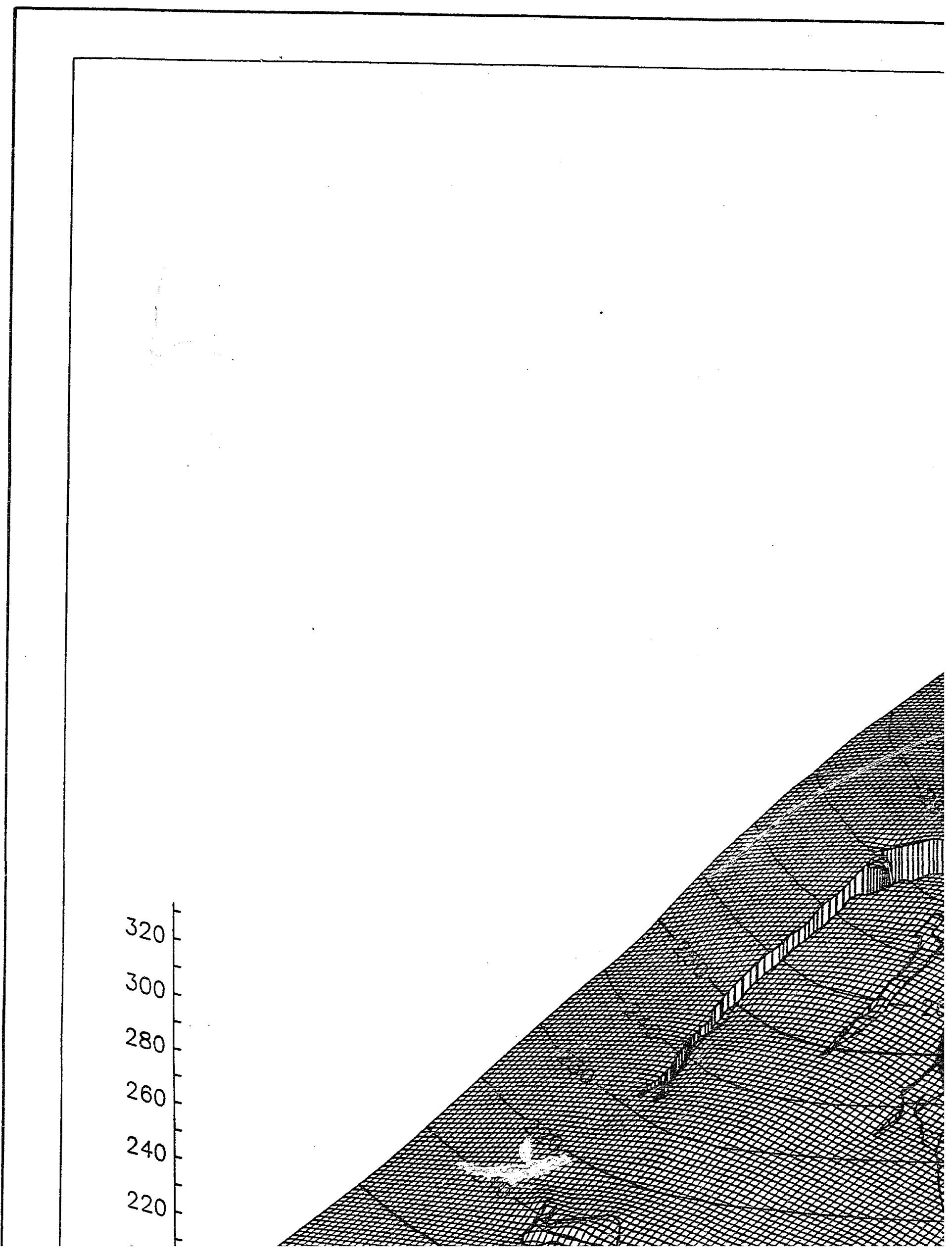




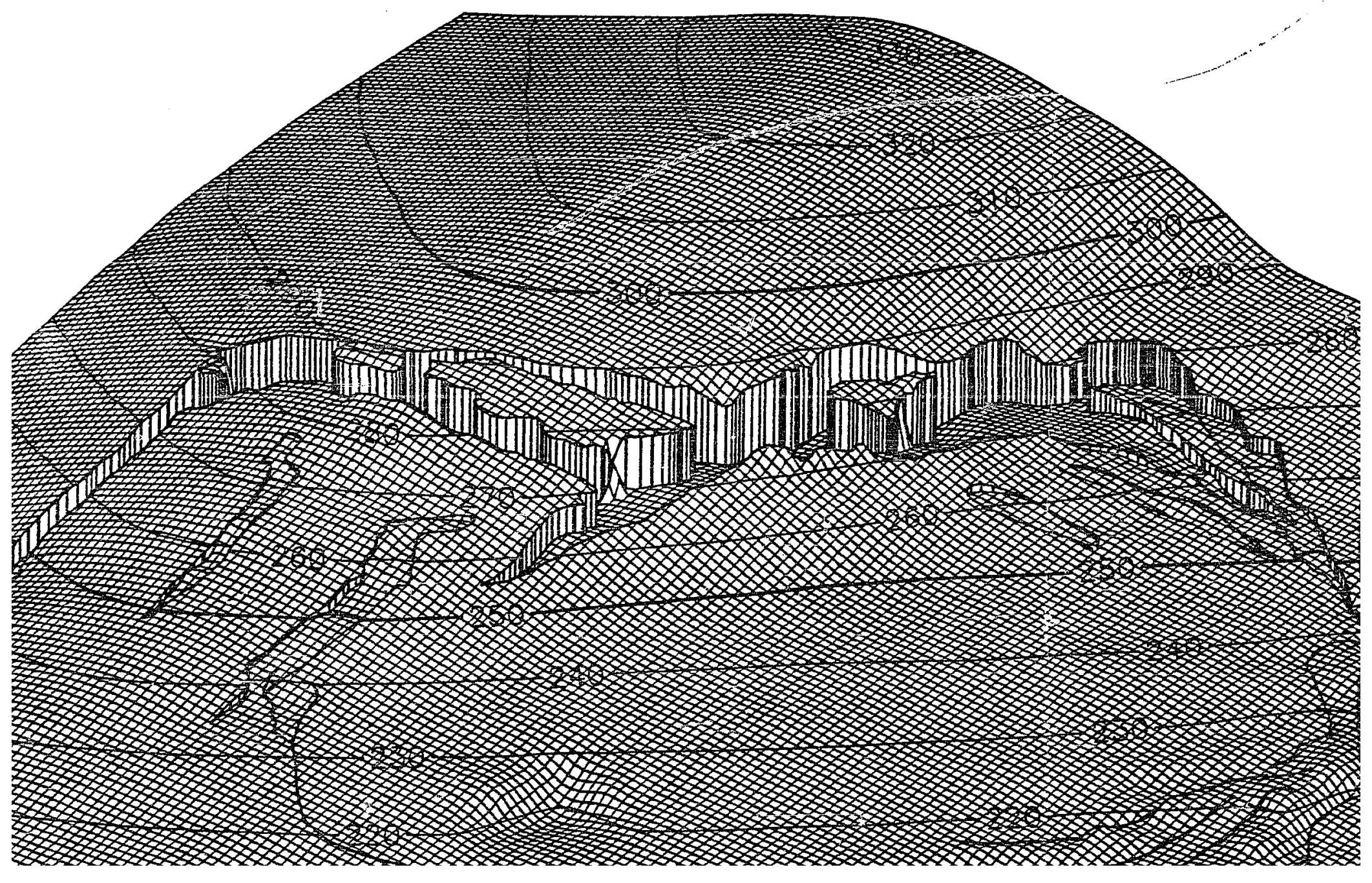




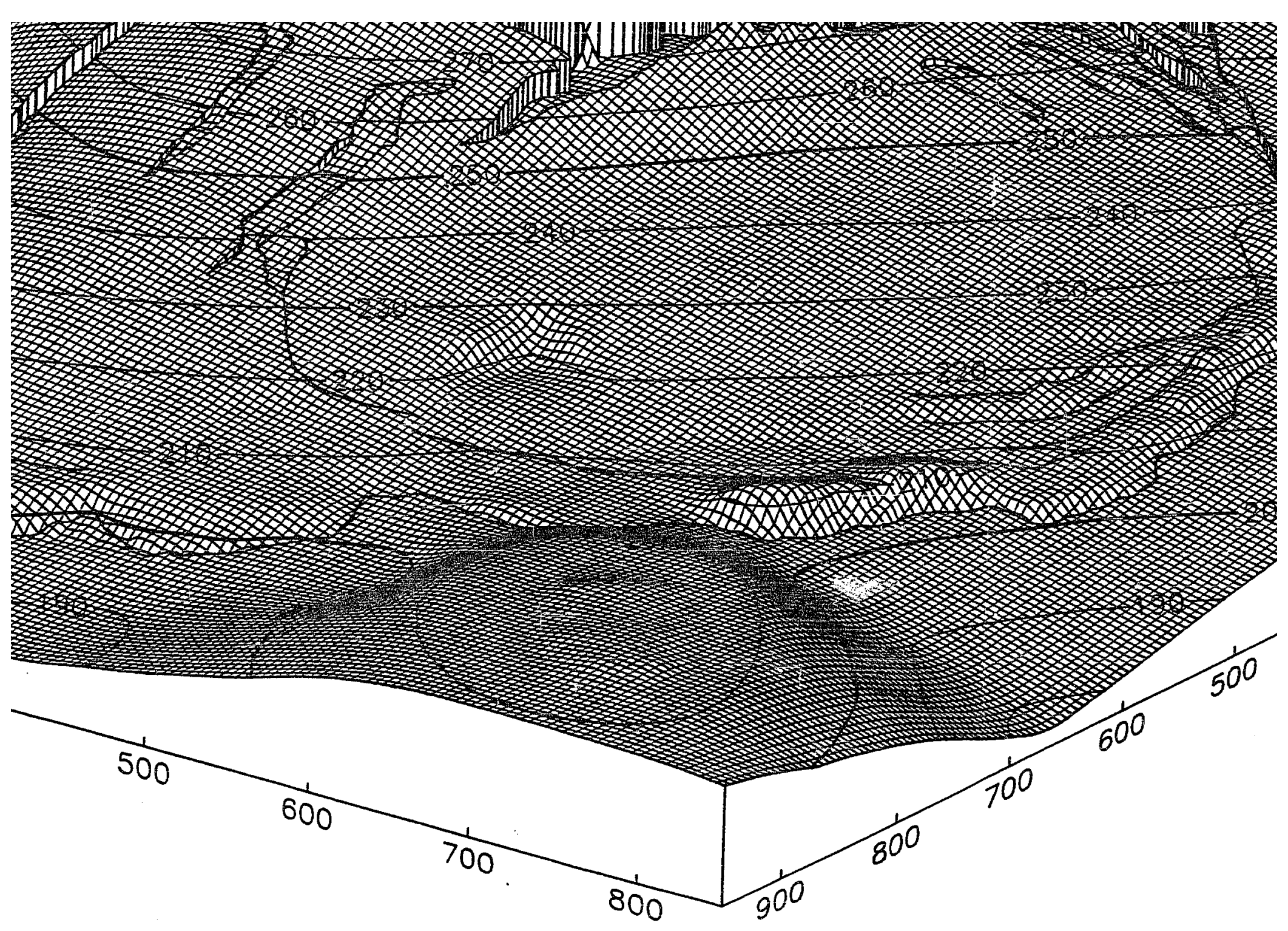




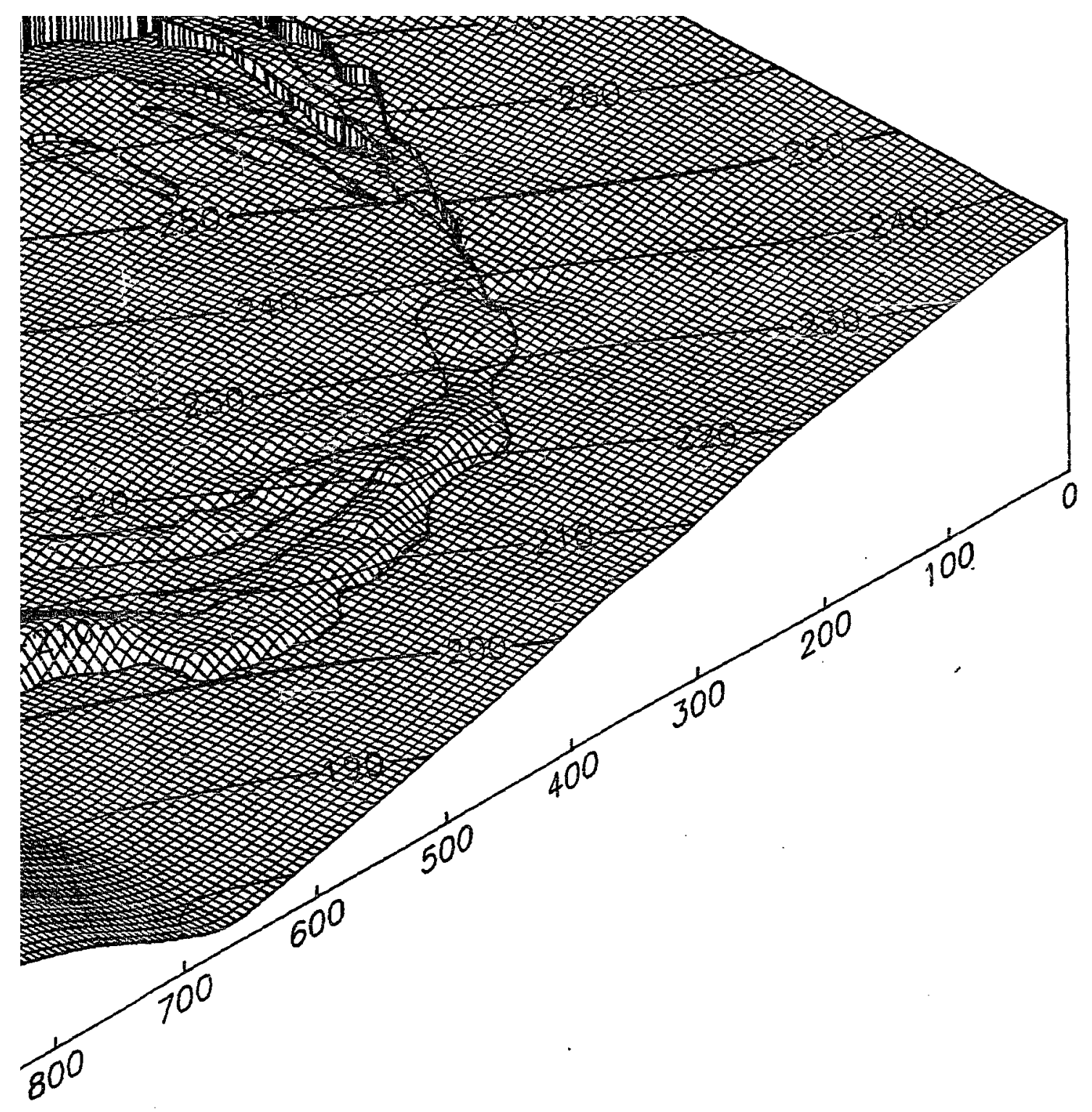

